Portland State University

PDXScholar

\title{
Amplifying Latinx Voice through Interview Study: Highlighting Mathematics Identity as a Pathway to Student Self-Empowerment and Academic Agency
}

Brea Justine Cohen

Portland State University

Follow this and additional works at: https://pdxscholar.library.pdx.edu/open_access_etds

Part of the Curriculum and Instruction Commons, and the Science and Mathematics Education Commons

Let us know how access to this document benefits you.

\section{Recommended Citation}

Cohen, Brea Justine, "Amplifying Latinx Voice through Interview Study: Highlighting Mathematics Identity as a Pathway to Student Self-Empowerment and Academic Agency" (2020). Dissertations and Theses. Paper 5456.

https://doi.org/10.15760/etd.7329

This Dissertation is brought to you for free and open access. It has been accepted for inclusion in Dissertations and Theses by an authorized administrator of PDXScholar. Please contact us if we can make this document more accessible: pdxscholar@pdx.edu. 
Amplifying Latinx Voice through Interview Study: Highlighting Mathematics Identity as a Pathway to Student Self-Empowerment and Academic Agency

\author{
Brea Justine Cohen
} A dissertation submitted in partial fulfillment of the
requirements for the degree of

\author{
Doctor of Education \\ in \\ Educational Leadership: Curriculum and Instruction
}
Dissertation Committee:
Anita Bright, Chair
Micki Caskey
Amanda Sugimoto
Steven Boyce
Donna Kalmbach Phillips

Portland State University

2020 
(C) 2020 Brea Justine Cohen 


\begin{abstract}
Nationally, the percentage of high school students taking higher-level mathematics courses (beyond Algebra 2) has increased from the late 20th century to the present. However, as compared to White high school students enrolled in advanced math classes, the rate is lower among students of color, specifically students who identify as Latinx, African American, or Native American. My school district (a suburban district in the Northwestern United States) is working to address this problem by implementing several district-wide initiatives that focus on increasing students' engagement in mathematics, which focuses teacher pedagogy on leveraging mathematics communities to support collaborative mathematics dialogue. The problem addressed in this study is whether these district-led initiatives are successfully supporting student mathematics identity, selfempowerment, and academic agency in ways that are culturally sustaining. The purpose of this interview study is to amplify the voices of several Latinx high school students identified by their mathematics teachers as being strong mathematics learners. The students can give essential insight into how the initiatives have supported their mathematics identity, self-empowerment, and academic agency, as well as detail what teaching strategies need to be enhanced to further support student mathematics learning. These students' voices are critical to the school district as we can learn from these students' mathematics experiences to holistically improve mathematics pedagogy. Key words: mathematics identity, self-empowerment, academic agency, mathematics discourse
\end{abstract}


Dedication

To the young learners of mathematics who bravely and humbly shared their lived experiences; thank you for letting your voices rise and be heard. Your contribution to mathematics education research is invaluable, and will be a catalyst for change for future generations of young mathematicians. 
Acknowledgements

Many thanks to my dissertation committee, Anita Bright, Micki Caskey, Amanda Sugimoto, Steven Boyce, and Donna Kalmbach Phillips. Your guidance and support throughout this journey have inspired and challenged me to greater heights as a researcher, as a teacher-leader, and as a learner.

To Anita Bright and Micki Caskey, my fearless and humble leaders. You skillfully cultivated in me a desire to be a life-long researcher. Thank you for your guidance and care, for gently pushing me to challenge myself, and for helping me to find my voice. I am honored to have learned from you and beside you.

To Donna Kalmbach Phillips, my mentor and friend. You have known me from my teaching infancy and have watched me develop and grow into the teacher-leader I am today. Thank you for your caring and energizing presence, your wise counsel, and for all of the cathartic walks over these last four years.

To my parents, Kirsten and Dick Roy, and Joe and Carole Cohen, my brothers and sisters-in-law, my nieces and nephews, your enduring love and support for me, and belief in me has carried me through this doctoral journey. Thank you for your incredible patience with me, and your precious presence in my life.

To my dear friends, Kylie, Anna, and McKenzie, for being life-supports, study partners, stress relievers, and advocates for taking study breaks. Thank you for your unceasing encouragement and sisterly friendship.

To the love of my life, Christopher Louis, thank you for your profound friendship, incredible patience, and steadfast love. I would not be where I am today without your APA expertise, your help with transcription, your formatting assistance, and your genuine 
and intentional care for me. Thank you for joining me on this amazing journey. I love you beyond words, and far beyond time.

To my colleagues, thank you for your immense support and continued conversation about how to better serve our students. Your passion for teaching and learning is seen and felt daily in your classrooms.

To all my students who have helped me to reflect on and transform my teaching practice; and have gifted me with your thoughts, perspectives, insights, and experiences, thank you. You have taught me more than you will ever realize, and I am forever changed. 
Table of Contents

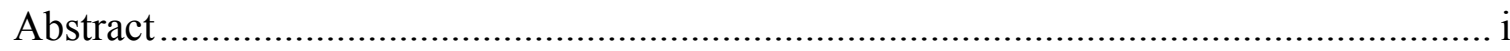

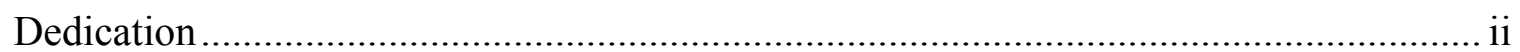

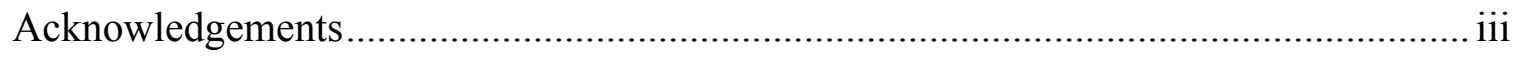

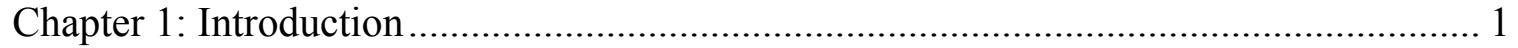

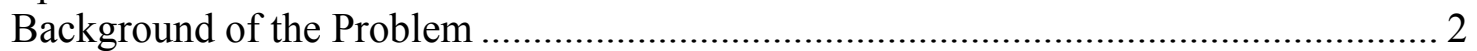

Statement of the Research Problem ................................................................................ 3

Significance of the Research Problem .......................................................................... 4

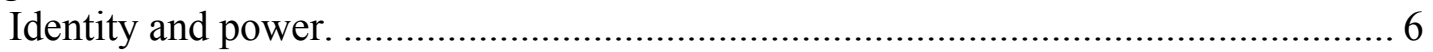

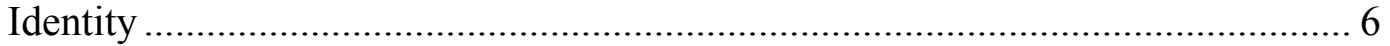

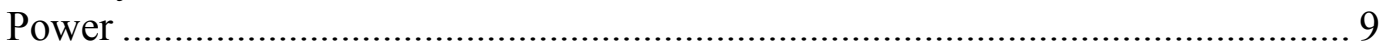

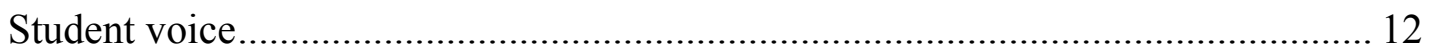

Presentation of Methods and Research Questions .................................................... 13

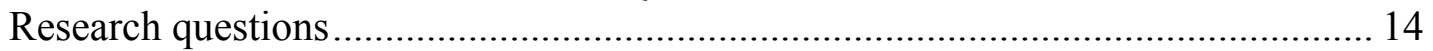

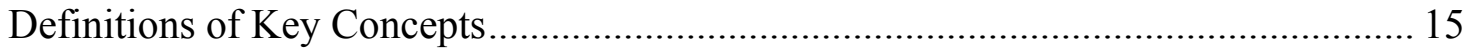

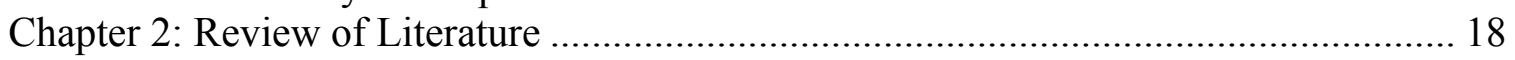

Theoretical Framework ........................................................................................ 18

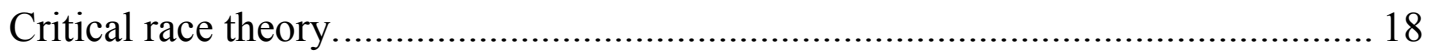

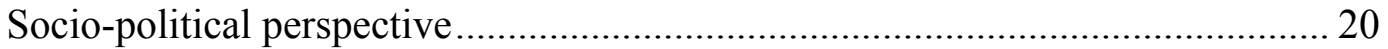

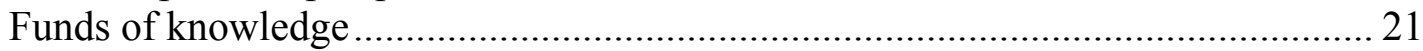

Critiques of critical race theory and funds of knowledge ...................................... 24

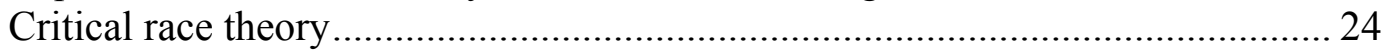

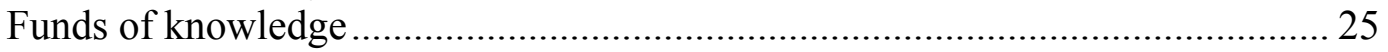

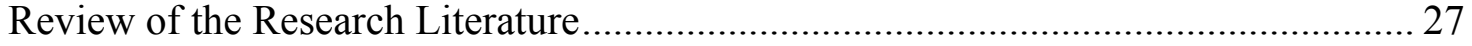

Examining inequity in mathematics education .................................................. 27

False idea of racial hierarchy of mathematical ability ...................................... 28

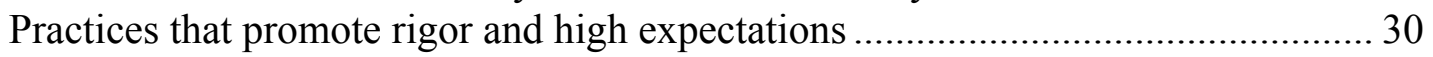

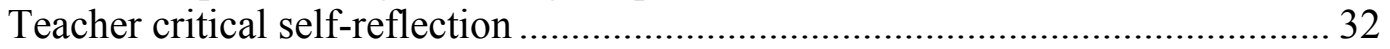

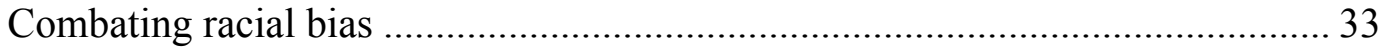

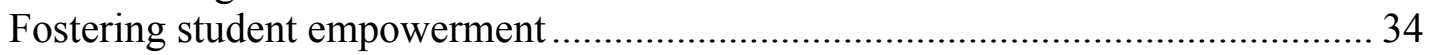

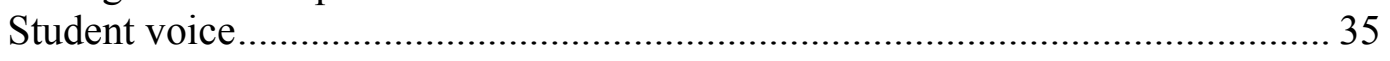

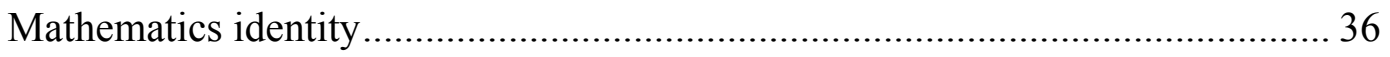

Encouraging mathematics dialogue ................................................................ 38

Enacting culturally responsive and sustaining pedagogy .................................. 45

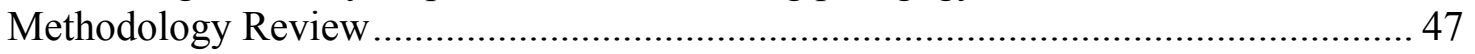

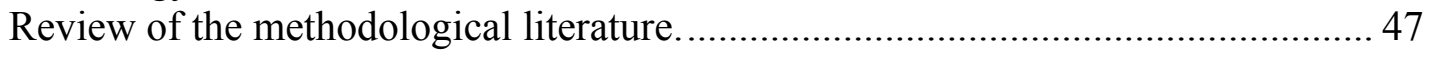

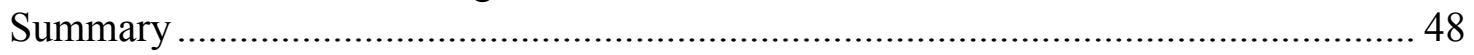

Summary of the research literature and application to the study .......................... 49

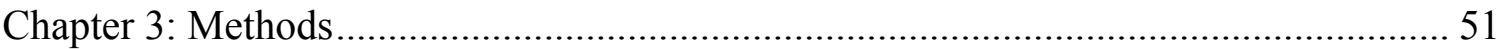

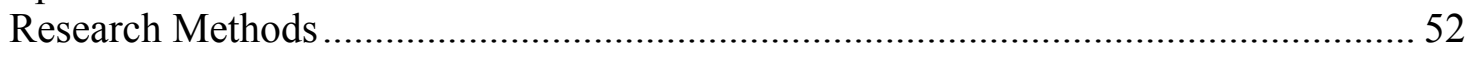

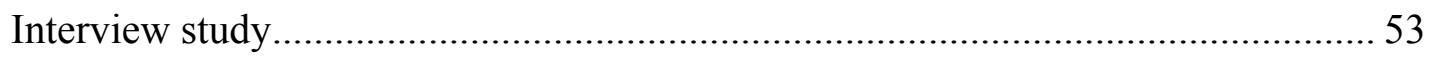

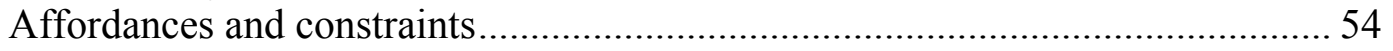

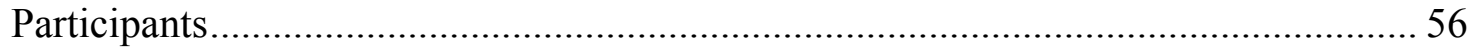

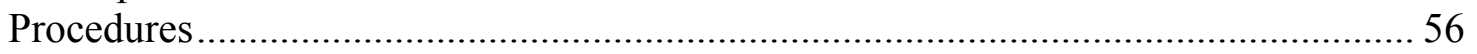

Participant recruitment and selection............................................................ 57 
MATHEMATICS IDENTITY vi

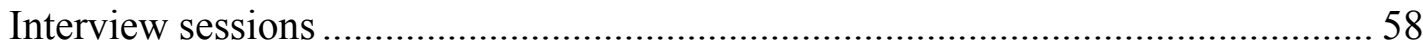

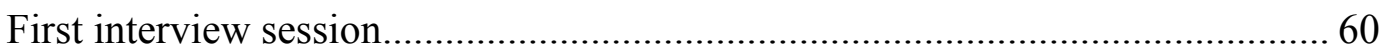

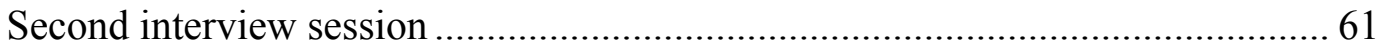

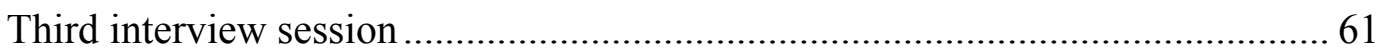

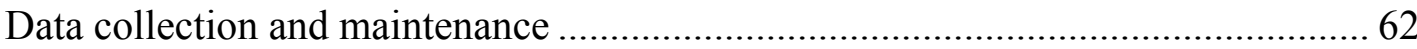

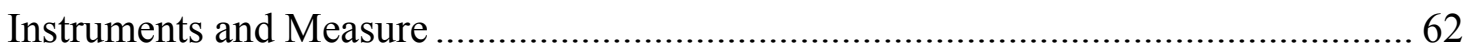

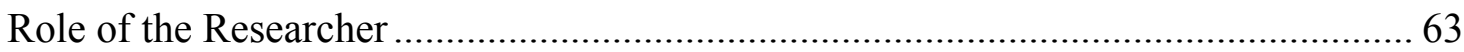

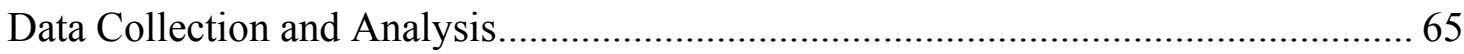

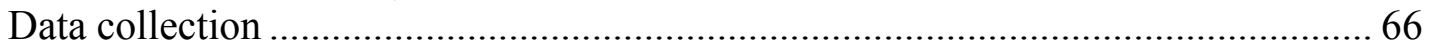

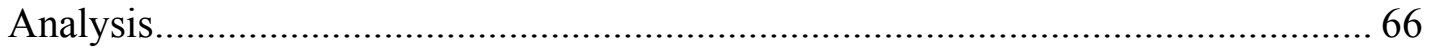

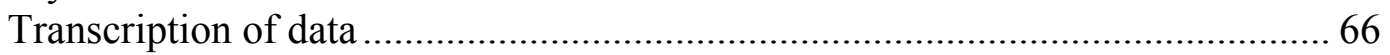



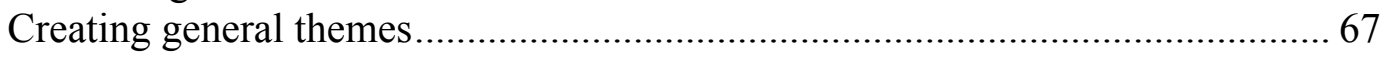

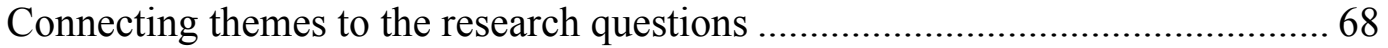

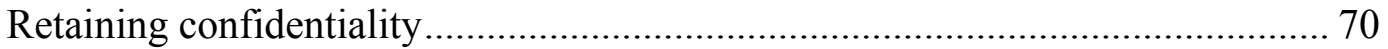

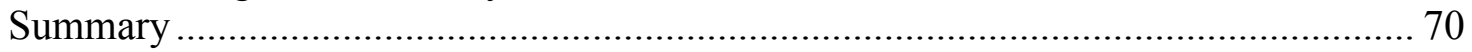

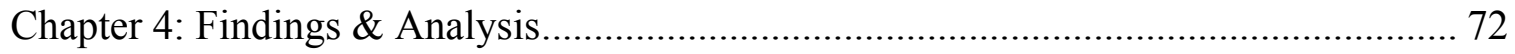

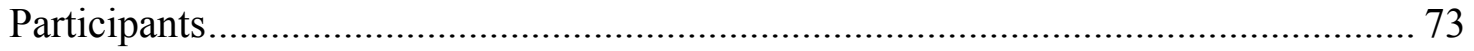

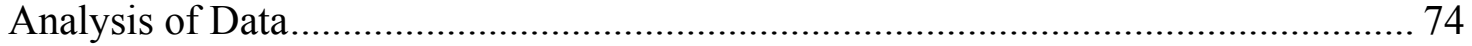

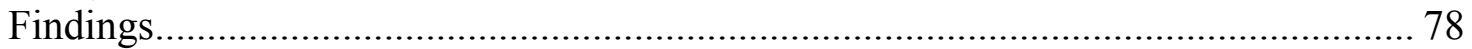

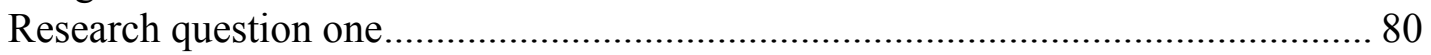

Theme one: External support systems - teachers and family/guardians ............. 81

Leticia's mathematics identity development .............................................. 82

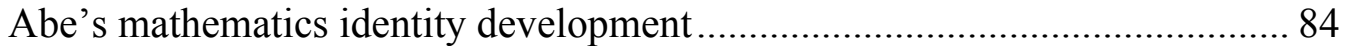

Jamie's mathematics identity development .............................................. 89

Theme two: Personal reflection on mathematics learning process ...................... 92

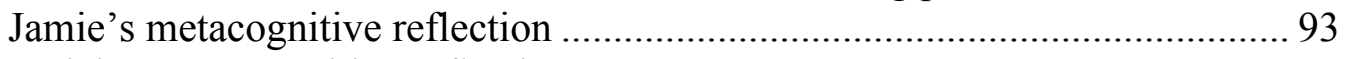

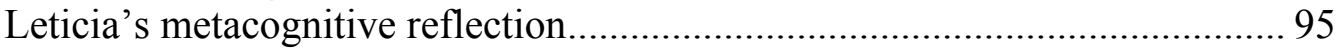

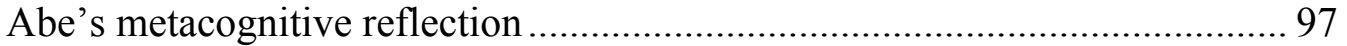

Research question two ................................................................................ 98

Theme one: Intentional and supportive classroom structure and environment for

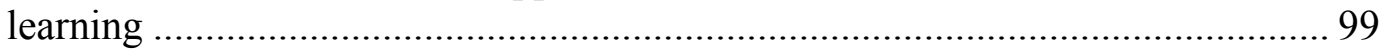

Abe's reflection on classroom structure and environment ............................ 99

Jamie's reflection on classroom structure and environment........................ 104

Leticia's reflection on classroom structure and environment ....................... 106

Theme two: Structures for collaboration with classmates through mathematics

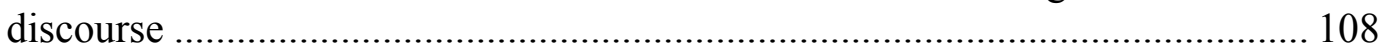

Jamie's reflection on collaboration and mathematics dialogue .................... 108

Abe's reflection on collaboration and mathematics dialogue........................ 111

Leticia's reflection on collaboration and mathematics dialogue .................. 114

Theme three: Teacher emphasis on mathematics literacy and relevancy .......... 116

Jamie's reflection on mathematics literacy relevancy ................................ 116

Leticia's reflection on mathematics literacy relevancy ............................... 120

Abe's reflection on mathematics literacy relevancy .................................. 122

Interpretation of Results............................................................................. 124 
MATHEMATICS IDENTITY vii

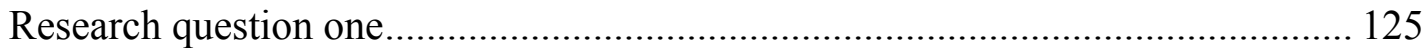

Theme one: External support systems - teachers and family/guardians ............ 125

Theme two: Personal reflection on mathematics learning process .................... 126

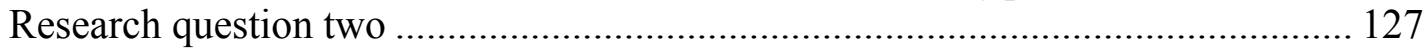

Theme one: Impact of classroom structure and environment on learning.......... 128

Theme two: Student collaboration through mathematics discourse .................. 129

Theme three: Emphasizing mathematics literacy and relevancy ....................... 130

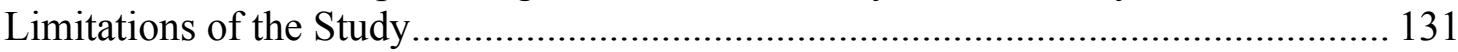

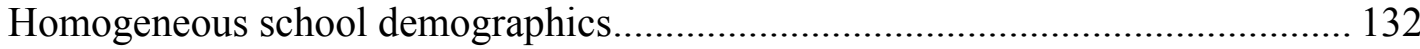

Participants with strong mathematics identities................................................. 134

Missing student voice from question creation and analysis.................................. 134

Chapter 5: Discussion and Conclusion .................................................................. 136

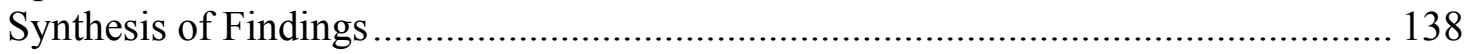

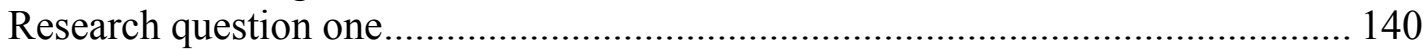

Theme one: External support systems — teachers and family/guardians ........... 140

Theme two: Personal reflection on mathematics learning process .................... 143

Research question two .................................................................................... 144

Theme one: Impact of classroom structure and environment on learning.......... 145

Theme two: Student collaboration through mathematics discourse .................. 149

Theme three: Emphasizing mathematics literacy and relevancy ....................... 153

Situated in a Larger Context ............................................................................. 156

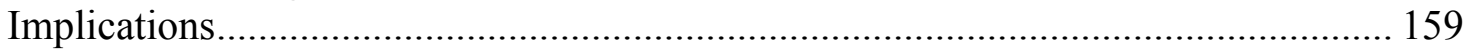

Building an academic community of learners ................................................... 160

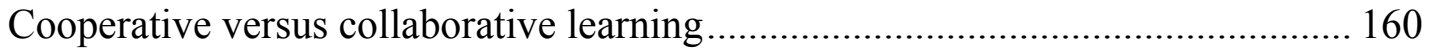

Increase mathematics literacy and relevance.................................................... 161

Future Considerations and Recommendations for Additional Research ................... 162

Interview students with seemingly less-robust mathematics identities ................. 162

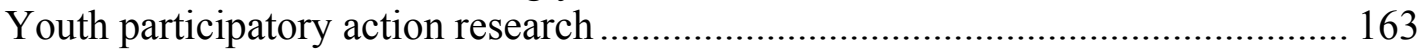

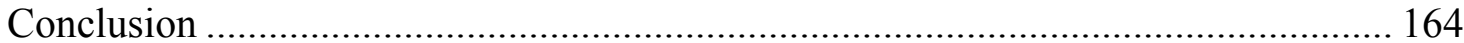

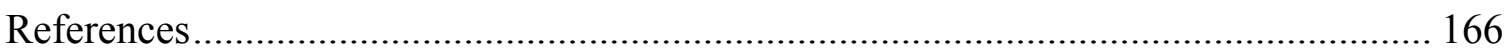

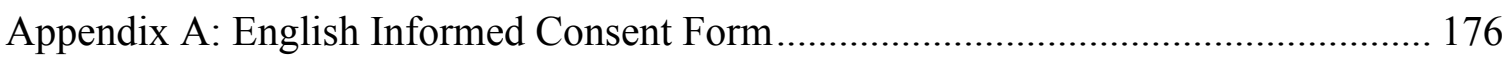

Appendix B: Spanish Informed Consent Form...................................................... 178

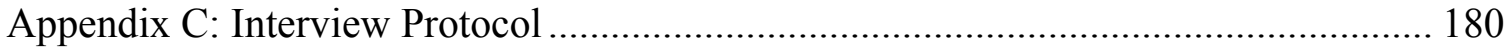

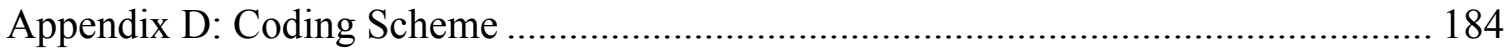




\section{Chapter 1: Introduction}

Nationally, the percentage of high school students taking higher-level mathematics courses (beyond Algebra 2) has increased from the late 20th century to the present. However, as compared to White high school students enrolled in advanced mathematics classes, the rate is lower among students of color, specifically among the Latinx (gender-inclusive form of Latina/o) population. This disproportionate lack of representation in advanced mathematics classes is the background to my problem of practice. The problem addressed in this study was whether the district initiatives surrounding collaborative teaching practices supported students in building their identities as mathematics learners, led to self-empowerment, and contributed to academic agency. A desired outcome of studying this problem would be an increase in the rates of Latinx high school students enrolling and being successful in advanced mathematics courses.

The disproportionate representation of students of color in higher mathematics classes is not unique to my classroom or school district. The racial diversity of our public school system is continuing to grow. According to the March 2018 U.S. Census Bureau, Population Division, the Latinx (referred to as Hispanic/Latino in the U.S. Census documentation) population will experience steady growth, as projected through the year 2060. Similarly, the 2017 Pew Research Center analysis noted this growth, even despite a then-stagnant population growth rate among the Latinx (Hispanic) population (attributed to the Great Recession), stating, "The analysis shows that the Hispanics continue to have the largest growth of an ethnicity and race group" (Martinez, 2017, para 5). As the demographics in the U.S. public education system continues to diversify, the 
need for holistic pedagogical change to ensure all learners are included becomes ever more critical.

\section{Background of the Problem}

Picture with me the following scenarios of two students who attend the same high school. Josue, a senior, lives at home with his mom and dad, uncle, and his three younger brothers. Neither of Josue's parents have documentation to show they are legally living in the United States. Josue's mother works in agriculture as a year-round fieldworker, and his father works in construction. Between both his parents' incomes, Josue's family is just below the federal poverty threshold.

Daisy, a sophomore, immigrated from Oaxaca, México to the United States by herself, leaving her family behind. She lives with her aunt in a two-bedroom apartment shared by her aunt's live-in boyfriend, and her three younger cousins. Instead of finding a part-job, Daisy is in charge of taking care of her cousins from the time she is finished with school until she puts them to bed at night.

Josue and Daisy are in a school district that has specifically focused on intentional mathematics community and mathematics dialogue through building purposeful student collaboration in the classroom. However, what is unclear is whether these initiatives are supporting students in building their identities as mathematics learners, leading to selfempowerment, and contributing to academic agency; thereby increasing the rate of Latinx high school students in advanced mathematics courses.

One of the reasons that my school district has focused on mathematics community and dialogue (Advancement Via Individual Determination, 2018; Weaver \& Dick, 2009) is because drastically fewer Latinx students take advanced mathematics courses as 
compared to their White high school peer group. According to the 2011 National Assessment of Educational Progress (NAEP) report, 14\% of White high school students took rigorous (pre-calculus or higher) mathematics courses, whereas only $8 \%$ of Hispanic high school students took rigorous mathematics courses (Nord et al., 2011). These percentages highlight an alarming reality that many high school students are not taking upper division math courses, and Latinx students are taking advanced classes at significantly lower rates than their White peer group.

While advanced math classes are not a predictor for success in higher education (i.e. college or university), advanced classes expose "students to college-level material in a supportive high school environment, where students are, presumably, more likely to receive the individualized attention they need to develop the study skills and habits of mind that will serve them well in college" (Klopfenstein \& Thomas, 2009, p. 876). Without equitable access to higher mathematics, equitable opportunities for higher education, higher paying jobs and global opportunity might not be attained for students of color, specifically those of African American, Native American, or Latinx descent. If our job as educators is to provide as many open doors of opportunity for our students as possible, equitable, rigorous, and empowering education must be accessible for all students.

\section{Statement of the Research Problem}

My research problem focused on the interplay between district initiatives emphasizing student collaboration through mathematics discourse and the ways teachers can help foster mathematics identity, self-empowerment, and academic agency in Latinx high school students. This research drew from critical race theory (with emphasis on the 
culturally sustaining pedagogy model) and funds of knowledge. I studied the mathematics identities of selected Latinx high school students because I wanted to find out how students can use mathematics as an advocacy tool for social justice and selfempowerment. My study built directly upon the key constructs within critical race theory (Delgado, Stefancic, \& Harris, 2012; Ladson-Billings, 2016; Parker \& Lynn, 2016; Smith-Maddox \& Solórzano, 2002), culturally sustaining pedagogy (Paris, 2012), and funds of knowledge (González et al., 1995; González, Andrade, Civil, \& Moll, 2001).

\section{Significance of the Research Problem}

Mathematics discourse has been a focus of district-wide initiatives in many school districts in Oregon, mine included. Specifically, my school district worked with Oregon Mathematics Leadership Institute (OMLI) to provide professional development for implementing collaboration-based teaching strategies in the classroom. The goal was to increase student academic achievement in mathematics through an emphasis on professional collaboration of teachers, and improve mathematics discourse of students in the classroom (Weaver \& Dick, 2009). Additionally, within the last four years (20152019), my school district has adopted Advancement Via Individual Determination (AVID) strategies, which also foregrounds student collaboration as a teaching tool for improving student academic achievement — that all students complete and are successful in rigorous high school courses, and graduate with college readiness so as to be successful in a competitive global society (AVID, 2018). AVID (2018) specifically emphasizes, "Our students work together to problem solve and to change the level of discourse in the classroom as they prepare for success" (para 3). 
Student-centered directives are becoming more commonplace as schools seek to create more relevant educational practices. Gay (2002) said of the AVID program that it promotes "strong elements of communal identity, cooperative learning, and reciprocal responsibilities in teaching college preparatory English curriculum to low-achieving African-American and Latino students" (p. 623). I desired to learn how these initiatives influenced students as these initiatives pertain to the development of student mathematics identity, self-empowerment, and pursuit of academic agency.

Students and their teachers bring their diverse backgrounds to the classroom. This diversity plays a role in how students understand mathematics. Swetz (2009) expressed, "In the case of mathematics, culture often expresses itself in the often-heard classroom questions: What is this stuff good for? When am I going to use it” (p. 30)? Taking this idea a step further, Gutiérrez (2013) suggested focusing on identity and power, and emphasized how standardizing the curriculum can strip away the ability for a teacher to make learning relevant and meaningful. Gutiérrez explained:

The rush to move onto the next mathematical concept (or response to intervention procedure) almost ensures we will not ask why this concept? Who benefits from students learning this concept? What is missing from the mathematics classroom because I am required to cover this concept? How are students' identities implicated in this focus? (p. 37)

Therefore, recognizing the power dynamic of mathematics education might begin to uncover how students' racial and mathematics identity can be better supported through rethinking mathematics teaching practices. 
Identity and power. The questions of "For whom is mathematics curriculum written?" and "How is curriculum being taught?" strike at the heart of the significance of my problem of practice because these questions speak directly to the issue of who holds the power in mathematics education. Gutiérrez (2008) related, “Addressing issues of identity and power is important for decentering the underlying assimilationist perspective in many mathematics education policy documents" (pp. 360-361). The idea that racial identity and the ways in which students construct their identity as mathematics learners is a shift toward empowering students to connect to mathematics on a deeper level. Gutiérrez (2013) stated, “This is not just about understanding students' identities in some kind of developmental, linear trajectory, or deterministic manner. It is about how identities are (re)constructed in spaces and moments" (p. 39). Through this statement, Gutiérrez invited mathematics educators to consider what it means to be a Latinx mathematics learner, and to consider the ways power influences mathematics education.

Identity. Educators, and members of society as a whole, often view mathematics as a colorblind content area, meaning that many people do not consider race to be a factor in mathematics education. At mathematics conferences, I have heard the most wellmeaning speakers claim that mathematics is the only content area without bias, and that mathematics is a universal language. The unfortunate truth is that there exists a racial and gender mathematics hierarchy (Martin, 2009). Martin (2009) argued that failure to recognize that mathematics continues to be a department that is "overwhelmingly White and male" and is a "space that normalizes and privileges Whiteness (and maleness) and influences societal beliefs about who can and cannot do mathematics" (p. 312). In nationwide mathematics initiatives that promote a "mathematics for all" agenda, the 
disquieting reality is "the emphasis on all students is symptomatic of an uneasiness, or unwillingness among many math education researchers and policy makers to grapple with the complexities of race and racialized inequality" (Martin, 2009, p. 311). When the complexities of race in education are not wrestled with at a national level, it is more difficult to address the complexities at the classroom level, which may make it harder for students of color to access equitable experiences, as compared to their White peers (Martin, 2009). If a person's measure of identity can be attributed to three particular elements: "a sense of belonging to a group; a sense of achievement within the norms of the group; and particular behaviors associated with belonging to a particular group" (Boaler, William, \& Zevenbergen, 2000, p. 4), then "socially constructed meanings for race are important in the everyday contexts in which individual students must struggle for mathematics literacy and negotiate both their racial identities and their identities as doers of mathematics" (Martin, 2009, p. 315). Students' racial identities must certainly be realized as an influential contributor to teachers' pedagogy.

Martin (2009) offered a helpful definition of mathematics identity, which I believe mathematics teachers should become familiar with as they begin to wrestle with the idea of racial and mathematics equity in their classroom. Martin stated:

Mathematics identity refers to the dispositions and deeply held beliefs that individuals develop about their ability to participate and perform effectively in mathematical contexts and to use mathematics to change the conditions of their lives. A mathematics identity encompasses a person's self-understanding and how they are seen by others in the context of doing mathematics. (p. 326) 
Therefore, I summarize mathematics identity with four key characteristics. The first is that students view themselves as mathematicians. How students view themselves as mathematics thinkers and learners inside the classroom can impact how they view themselves as mathematics thinkers and learners outside the classroom, and how students actively participate in developing their mathematics identities. Mathematics identity, like any other identity, is not confined within the four walls of a school classroom. The second characteristic of mathematics identity incorporates how a student is seen within a community of learners. This relates to how the student is seen by their peers as an active participant and contributor to the learning process. The third characteristic is that the student realizes that identity is not static. Who they are as a learner grows as the student wrestles with concepts and challenges their mind. The last characteristic is that students seek empowerment through the application of what is learned. This refers to how students critically use mathematics to actively work toward transforming their lives.

Supporting students of color as they build their mathematics identity may begin primarily with teachers looking beyond what national testing statistics say about their students' cultural subgroup (the term "sub" only refers to a group within a group, and is not meant to carry a negative connotation). Martin (2009) stated, "Goals that are motivated by a singular focus on "closing the racial achievement gap" carry with them assumptions about the inferiority of African American, Latino, and Native American students" (p. 298), and to become higher achieving, one must become less African American, Latino, or Native American. Gutiérrez (2008) asserted, “A greater focus on Latinas/Latinos and ELLs in learning contexts is important for understanding their needs, moving beyond stereotypes, attending to their strengths, and countering the negative 
image that is offered by standardized test scores and group comparisons" (p. 361). I believe the same holds true for African American and Native American students, as well as for students from other historically marginalized populations. Instead, Martin encouraged teachers to "better understand and appreciate students' racial, academic, and mathematics identities and to more closely examine school and classroom practices to determine which of these practices promote positive and negative identities among students" (p. 304). Teachers can foster a healthy learning environment by seeking to understand how to support their students' culture, race, and academic aspirations by evaluating their own pedagogy as it affects student mathematics identity.

Mathematics classrooms can support students in fostering a healthy mathematics identity by giving voice to students of color, especially those of African American, Latinx, or Native American heritage. Gutiérrez (2008) explained, "There is little recognition of the linguistic and cultural resources that marginalized students bring to the mathematics classroom or to the discipline of mathematics" (p. 361) and suggested, "Ideally, every student should see herself or himself reflected in the curriculum, as well as learn about others" (p. 360). Studies of mathematics education have done very little to “privilege the voices, and counterstories, of African American, Latino, and Native Americans in this way" (Martin, 2009, p. 327). If students are affirmed in learning experiences that foster racial and mathematics identity construction, and give voice to their lived experiences, students may feel an empowered sense of agency to use mathematics as a mechanism for change.

Power. Fowler (2013) expressed the social/political power that members of a dominant culture possess (over those who do not belong to the dominant culture) can 
clearly be seen as a mobilization of bias. Mobilization of bias is "bias experienced by minority children in schools, bias encountered by women who enter school administration, and bias in school choice policies" (Fowler, 2013, p. 33), and, I would add, bias in how teachers enact their curriculum. Because public education was originally established for wealthy, White, English-speaking men, Fowler explained, "public education is advantageous to those who belong to one or more of these social categories and disadvantageous to those who do not" (p. 32). Schools and policies still reflect these biases toward the White, middle to upper class, culturally dominant group, as the majority of the policymakers are a part of the White, middle to upper class demographic (Fowler, 2013). Students who do not identify within the culturally dominant group might struggle to understand, and successfully maneuver around, the educational system and teacher pedagogy.

The White, culturally dominant bias is especially important to deconstruct for public school teachers for two critical reasons. First, the 2015-2016 National Center for Education Statistics (NCES) reported $80.1 \%$ of the public teaching force is White (U.S. Department of Education, 2017). As a White, middle class woman who teaches in a school district that is predominantly Latinx, understanding this bias was an imperative measure as I sought to engage in equitable, culturally relevant, responsive, and sustaining teaching practices with my students.

Second, teachers have a substantial amount of power in the classroom with respect to how they choose to involve their students in the learning process. In recognizing this power, teachers can help their students: “(1) understand the power structure in the classroom and beyond, (2) survive and thrive in and through power 
structures, and (3) work to change inequitable, racist, and unjust power structures that they encounter in their school and other environments" (Milner, 2011, p. 66). LadsonBillings (2017) explained that the failure of the educational system to involve students in their education in such a way as to empower the student to connect with the problems in their lives "is exactly why students do not trust schools to be places that deal honestly and forthrightly with the issues of their lives" (p. 146). Gutiérrez (2013) affirmed that power, if instead of being used against others, is "institutionalized in discourses, then students who have been marginalized by society have the ability to construct a counter narrative (either though voice or actions) that justifies their position and affirms their self-worth" (p. 52). Inviting students into their education to make sense of their academics, as it pertains to their lived experiences, can build trust and a sense of belonging, in that the student's voice is heard and valued.

Taking these ideas of power to a more granular level, Milner (2011) suggested that teachers might "pose questions which help students locate answers to questions and area of interest, resulting in a teacher/students interaction that is dynamic and evolutionary" (p. 66). Fostering this type of teaching/learning experience can help students to become active participants in their learning, and better "understand that learning is an ongoing process and that they can garner power through knowledge construction and acquisition” (Milner, 2011, pp. 66-67); that students are not merely automatons waiting to fulfill order. Gutstein (2009) ardently argued against mathematics education as a means to fuel a capitalistic agenda, instead viewing "mathematics students as investigators of social reality and as advocates and actors for social change" (p. 138). Fostering student agency in their learning can empower the student to further academic 
heights, unbounded by the dominant culture's political agenda (which may or may not have the best interests of students in mind).

Student voice. As a mathematics educator of 12 years, I am embarrassed to admit how few times I have asked my students what I could do better; what they needed from me to strengthen their mathematics identity, self-empowerment, and academic agency; and their thoughts on the district-implemented approach of focused mathematics dialogue (as student voice was not sought after by district administration before implementing the focus on mathematics dialogue). I am not a novice teacher; I have won a prestigious award recognizing excellence in teaching; I have participated in extracurricular activities with my students; I have attended band concerts, plays, and ballgames of all sorts. Yet, I have been incredibly humbled in recognizing the immense flaw and disservice of neglecting student voice as a pedagogical foundation. Milner (2015) commented, "In my experience, I have found that we-researchers, teachers, principals, counselors, parents, policy makers — often spend time talking about students and not enough time talking and listening to them" (p. 70). I am as guilty of this as many educators, administrators, policy makers, school boards, and the like. It is not out of an uncaring heart, but rather disillusionment that I (as a teacher) have all the answers. In reality, I am not the "answer keeper," and have much to learn from the voices of my students. Student voice, Milner explained:

can help us identify areas that need to be addressed in ways that people outside their situation cannot. Students know their experiences better than anyone else. In addition, these students speak to common attitudes, practices, and experiences that can influence student learning and social development. (p. 74) 
The focus of this study was on amplifying student voice precisely because of its inherent value. Asking students to participate in their academic journey in this manner is an important step in moving toward transformational academia.

\section{Presentation of Methods and Research Questions}

Student voice, especially in the case of students who have historically been marginalized, quite nearly does not exist in scholarly literature. In his educational research regarding Chicano students, Pizarro (1998) was

shocked, although not surprised, by the fact that Chicanas/os and their voices had been almost completely excluded from educational research. Even the research that addressed the critical problems facing Chicanas/os in the schools did not include the students' perspectives to any substantial degree. (p. 59)

In this qualitative research, my aim was to amplify the voices of Latinx students. I identified three students whose voices could add substantially to the extant knowledge of mathematics education, specifically as it pertains to identity, self-empowerment, and academic agency, and as connected to the issues of discourse and engagement in mathematics.

Student voice was a crucial element of design for this research as student voice is the element that is typically missing within educational research. Therefore, I interviewed three high school seniors (aged 17) about teaching practices that they recognized to have supported their mathematics identity and agency toward continuing in mathematics, and the role that mathematics plays in their lives. The purpose behind choosing to interview seniors is that by their fourth year of high school, students have a clearer picture as to who they are as learners, can better articulate their identity as a 
mathematics learner, can recognize which teaching techniques best support their learning, can identify specific parts of their history that have impacted their identity as mathematics learners, and (in general) have a longer history as mathematics learners. I believe seniors in high school have a unique perspective on their mathematics identity, and can influentially contribute to research. Therefore, I chose to amplify their voices. Opening a safe space for students to create their counter-narrative can provide impetus for deepening self-empowerment and academic agency.

I will bring the results of the analyzed data as suggestions for change to the mathematics department and the district curriculum department. It is an imperative part of the process to affirm that the student's voices are heard beyond the interviews. Student voice is a piece of critical learning for teachers, and the school district as a whole. Bringing students' words to the attention of "the people in power" can further engage students in their academic pursuits, foster self-empowerment and academic agency, and bring transformational changes to the school district for years to come.

As is the case in many districts across the United States, my students are experiencing a mathematics curriculum focused on engaging mathematical discourse. However, to date, very little research incorporates student-voiced thoughts about what this experience has been like. Based on my review of the context, the history of the problem, and the urgent need for student voice to be amplified, the following research questions emerged.

Research questions. The research questions that guided my study were:

1. In what ways do high-performing Latinx high school students describe the development of their mathematics identities? 
2. What pedagogical methods (ways of teaching) do high-performing high school students find the most meaningful as mathematics learners?

\section{Definitions of Key Concepts}

Although previously alluded to in this text, in this section, I define key terms used throughout this study to lend clarity to the reader.

Culturally relevant pedagogy emphasizes using students' cultural background and knowledge as a teaching tool within the classroom with the specific purpose of increasing academic achievement among students who have been marginalized by the dominant culture (Ladson-Billings, 1995).

Culturally responsive teaching is a pedagogy defined as a focused approach on students' cultural background to support academic achievement. Educators using this pedagogy teach students to be proud of their own and others' cultural backgrounds, connect home and school experiences, use a variety of teaching strategies that support diverse learning styles, and integrate multicultural materials and curriculum into daily teaching (Gay, 2000).

Culturally sustaining pedagogy "seeks to perpetuate and foster — to sustainlinguistic, and cultural pluralism as part of the democratic project of schooling" (Paris, 2012, p. 95), to diminish deficit-mindedness by nurturing multiculturalism, while recognizing "culture as dynamic, shifting, and ever changing” (Paris, 2012, p. 94).

Latinx is a gender-neutral form of Latina/o that I will be using throughout this study. According to Passel and Taylor (2009), the Hispanic or Latina/o term generally refers to a person who originates from a Spanish-speaking nation, including Spain, 
Mexico, Central America and South American countries (not including Portugal or Portuguese-speaking Brazil).

Mathematics discourse or mathematics dialogue (Boaler \& Greeno, 2000; Boaler et al., 2000; Gutiérrez, 2013; Weaver \& Dick, 2009; Wedekind, 2011) is a pedagogical tool that emphasizes collaboration as a means for fostering deeper conceptual understanding. My school district has adopted several initiatives across all grade levels that have focused on the implementation of mathematics dialogue as a means for increasing students' academic achievements.

Mathematics identity has four key characteristics (Martin, 2009). The first characteristic is that students view themselves as mathematicians. The second characteristic incorporates how a student is seen within a community of learners. The third characteristic is that the student realizes that identity (mathematics identity or otherwise) is not static. The last characteristic is that students seek empowerment through the application of what is learned.

Mathematics instruction is a pedagogy that "build[s] on the thinking, interests and experiences" (Tate, 1995, p. 168) of the culturally diverse student body. Key factors of math instruction include investigating and problem-solving mathematics in application scenarios, justifying solutions, and applying concepts to support basic mathematical principles (Tate, 1995). I focused exclusively on algebra through calculus courses.

Students of color are students who are not members of the dominant race, which in the United States is identified as White. In my study, I focused specifically on students in the Latinx demographic. 
A public school is a government-established organization that provides free education to all enrolled students. Every state's Department of Education allocates their own school funding system (U.S. Department of Education, 2014). However, "almost every state funds schools based on property taxes. Those areas with property of greater wealth typically have better funded schools" (Ladson-Billings, 2016, p. 27). For this study, I only considered public high schools in Oregon. 


\section{Chapter 2: Review of Literature}

The problem addressed in this study was whether district-driven initiatives focused on collaborative teaching practices are supporting students in building their identities as mathematics learners, self-empowerment, and academic agency. The purpose of this study was to heighten the voices of several Latinx youth identified by their mathematics teacher as being strong mathematics learners. Extant research suggested that fostering students' mathematics identity plays a supporting part in building student self-empowerment and academic agency, which may lead students to elect to take advanced mathematics classes.

In this chapter, I discuss the importance for teachers to recognize and build upon students' funds of knowledge, the impact of teachers and students creating a mathematics community based on using intentional mathematics dialogue, maintaining high expectations for critical thinking, and building space for inquiry. I analyze these ideas through the lens of the following theoretical framework.

\section{Theoretical Framework}

In this section, I evaluate critical race theory (CRT) and funds of knowledge (González et al., 1995; González et al., 2001) with respect to my problem of practice. I look directly at the how the framework support equitable and intentional mathematics instructional strategies, and explain the connection to my research questions.

Critical race theory. The critical race theory (CRT) "movement is a collection of activists and scholars interested in studying and transforming the relationship among race, racism, and power" (Delgado et al., 2012, p. 3). The difference between CRT and other civil rights movements is that CRT "questions the very foundations of the liberal 
order, including equality theory, legal reasoning, Enlightenment rationalism, and neutral principles of constitutional law" (p. 3). In connecting these key ideas to the field of education, Ladson-Billings (2016) explained that teaching strategies often carry the assumption that students of a racial minority are lacking in academic ability. LadsonBillings argued, "This race-neutral perspective purports to see deficiency as an individual phenomenon. Thus, instruction is conceived as a generic set of teaching skills that should work for all students" (p. 25). Proponents of CRT aim to refute the deficiency model by insisting that race must be considered in teaching strategies (and not looked on as a deficit to learning) and assert that all students, regardless of race or SES level, have the ability to be academically successful (Ladson-Billings, 2016). Without reforming this practice, "one of the basic inequalities of schooling will remain in place and virtually guarantee the reproduction of the status quo" (p. 27). It is critical for teachers to rethink instruction, taking into consideration the demographic make-up of their communities of students.

These are not new ideas in the realm of education, but CRT ideologies "represent a collective challenge to the existing methods of conducting research on race and inequality" (Smith-Maddox \& Solórzano, 2002, p. 68). Ladson-Billings (2016) explained, "If we are serious about solving these problems in schools and classrooms, we have to be serious about intense study and careful rethinking of race and education" ( $\mathrm{p}$. 28). Parker and Lynn (2016) reiterated this exact thought in their remark, "Therefore, the future of CRT and its place in qualitative research will partially depend on the efforts made by researchers and scholars to explore its possible connections to life in school and communities of color" (p. 150). Rethinking, reforming, and remodeling mathematics 
instruction with student identities in mind can encourage and support students to reach higher self-empowerment and academic agency.

Socio-political perspective. Rooted in critical race theory, people who use the socio-political perspective in mathematics examine the existence of power in mathematics education, and thus its ability to empower students (Valero, 2004). Valero explained, "The examination of power requires critique as a means to offer a counterpart of naïve views about the way in which mathematics and mathematics education are implicated in the creation and maintenance of particular social structures" (p. 11). Additionally, Gutiérrez (2013), explained:

CRT seeks to privilege the voices of scholars of color and the experiences of students and teacher and to work against popular discourses that suggest such experiences are subjective, illegitimate, or biased. As such, common conceptual tools are counter-narratives and storytelling. (p. 42)

Rethinking mathematics education practices with a sociopolitical mindset can be the beginning for pushing against the dominant culture and to offer counter-narratives that affirm the voices of those who have historically been marginalized.

Foundational to teaching with equity and social justice is "supporting students" sociopolitical (or critical) consciousness" (Ladson-Billings, 2017, p. 145). The sociopolitical perspective helps students to cultivate a "critical consciousness that allows them to question the veracity of what they read in classrooms and pose powerful questions about social, cultural, economic, political, and other problems of living in a democracy that attempts to serve a diverse populace" (Ladson-Billings, 2017, p. 146). Teaching through a sociopolitical lens seats power and ownership of education with the 
student. Choosing projects and materials that resonate with the student based on the students' interest directly impacts the student (Ladson-Billings, 2017). Gutiérrez (2013) offered, "By thinking critically about the benefits of and drawbacks to formatting realities with mathematics, we might be more deliberate in how and when we want to use/create mathematics in our everyday lives" (p. 47). Ladson-Billings (2017) explained that the failure of the educational system to involve students in their education in such a way as to empower the student to connect with the problems in their lives "is exactly why students do not trust schools to be places that deal honestly and forthrightly with the issues of their lives" (Ladson-Billings, 2017, p. 146). Gutiérrez affirmed that power, if instead of being used against others, is "institutionalized in discourses, then students who have been marginalized by society have the ability to construct a counter narrative (either though voice or actions that justifies their position and affirms their self-worth" (p. 52). This affirmation can empower the student.

Funds of knowledge. Learning students' funds of knowledge is a fundamental aspect of teaching, as students' home lives and community involvement affect their school lives, and vice versa. Funds of knowledge is defined as " the historically accumulated bodies of knowledge and skills essential for household functioning and well-being” (González et al., 2001, p. 116). District-wide initiatives, such as supporting intentional mathematics dialogue through student collaboration, is one way of embracing students' funds of knowledge because students are encouraged to offer their knowledge and connection to the mathematics concepts through their lens of understanding. Furthermore, teachers can better understand their students when they first understand the community and home lives of their students (to the greatest extent possible), 
acknowledging that teachers will never know or understand everything in the lives and histories of their students. González et al. (2001) researched the effect of teachers' understanding of the cultural background and home lives of their students. Just as SmithMaddox and Solórzano (2002) suggested a need to understand the students' community and cultural background (by teachers visiting and talking with community members), home visits were the primary aim of the research behind understanding students' funds of knowledge. To combat a deficit mindset (teachers viewing their students in terms of lacking knowledge), the basic principle of "funds of knowledge" is to focus on what knowledge the student brings into the classroom, and thereby building a foundation for academic growth (González et al., 1995). González et al. (2001) explained, “Teachers venture[d] into their students' households and communities, not as teachers attempting to convey educational information, but as learners seeking to understand the ways people make sense of [the students'] everyday lives" (p. 116). Teachers became researchers, and "were offered a format to think, reflect, and analyze with others and to produce the knowledge necessary to transform their teaching in positive ways" (González et al., 1995, p. 445). Transformative teaching can occur when teachers venture to connect with their students' funds of knowledge.

Changing the way teachers view culture is the first classroom application of a funds of knowledge framework. González et al. (1995) expressed that culture was not merely a random assortment of traditions and holidays. Rather, culture is a way of living: the way in which people understand their circumstances, and the ways people use their experiences to build knowledge. In recognizing culture as a way of living, a deficit mindset can be counteracted. González et al. (2001) expressed "This broader view of the 
political ecology of households helps to reconceptualize them [households] not as the source of barriers to educational attainment, but as repositories of resources that can be strategically tapped" (p. 117). Students begin their educational learning in their households; therefore, students' informal learning can strengthen their formal learning. Extending these ideas, González et al. (2001) proposed the question, "Could a funds of knowledge methodology, through ethnographic understanding of a community, reveal mathematical funds of knowledge that could impact the classroom pratice" (p. 117)? To answer this question, González et al. (2001) consulted the works of Vygotsky. Specifically, Vygotsky's concept of the zone of proximal development (ZPD) (Vygotsky, 1978) revealed a cycle of learning. Vygotsky (1978) stated, "Thus, the zone of proximal development permits us to delineate the child's immidiate future and his dynamic developemntal state, allowing not only for what already has been achieved developmentally but also for what is in the course of maturing" (p. 33). The child's developmental state of being is built upon while at school. Daily lived experiences affect in-class comprehension of mathematical concepts, and vice versa. This cycle describes a “conscious awareness and control onto the everyday” (González et al., 2001, p. 121). The mathematical concepts taught in school and the life experiences of students outside of school are interlocked and cannot be separated from one another. Vygotsky (1978) argued that if students' lived experiences are successfully intertwined with school learning, then, "it schould reveal to the teacher how developmental processes stimulated by the course of school learning are carried through inside the head of each individual child" (p. 35). Educators can build their understanding of students' lived experiences by making a pointed effort to learn about their students' interests, family, and community 
activites, and connect those experiences to what is being taught and learned in the classroom.

Critiques of critical race theory and funds of knowledge. Studying the critiques of these theories is equally important in taking a holistic approach to understanding my problem of practice. While these constructs are resonant and relevant, they are not necessarily without limitation.

Critical race theory. Learning about how lived experiences impact a person is a defining element in understanding how race impacts education. Critics of critical race theory suggest that the storytelling narrative approach lacks an objective, factual basis and instead draws from subjective experiences and is intended to elicit an emotional response, rather than an outcome or statement based on tangible, externally verifiable facts. One such critic, Litowitz (2016), suggested a concern with storytelling being that storytelling "can lead in any and every direction, politically speaking" (p. 303). The storytelling narrative can influence the way in which people lean politically because narrative "plays on emotion, instead of reason, and therefore it can convince people to adopt a position without giving them a doctrinal basis for it" (Litowitz, 2016, p. 303). Litowitz argued that CRT should be more unified in theory and purpose by incorporating more externally-validated, evidence-based facts, rather than relying simply on piecedtogether subjective narrative alone. However, while this is perhaps a valid point within the frameworks Litowitz references, for the purposes of my research, student perspective was an imperative and urgent piece of data collection, especially seeing as though student voice in education is already so rarely validated in research. 
Similar to the arguments of Litowitz, Farber and Sherry's (2016) critique of critical race theory centered the small number of documented "voice[s] of color" (p.313). Farber and Sherry posited that due to the lack of empirical and concrete examples of voice of color, there is not sufficient physical evidence to evaluate voice of color. Farber and Sherry argued, "Of course, the difficulty in describing the voice of color does not disprove its existence, but it does make analysis more difficult" (p. 314). Farber and Sherry argued that voice of color through storytelling is subjective and inconsistent across the board. Furthermore, Farber and Sherry explained, "Without a clearer conception of the "voice of color," it is difficult to assess the arguments on behalf of its existence" (p. 315). Therefore, these authors argue CRT lacks evidence from multiple perspectives, and lacks consistency in storytelling content and purpose, which for Farber and Sherry, undermines the theory as a whole. Nevertheless, CRT remains as a valid and valuable frame for my research, because it is impossible for every person to have exactly the same life narrative. Consistency across storytelling is not what is critical. The critical matter at hand is for Latinx high school students' mathematics counter-narratives to be heard and valued. Each story has merit and can have a direct impact on teacher pedagogy.

Funds of knowledge. For professional educators, the "funds of knowledge" theory is foundational in working against deficit-mindedness, and instead highlights students' assets. As such, it is important to view possible limitations. In her critique of specific funds of knowledge terms, Oughton (2010) viewed the term "funds" as a critical word to evaluate. The word "funds" can imply limitations in that one person's fund can be more filled than another person's fund, or that a fund can be depleted. Oughton 
suggested a different metaphor, one of a "village or a pool" (p. 72). These terms seemed more appropriate because they are a "source which is filled without intention or directed effort on anyone's part, yet which can be drawn upon by any member of the community and is not diminished through use" (Oughton, 2010, p. 72). The village or pool metaphor, therefore, does not posit deficit-mindedness, and as such, may be a more flexible term than funds. However, given that a wealth of extant research specifically invokes the concept of "funds" (González et al., 1995; González et al., 2001; SmithMaddox \& Solórzano, 2002), I choose to employ this term because of the foundational principle that all students come to school with a vast quantity of knowledge from their lived experiences. Therefore, using the term "funds" does not detract from the focus of teachers learning and building upon students' strengths and abilities.

Rios-Aguilar, Kiyama, Gravitt, and Moll (2011) also critiqued the funds of knowledge approach, arguing, "a funds of knowledge approach should also be studied from a capital perspective" (p. 167). As such, Rios-Aguilar et al. addressed three specific limitations of funds of knowledge: “(1) an overemphasis on the 'recognition' of funds of knowledge, (2) use of a single methodological approach, and (3) dependence on adult household practices as the primary unit of analysis" (p. 166). Rios-Aguilar et al. argued that the funds of knowledge approach did not expressly examine the role of power in the educational system as a whole, and therefore suggested, "a capital perspective can help link broader contextual issues such as power with classroom, social class, and household dynamics" (p. 171). Not only is it important for teachers to recognize students' funds of knowledge, it is imperative that students recognize their own funds of knowledge and convert their knowledge into capital (Rios-Aguilar, Kiyama, Gravitt, \& Moll, 2011). 
Students converting their funds of knowledge to a more observable form of capital (for example, through increased graduation rates, higher grade point averages, lower teenpregnancy rates, higher rates of students attending and graduating from college, etc.) might provide a clearer picture of how building upon funds of knowledge can lead to measurable and observable academic success. In spite of this critique, again, I chose to use this term based on the extensive research about funds of knowledge relating the fundamental principle of combatting deficit-minded teaching by recognizing and using students' funds of knowledge. Asset-minded teachers start with understanding their students' lived experiences. Attaining asset-minded teaching is the critical element addressed in this study, and the essence of funds of knowledge.

\section{Review of the Research Literature}

Research surrounding mathematics identity and student agency points toward increasing student voice in the classroom and making curricular connections to students' lived experiences. Teachers can help foster a strong mathematics identity in students through increasing mathematics literacy and dialogue, which can lead to increased student academic agency and self-empowerment. In recognition of this research, my school district has implemented several initiatives that specifically focus on the use of student collaboration through mathematics dialogue. In the section that follows, I address the research behind mathematics dialogue, as well as the important and influential role a teacher can have in relationship with their students and classroom environment.

Examining inequity in mathematics education. At the core of examining mathematics education, it is essential to recognize that mathematics is not race-neutral (Martin, 2009). Many educators have believed in the idea of a historical hierarchy of 
perceived mathematics ability, which pins those who identify (or who are identified as) as people of color — specifically Latinx, African American, and Native American — with lower mathematics ability as compared to their White counterparts (Martin, 2009). The belief in this false hierarchy has influenced mathematics curriculum, pedagogy, policy, and practice. As an example, mathematics pedagogy, especially in the advanced mathematics classes, has changed very little over the last century in that many mathematics classrooms remain very traditional: teacher reviews homework, teacher lectures, students take notes, students receive their homework assignment; repeating the same pattern day in and day out (Martin, 2009), a set of practices which have historically tended to serve White, middle class students especially well.

Working to challenge and disrupt the ideas underpinning this pattern of behaviors, Boaler, William, and Zevenbergen (2000) suggested, "Learning is a social activity which encompasses the relations between people and knowing” (p. 6). Within that social activity, namely mathematics education, students are figuring out who they are and what place they have within this community of learners (their identity), and the power they possess for transforming their learning experiences. Examining mathematics education from a sociopolitical standpoint can shine a light on how to make substantial, meaningful, and critical changes in public education.

False idea of racial hierarchy of mathematical ability. The false idea of a racial hierarchy of mathematical ability is rooted in hundreds of years of social constructs in mathematics. Much extant research in mathematics education, policy, and practice has been based on this hierarchical premise (Martin, 2009). In the process of upholding this social construction, Martin (2009) explained, "Existing mathematics education research 
and policies have facilitated the social devaluation of African American, Latino, and Native American students with respect to mathematics literacy, while affording social appreciation to many White and Asian American students" (p. 318). While students of Asian descent have been afforded a higher status of mathematical hierarchy, it is "limited to those occasions that serve the purpose of distinguishing between 'good' and 'bad' minorities" (Martin, 2009, p. 319), with the intent to prove that if one minority group can be successful, then claims of racism are argued to be debunked (Martin, 2009). Interestingly, while White/African American, White/Latinx, or White/Native American comparisons are prolific in mathematics "achievement gap" reports, very rarely is a White /Asian achievement gap discussed (where Asian or Asian-American students perform higher than their White counterparts). Martin elaborated on this rarely discussed comparison, noting an absence in the literature, "especially in ways in which limited cognitive abilities, poor motivation, and dysfunctional family backgrounds are used to denigrate White students" (p. 319). There remains a tendency to blame teacher incompetence or a lapse in curriculum design when White underachievement is reported (Martin, 2009). The history of false hierarchy of mathematics ability can contribute to a deficit mindset and low expectations held by teachers about their students of color, specifically those of Latinx, African American, or Native American descent.

Unfortunately, it has been, and continues to be, a common practice to dilute the educational expectations for students of color (Delpit, 2012). Students of color, specifically those of Latinx, African American, or Native American descent, historically have been held to lower academic expectations as compared to their White peers. Remedial work expectations are especially harmful, as "busy-work" (i.e. repetitious 
worksheets emphasizing basic rote skills) do not require the use of critical thinking. Expecting students to grow and use critical thinking skills is an urgent matter. Delpit (2012) emphasized, "Only those who are authentically and critically literate can become the independently thinking citizens required for a society's evolution. The opportunity to achieve such levels of literacy is even more critical for those whom the larger society stigmatizes" (p. 128). Maintaining high expectations and teaching critical thinking and critical literacy (including mathematics literacy) is imperative for students as they learn to question and critically analyze the dominant culture's discourse and speak their counternarratives.

Practices that promote rigor and high expectations. While my focus is directly on amplifying student voice, teachers' attitudes toward, and level of expectations for, their students can either foster or stifle student mathematics identity, selfempowerment, and academic agency, due to teachers' power in the classroom. A teacher's words and actions directly impact their students' academic lives. Therefore, I believe it is important to emphasize how profoundly teachers can influence the (positive or negative) development of their student's mathematics identity, especially when considering students of color from African American, Latinx, or Native American descent.

A key issue in deficit-mindedness in teachers is racial bias and stereotyping of their students' academic ability or potential. Steele (1997) expressed:

For students from groups in which abilities are negatively stereotyped in all or some school domains and yet who remain identified with those domains, this 
threat may be keenly felt, felt enough, I argue, to become a further barrier to their identification with the domain. (p. 617)

Teacher racial bias — even unintentional bias_ can negatively affect students' personal academic expectations. African American, Latinx, and Native American students can be thusly affected by "stereotype threat - the threat of being perceived as fitting a negative stereotype or the fear of poor performance confirming that stereotype" (Martin, 2009, p. 317), by which students internalize, and subsequently meet the lower expectations.

Therefore, as teachers become more aware of their own biases that might perpetuate stereotype threats (e.g., women perform poorly in math as compared to their male counterparts; African American, Latinx, and Native American students academically underperform as compared to their White peers) in their classrooms, they can work to undo damaging misconceptions by securing students "in the belief that they will not be held under the suspicion of negative stereotypes about their group" (Steele, 1997, p. 624). One way teachers can work to counter stereotype threats is through an asset approach. Steele (1997) suggested three specific asset-based approaches to teaching: a) building an optimistic, mentoring relationship with students; b) challenging students with a high level of work that "conveys respect for their potential and thus show them that they are not regarded through the lens of an ability-demeaning stereotype" (Steele, 1997, p. 625); and c) emphasizing a growth mindset over a fixed intelligence (Dweck, 2008). Establishing a trusting and respectful relationship that upholds high expectations and reassures students that learning is a process is foundational in an assetbased approach to teaching and learning. 
An asset-based approach to teaching mathematics can increase student identity as a growing mathematician, leading to student self-empowerment and academic agency. Milner (2011) provokingly suggested this question: "What do I, as a teacher, need to change in order to better meet the needs of all my students" (p. 60)? A critical first step in teaching with an asset approach is through self-reflection of current practice to illuminate any pre-existing bias.

Teacher critical self-reflection. It is important for teachers to challenge their own racial biases. Gorski (2013) explained that teaching strategies would be ineffective if teachers believed that skin color or poverty was an indication of lacking intellectual promise. Similarly, Howard (2003) stated that it is imperative for teachers to understand that the classroom will continually become more diverse in language, race, ethnicity, culture, socioeconomic status, and so on.

In recognizing these diversities within the classroom, Howard (2003) suggested teachers must then "be able to construct pedagogical practices that have relevance and meaning to students' social and cultural realities" (p. 195). Through the lens of culturally sustaining pedagogy, teachers must primarily reflect critically on their own lived experiences and biases. Howard explained, "Critical reflection requires one to seek deeper levels of self-knowledge, and to acknowledge how one's own worldview can shape students' conceptions of self' (p. 198). It is imperative for teachers to introspectively question the way their personal biases affect their belief of the potential academic achievement of their students (Howard, 2003). Howard indicated that critical reflection "can be useful in helping teachers recognize if they consciously or subconsciously subscribe to deficit-based notion of culturally diverse students" (p. 198). 
Milner (2011) continued, "Through reflection, teachers can begin to deal with some authentically real racialized issues that could bring them into new levels of consciousness" (Milner, 2011, p. 60). Through critical reflection, teachers can begin to recognize where they might have racial, cultural, socioeconomic, or other unintended biases.

Combating racial bias. Most teachers have the best intentions for their students, and yet, it is possible to intentionally or unintentionally rate or evaluate student ability based on their background or race. Milner (2011) suggested, "Teachers' thinking about their students, about their students' abilities, and about their students' established knowledge and possibilities can serve as a precursor to what is possible instructionally" (p. 61). Deficit-mindedness toward a students' academic ability can stifle not only the student's academic growth, but also the teacher's ability to involve the student in learning. Milner continued, “Deficit-minded/thinking-teachers' perceptions that culturally diverse students do not already possess skills, knowledge, and attitudes to succeed and learn can result in the development of curriculum and instruction that falls short of optimal teaching and related educational opportunities" (p. 61). If a teacher sets high expectations, and believes their students can achieve those high expectations, it is more likely that the student will strive to meet those expectations and become empowered through their learning process.

When teachers actively work against biased teaching strategies, they can better counteract implicit or explicit racism (Howard, 2003). Developing an "antiracist pedagogy requires teachers to adopt a commitment to thinking, feeling, and acting in ways that combat racial discrimination in schools" (Howard, 2003, p. 199). An antiracist 
stance in education can help teachers to cultivate a deeper understanding of culture and race. A teacher with an antiracist stance can examine how race is impacted by educational politics and policies increases knowledge of multiculturalism, and advocate against racial inequities in all facets of life (Howard, 2003).

Asset-minded teachers recognize their students' funds of knowledge, and that students bring a "wealth of knowledge into the classroom that must be tapped into in order to capture students' interests and their engagement" (Milner, 2011, p. 62). Looking upon students as carriers of knowledge promotes the belief that students bring valuable learned experiences into the classroom that can be used as a bridge between themselves and their teacher so as to enrich the classroom learning and transform the students' outside-of-class learning. Milner (2011) emphasized, "To be effective educators, it is critical for teachers and other school personnel to center their practices at the intersection of students' home and school lives" (p. 68). Building instructional practices that incorporate the students' funds of knowledge foundationally recognizes student assets and can energize and give identity and agency to the student in their learning.

\section{Fostering student empowerment.}

We believe in an educational system that will give to our people a knowledge of self. If a man does not have knowledge of himself and his position in society and the world, then he has little chance to relate to anything else. (Black Panther Party Platform and Program, 1966, para 5)

I began this section with this Black Panther quote because from my experience, identity plays a poignant role as students develop as learners, and can lead to self- 
empowerment and academic agency. Building a students' sense of self may simply begin with asking students what academic supports work or do not work for them.

Student voice. In 2010, the Oregon Department of Education (ODE) adopted Richard Elmore's “Instructional Core” (Oregon Department of Education, 2010). The Instructional Core links 'teachers' knowledge and skill, students' engagement in their own learning, and academically challenging content" (ODE, 2010, para 1) as the three interlocking components of academic success. I believe student engagement and student voice are linked, as they both lead to student academic agency and self-empowerment. Moreover, student voice is a critical tool that more often than not sits in the educational toolbox, unused. As mentioned earlier, Milner (2015) commented, "In my experience, I have found that we-researchers, teachers, principals, counselors, parents, policy makers - often spend time talking about students and not enough time talking and listening to them" (p. 70). Empowerment comes from within a person; it takes time to mature and develop.

Valuing students' voice in their education is a key (and what should be obvious) first step. Student voice "provides insights for teachers but also creates the type of environment that encourages students to be active participants in the kind of education they receive, deserve, and aspire to experience" (Milner, 2015, p. 70). An important aspect of fostering student voice is making time for students to reflect on their learning. Incorporating time for students to reflect on their work within small groups opens the door for making further connections with mathematical ideas and problem solving. Wedekind (2011) remarked, "When students are working together in a small group, the focus of active listening, explaining, and responding is amplified. All members must 
work together to keep the dialogue going" (p. 92). Similarly, reflective questioning leads to a firmer conceptual understanding, which promotes greater mathematics literacy and fluency. Students who participate in voicing their learning experiences can develop increased agency by recognizing that their voices, their ideas, their thought processes, and their understandings of mathematics enriches the learning community both inside and outside the mathematics classroom.

Mathematics identity. Students' mathematics identity is a foundational platform for students to develop academic agency. Boaler et al. (2000) related, "In mathematics classrooms, students learn more than the mathematics - they learn what it is like to be a member of that community of practice, and whether or not they want to become participants" (p. 6). Peer interaction can support the growth and strengthening of mathematics identity, all depending on how secure the student feels as a part of the group of learners. As identified by Boaler et al., being a part of a group can be seen to be a key component of a sense of self and the developing self-concept whereby members develop a keen sense of the value of the group and group membership and as a consequence derive considerable self-esteem from belonging to a particular group. (p. 4)

Students are able to "develop a sense of self in relation to that community of practice" ( $p$. 4). This is important because as students build a positive self-concept and confidence as mathematics learners, students can simultaneously build self-empowerment. Identity is a fluid sense of being, fostered "as something you do, not something you are" (Gutiérrez, 2013, p. 45). In fostering positive, active, meaningful mathematics 
identities, it is important that the students view themselves as active thinkers and doers of mathematics. Wedekind (2011) contributed:

In order to achieve a deep and true understanding of mathematics, children must first see themselves as becoming mathematicians. They must identify themselves as mathematicians, take on the responsibility of learning to do the work of a mathematician, and make meaning of their world through mathematics. (p. 11) Students' lived experiences can foster a stronger mathematics identity and connection to their learning of mathematics, which might further students' selfempowerment and academic agency toward pushing against inequity. Making sense of mathematics, Gutiérrez (2013) explained, can help students make sense of data in ways that help them see the humanity behind the numbers and to use mathematics as a tool for exposing and analyzing injustices in society and as a means for convincing others of a particular (often nondominant) point of view. (p. 41)

Students' racial identities are inextricably part of their mathematics identities. Making meaning of a mathematical task in context to ones' own lived experience can be selfempowering because the math is made increasingly relevant to the student. Teachers learning from students' interpretations of mathematics concepts, and 'being open to the multiple meanings that students place on mathematical practices and offering an educational setting where those meanings can be valued and build upon is a step in the right direction" (Gutiérrez, 2013, p. 55). Students' mathematics identities, along with teachers' mathematics identities should inform and engage with one another in the learning process (Gutiérrez, 2013). 
It is also critical to state that as much as community can healthily support a student's mathematics identity, if a student does not feel connected to the community, the strength of their mathematics identity may not be as strong as a result of not feeling a sense of academic belonging. In the case of some students, "there is a greater synergy and sense of belonging whereas for others, there is a sense of rejection and hence little sense of identity within the community of practice" (Boaler et al., 2000, p. 5). LadsonBillings (2011) agreed, stating, "When poorly managed, cooperative learning creates unequal workloads and instances in which students exclude other students from the process" (p. 37), the connectedness within mathematics community may be undone.

The principle of connectedness to mathematics (inferring identity with mathematics), instead of ability to do mathematics (inferring a student can or cannot do mathematics) may be an essential ideological change within the mathematics classroom. Especially, Gutiérrez (2013) stated, "With the ability myth strong in the United States, most citizens who do not meet with success in mathematics early in their lives assume they just are not smart enough to have mastered it" (p. 47). It takes concerted time and energy to build a community of mathematicians, a classroom in which students identify as mathematicians both individually and collectively (Wedekind, 2011), and feel a sense of academic agency and self-empowerment to use mathematics as a means for social change.

Encouraging mathematics dialogue. One way to foster mathematics identity in a mathematics classroom is through mathematical dialogue. Mathematics communities built upon intentional mathematical dialogue can deepen conceptual understanding, make 
the subject material more culturally relevant to the student, and increase student agency. Gutiérrez (2013) explained:

Learners as active inquirers and participants in problem-posing dialogue are important parts of critical mathematics education. Through dialogue, learners are given opportunities to express themselves and act on their knowledge. In this way, students are offered a greater number of choices in how they can interact as citizens. (p. 41)

Classroom community can engage and empower students as both individual and community learners. Establishing classroom norms about mathematics discourse is a critical element in building the expectation for students to talk about mathematics. However, talking about mathematics can be different from having others kinds of conversations. Franke, Kazemi, and Battey (2007) explained the difference between social norms and sociomathematical norms as, "Knowing that one is expected to explain one's thinking is a social norm; knowing what counts as an acceptable mathematical explanation is a sociomathematical norm" (p. 239). The required or expected depth of explanation, justification, and reflection are sociomathematical norms.

Building the type of classroom community that supports constructive talk about mathematics can nurture a sense of academic agency in students as teachers expect students to participate in meaningful mathematical discourse; that "Students are expected to be co-authors, with their teachers, of their understanding of mathematical principles and procedures" (Boaler \& Greeno, 2000, p. 178). In their study of high school students in advanced mathematics, Boaler and Greeno (2000) learned, "The students appreciated the opportunity to discuss their work, partly because their discussions gave them deeper 
insights into the mathematics they met, but also because their discussions changed the nature of the classroom environment" (p. 178). The students appreciated the relationships that were built not only with their understanding of the mathematics concepts, but also of who they were as mathematicians (Boaler \& Greeno, 2000).

Boaler et al.'s (2000) interview research on students' confidence in the mathematics classroom consisted of " 120 interviews with secondary schools students of mathematics aged from 14 to 18 in England and the United States" (p. 3). Researchers combined data from two studies. In the first study, 48 students were interviewed from six different schools' Advanced Placement (AP) classes from the United States. The second study incorporated interviews of 72 students from six different schools in England (Boaler et al., 2000). The two studies focused on "the nature of confidence in mathematics" (Boaler et al., 2000, p. 6) and a "range of issues related to their mathematics classrooms" (p. 6), respectively. The research showed several examples of two specific types of secondary mathematics classroom communities; one that supported a traditional (individualistic) community of learners, and one where "students spent lesson time discussing the different questions, as a class, and in small groups" (p. 7). Several core ideas evolved from interviews with the students. In the more traditional communities, students "unanimously described mathematics as a procedural, rule-bound subject" (p. 7) where many of the students "regarded the exclusive act of practicing procedures as inconsistent with the development of a broader, conceptual understanding" (p. 8). The students in the traditional mathematics community lacked connectedness to the content, and an understanding of its purpose as it related to their lives. 
When students see mathematical application simply through the eyes of their textbook, then personal connection, identity, and purpose can be lost. Wedekind (2011) suggested, "There is a world of difference between "word problems" at the end of a textbook lesson and problem solving that is contextually relevant to your math community" (p. 85). As a champion for social justice mathematics, Gutstein (2009) also argued, "First, students should develop a deeper capacity to critically understand social reality, both their immediate and broader contexts" (p 158). Gutstein (2009) reinforced the idea that students can make better sense of their lived experiences in the world when a sense of social and academic agency is established as a learning tool. Gutstein (2009) emphasized, "Students develop the mathematical competencies needed for access and opportunity, but also to read and write the world with mathematics" (p. 158). Building a mathematically literate, socially adept community of learners might be one of the links in fostering student mathematics identity, self-empowerment, and academic agency.

Boaler and Greeno (2000) found that in the community where students were working with one another in discussion about the mathematics concepts, "This act of negotiation and interpretation meant that mathematics did not appear to the students to be an abstract, closed and procedural domain, but rather was seen as a field of inquiry that they could discuss and explore" (p. 8). Students' mathematics identity was strengthened, and their motivation to understand the meaning behind their math was heightened through their classroom discussions of the mathematics concepts. Establishing a mathematics community surrounding student discourse can aid in increasing student conceptual understanding and demystify abstract topics. 
Interestingly, however, Boaler et al. (2000) discovered students' academic agency was not heightened in either of the two classroom communities, because students were not seeing how the math directly impacted their lives; a personal connection and sense of agency with mathematics were not established.

Despite being relatively successful mathematics learners, [students] reported disliking mathematics, not because the procedural nature denied them access to understanding, although that was important, but because their perceptions of the subject as abstract, absolute and procedural conflicted with their notions of self, of who they wanted to be. (p. 8)

Along the same lines, O'Brien, Martinez-Pons, and Kopala (1999) suggested, "reassessing the way in which mathematics is taught may be necessary; for members of minority groups, developing ways of improving ethnic identity as part of the effort to improve self-assessment of mathematics skill also may be required" (p. 232). Mathematics dialogue can foster students' confidence in math class. But, to support student academic agency, connection to students' lived experiences and future aspirations need to be infused in the curriculum and mathematics dialogue. Rethinking the way that mathematics is taught may be a key ingredient in improving the academic agency of Latinx students.

So often in traditional advanced mathematics classes, students spend the majority of their time practicing procedures without making holistic connections to the bigger mathematics concept. The intention of rote practice, so commonly used in mathematics classes, might be that "students will become conversant in the use of the different procedures and be able to use them in a range of mathematical situations" (Boaler $\&$ 
Greeno, 2000, p. 180). However, passivity in learning through rote computation can decrease students' identity as mathematicians, their personal connection to what they are learning, limit their understanding of the bigger mathematical idea and stifle their critical thinking skills, which go beyond the math classroom, such as being able to process, problem solve, synthesize, analyze and justify actions. Boaler and Greeno (2000) explained:

In didactic mathematics classrooms, students' participation is defined by textbooks, rules, and procedures - they are excluded from the negotiation or development of procedures; they are restricted in their application of selves; and their ideas, inventiveness, and general agency do not appear to be valued. (p. 189) Boaler and Greeno's (2000) study comparing students' level of mathematical confidence from two different learning communities (one a traditional classroom, and the other a classroom focused on student-led collaboration) consisted of 48 students, with eight students in each of six participating high schools. In semistructured interviews, "researchers interviewed two girls and two boys that the teacher of AP calculus identified as mathematically confident, and two girls and two boys that the teacher identified as lacking confidence, in each of the six classes" (Boaler \& Greeno, 2000, p. 175). In two of the high schools, teachers "encouraged students to work on questions collaboratively" (Boaler \& Greeno, 2000, p. 176). In the other four high schools, students "described mathematics classes as individual environments in which their role was to practice and repeat the procedures teachers demonstrated" (Boaler \&Greeno, 2000, p. 176). There were stark differences between the students' identity as mathematics thinkers in the two different learning environments. Of the more traditional classrooms, Boaler and Greeno 
(2000) noted, "Some of the students regarded thinking practices to be an unnecessary part of their mathematical experiences" (p. 179). This is in direct contrast to the students in the more collaborative classrooms.

Of these two collaborative classrooms, Boaler and Greeno (2000) explained students, "did not describe mathematics as an abstract, closed, and procedural domain, but as a field of inquiry that they could discuss and explore" (p. 182). In the traditional classrooms, the students lost (or maybe never established) their connection to mathematics, lost their connection to why what they were learning was so important, and lost their connection to why and how mathematics was effective and made a difference in the world (Boaler \& Greeno, 2000). Furthermore, “A large proportion of the students interviewed appeared to reject mathematics because the pedagogical practices with which they had to engage were incompatible with their conceptions of self' (Boaler \& Greeno, 2000, p. 186). The students' identities as learners of mathematics were stifled because of a feeling of personal disconnect with what they were learning, that "there was a distinct inconsistency between the identities that were taking form in the ebb and flow of their lives and the requirements of AP-calculus classrooms" (Boaler \& Greeno, 2000, p. 187). Furthermore, and perhaps most importantly, students "were not prepared to give up the agency that they enjoyed in other aspects of their lives, or the opportunities to be creative, use language, exercise thought, or make decisions" (Boaler \& Greeno, 2000, p. 187). This is the danger in not creating a learning community that establishes relational mathematical dialogue, fosters critical thinking, invites creativity, relates to students' cultural and mathematics identities, and empowers students to be change agents. 
Enacting culturally responsive and sustaining pedagogy. The aforementioned elements of classroom community (intentional mathematics dialogue, fostering critical thinking (metacognition and reflection), inviting inquiry, building mathematics identities, and nurturing self-empowerment) are encapsulated within the framework of culturally sustaining pedagogy. Culturally sustaining pedagogy is an expansion of culturally relevant (Ladson-Billings, 1995) and culturally responsive (Gay, 2002) pedagogies.

Ladson-Billings (1995) conducted a study to learn from teachers who practice culturally relevant pedagogy in their classrooms to "argue for its centrality in the academic success of African American and other children who have not been well served by our nation's public schools" (p. 159). Eight highly effective teachers in an urban setting participated in ethnographic interviews. These teachers had been "initially selected by African American parents who believed them to be exceptional” (LadsonBillings, 1995, p. 162). Additionally, Ladson-Billings (1995) “solicited principals' recommendations" (p. 162), and "those teachers whose names appeared as both parents' and principals' recommendations were asked to participate in the study" (p. 162). Of the participants, Ladson-Billings (1995) explained, “All of the teachers identified strongly with teaching. They were not ashamed or embarrassed about their professions. Each had chosen to teach, and more importantly, had chosen to teach in this low-income, largely African American, school district”' (Ladson-Billings, 1995, p. 163). Furthermore, culturally responsive teachers have a continuous and professional relationship with their students, "extending beyond the classroom and into the community" (Ladson-Billings, 1995, p. 163). From my professional experience, drawing from students' backgrounds and life within the community can enrich and elevate classroom learning, and used in 
conjunction with mathematics dialogue can further support student mathematics identity, self-empowerment, and academic agency.

Gay (2009) advocated for culturally responsive teaching to be interwoven into the mathematics classroom by intentionally analyzing teaching practices, strategies, materials and curriculum for their cultural relevance for students of differing ethnic backgrounds; structuring the classroom environment to support mathematical learning and foster a high level of confidence in all students; and using a variety of instructional tools to measure student mathematical achievement. Gorski (2013) added that teachers using culturally responsive teaching strategies maintain high academic expectations, make family involvement a priority, add art and physical activity into the curriculum, highlight student and family strengths, use kinesthetic activities in class, evaluate curriculum for SES bias, support literacy proficiency, and frequently connect with families. These strategies, Gay (2009) explained, "comprise the core of the culturally responsive pedagogical knowledge and skills for math teachers" (p. 200). When teachers incorporate a culturally responsive pedagogy, and intentionally reflect on their daily teaching strategies, then "we can say, with confidence, that genuine progress is being made toward accomplishing academic equity and social justice in mathematics education for African, Asian, European, Latino, and Native Americans, for poor and middle class students" (Gay, 2009, p. 204). Rethinking mathematics education by teaching through a pedagogy that promotes equity and strives for social justice can directly impact students' mathematics identity, selfempowerment, and academic agency.

Additionally, Paris (2012) extended ideas about culturally responsive teaching. To maintain a high level of expectation for academic achievement, Paris introduced the 
construct of culturally sustaining pedagogy, which "seeks to perpetuate and foster- to sustain — linguistic, literate and cultural pluralism as part of the democratic project of schooling” (p. 95). Paris's ideas on culturally sustaining pedagogy are deeply intertwined with and extend from constructs of culturally relevant pedagogy. As such, teaching with and for equity and social justice can empower the student to use mathematics as a motivational change agent in their lives. Teaching with a social justice and equity lens is a critical first step.

\section{Methodology Review}

In the final section of this chapter, I provide a brief review of the methodological literature to identify and justify the methodologies I will use to answer my research questions. The specific methodology that I use, and will discuss further, is phenomenological interviewing.

Review of the methodological literature. Most teachers desire to improve their practice; to make the classroom a welcoming and safe environment that oozes learning from every corner, one that invites students to engage in their education and talk through challenges. But, how do teachers know how to best do this in their classroom? Perhaps, teachers should ask their students. The purpose behind inviting Latinx students into my research through interviews is because their lived experiences as mathematics students can shine a light on teacher pedagogy. My research questions seek to answer how teachers can better support students in developing and growing students' sense of being a mathematician (mathematics identity), and to what extent the district implemented math discourse assists students in deepening their mathematics understanding. I echo the sentiment of Pizarro (1998) when he said: 
I knew that interactive research had the possibility of providing both more detailed understandings of the school experiences of Chicanas/os and, in turn, ideas as to how we might make change for these students. From experience, I also knew these students were bright and had critical insights to share. (p. 59) I chose interview studies as a qualitative research methodology because in-depth interviews with students can be a conduit for students to have a voice in strengthening their education and making it more meaningful and relevant. Seidman (2013) stated, “The goal of researchers' using a phenomenological approach to interviewing would be to come as close as possible to understanding the true "is" of our participants" (p. 17). Interview studies, based in phenomenology, focus on the participant's lived experience (Merriam \& Tisdell, 2016; Seidman, 2013). My dissertation focuses on the importance of student voice, recognizing that student voice is, more often than not, left out of research in education. How better to understand students' lived experiences as mathematics learners than from the students themselves? Students' lived experiences are exactly what teachers need to know more about as a measure for critiquing and rethinking current pedagogical structures. In-depth interviews can illuminate what best supports students' mathematics identity, self-empowerment, and academic agency. There is a preponderance of information that suggests that this method is justified and data collected and analyzed from students' responses will serve as a jumping-off point for making real suggestions to transform current mathematics classrooms through building and growing mathematics identity, motivating self-empowerment, and fostering academic agency.

\section{Summary}


Several salient concepts and ideas have risen through intensive review of the preceding literature. I summarize these concepts, and offer a rationale for my proposed methodology later in this section.

Summary of the research literature and application to the study. Research has suggested that mathematics identity is fluid, changing, evolving (Gutiérrez, 2013; Martin, 2009, 2013) as the student interacts with their teacher, peers, family members, and community. Teachers who acknowledge that false racial hierarchies exist in mathematics can work actively with their students to create a counter-narrative about who can identify as a mathematician (Gutiérrez, 2008; Martin, 2009). Mathematics identity can be supported through intentionally constructed mathematics learning communities, where students are held to clear and high expectations, offered rigorous academic learning opportunities, and are positioned to see the value and purpose in what they are learning (Boaler \& Greeno, 2000; Boaler et al., 2000; Ladson-Billings, 1995, 2011, 2016, 2017; Milner, 2011).

Within carefully established mathematics communities, students may strengthen their mathematics identity through culturally relevant and sustaining teaching practices (Ladson-Billings, 1995, 2011, 2016, 2017; Paris, 2012). One such practice is through the use of mathematics dialogue (Boaler \& Greeno, 2000; Boaler et al., 2000; Gutiérrez, 2013; Wedekind, 2011). Discourse with the teacher and their peers about mathematics (through writing, speaking, reflecting) in mathematics class can strengthen a students' connection to what they are learning, their ability to connect to the content at a higher level, and can help students begin to see how mathematics exists in their lived world. Mathematical dialogue can open the door for explanation, justification, clarification, 
analysis, and reflection. Students can achieve a deeper understanding when they are facilitating their learning, and in doing so, can garner a stronger sense of identity as a mathematics learner. A stronger mathematics identity can encourage student selfempowerment and academic agency to see the ways in which mathematics is intertwined in their lived experiences, and can help students to use mathematics to enact social change.

As is the case in many schools in the United States, many mathematics classrooms in the high school where I teach are structured such that students are assigned seating in cooperative learning groups. The intention is that, with teacher facilitation, students will engage in mathematics dialogue throughout the year. My study explored the ways district-directed initiatives specifically focused on student collaboration strategies may support students in building their identities as mathematics learners. A connection to my focus was on the practice of student grouping and student mathematics dialogue in an effort to understand whether students identify this pedagogical technique as one that fosters mathematics identity. My study also sought to understand what teachers are doing well, or could do differently to better support students in cultivating mathematics identity, self-empowerment, and academic agency. Student voice is a powerful and underused tool in reforming educational practices. Hearing from students about teaching practices that have fostered mathematics identity can greatly contribute to current mathematics education research. 


\section{Chapter 3: Methods}

The background to the research problems addressed in this study relates to the smaller representative proportion of Latinx high school students enrolling in and being academically successful in higher-level mathematics classes, as compared to their White peers. In effort to support and deepen students' connection to and understanding of mathematics, my school district has focused on (previously mentioned) district-wide initiatives specific to mathematics discourse. My specific research problem was to explore the ways in which these initiatives support students in building their identities as mathematics learners, and to explore the ways this may have contributed to their selfempowerment and academic agency. The purpose of this study was to magnify the voices of several Latinx youth identified by their mathematics teachers as being strong mathematics learners. I desired to learn from my participants about their journeys as mathematics students, and how specific teaching practices regarding mathematics communities and mathematics dialogue support their mathematics identities, selfempowerment, and academic agency. I also desired to hear student-generated suggestions for how teachers may better support student mathematics identities, selfempowerment, and academic agency. Research in mathematics education, as previously stated, has mostly centered on policy and pedagogy from the vantage point of those who are in power (teachers, administration, policy makers, etc.), and has very rarely invited students to speak into the academic affairs that are directly related to their learning. This led to my research questions:

1. In what ways does a select group of high-performing Latinx high school students describe the development of their mathematics identities? 
2. What pedagogical methods (ways of teaching) does a select group of highperforming high school students find the most meaningful as mathematics learners?

To highlight and amplify student voices in this work, I have elected to use phenomenological interviews as my primary research method. Interviews are particularly important to, and in support of, my research questions because lived experiences cannot always be adequately understood through surveys or questionnaires. Glesne (2011) relayed, "The opportunity to learn about what you cannot see and to explore alternative experiences of what you do see is the special strength of interviewing in qualitative inquiry" (p. 104). Student voice provided the opportunity to explore mathematics pedagogy from an alternative point of view, and afforded deeper insight into student experience considering the development of their mathematics identity, selfempowerment, and academic agency.

\section{Research Methods}

As a high school mathematics teacher, I constantly reflected on how to make my practice more equitable and impactful for my students. Over the course of my 12 years of teaching in classes that had a high percentage of Latinx students, I have found that asking students to reflect on their learning (to consider what helps them retain information and think more critically about what they are learning) has helped to improve my practice and my students' sense of ownership in their learning. As previously mentioned, I believe that through student voice, it is possible to learn more about how to improve mathematics pedagogy so as to encourage self-empowerment and academic agency. As a teacher, and as a researcher, I desired to know more about what 
mathematical teaching practices students indicate as being supportive of building their mathematical identity, and what practices they believe needed to be implemented to further support student identity, self-empowerment, and academic agency.

The school district that was the context for this research study has adopted the Instructional Core (Oregon Department of Education, 2010), which highlights student engagement. Student voice is an essential element of student engagement, and interview research elevated the voices of students in this critical study.

Interview study. The context of my research was within this school district, which is the school district where I have taught for 12 years. Therefore, my choice of interviewing as a research method was driven by the phenomenological essence of my research questions. As Vogt, Gardner, and Haeffele (2012) explained, “one's choice of design should be driven by the research question, the context in which one is trying to answer it, and the objectives of the research" (p.49). Uplifting student voice through interviews was a logical research collection decision.

Interviews are a common form of collecting qualitative data, and were imperative for my research. Interviews are the essence of student voice. The purpose of interviews was to collect information about what cannot be directly observed. Merriam and Tisdell (2016) explained, "Interviewing is necessary when we cannot observe behavior, feelings, or how people interpret the world around them" (p. 108). Understanding the lived experiences of students is an integral element of refining teaching practice. Seidman (2013) explained, "At the heart of interviewing research is an interest in other individuals' stories because they are of worth" (p. 9). As a critical teacher/researcher, students' stories - their understanding of their academic history, their mathematics 
identity, and how to better foster student agency — were imperative to hear and understand. Learning and making meaning from their experiences is at the heart of interview research, and was what directed my study.

Glesne (2011) suggested that planning a series of interviews with a participant "so that rapport can be established and time can be sufficient for learning from respondents" (p. 107) was important. Seidman (2013) agreed that the interviews should be conversational in nature. This act can build appropriate rapport with the interviewee(s) and can show respect and genuine interest in the participant.

The length of the interview should be appropriate as per the age of the participant. Seidman (2013) specifically uses three, 90-minute interview sessions over the course of two to three weeks to collect data from participants. Glesne (2011) suggested, "An hour of steady talk is generally an appropriate length before diminishing returns set in for both parties" (p. 119). For the purposes of my research with high school students, my interviews were a maximum of 60 minutes, with a series of three separate interviews per student. I detailed the three interview sessions in the upcoming section.

Affordances and constraints. One of the affordances of interview studies is that the interviewer does not have to be an expert about their topic, but they should be knowledgeable and comfortable with their topic. In this way, the researcher is learning from the participant(s) about their topic in a candid manner (Seidman, 2013).

Highlighting related ideas, Giorgi (2012) explained, "[The researcher] refrains from bringing in non-given past knowledge to help account for whatever [the researcher] is present to. [The researcher] concentrates on the given as a phenomenon and everything that is said about the phenomenon is based upon what is given" (pp. 4-5). Further, 
Englander (2012) recognized that even when the researcher has background knowledge of the phenomenon, it might be in the best interest of the researcher to put aside their preconceived notions of the phenomenon so that new insights might be gained.

Another affordance is that the researcher meets several times with the participant(s), which can increase the authenticity and richness of the conversation, as the researcher and participant grow more comfortable with the process. In addition, meeting with a participant more than once enables the researcher to clarify uncertain passages. Englander (2012) surmised, "It is important to understand that if certain passages are unclear, it is not justifiable, later on in the analysis, to start making theoretical interpretations to make such passages appear more clear" (p. 33). Meeting multiple times allows for the researcher to member-check with the participant, thereby increasing the validity of the researcher's interpretation and remaining authentic to the participant's voice.

Meeting more than once with the participant can also become a constraint if the participant and the researcher become too comfortable with each other. This could endanger the appropriateness of the researcher/participant relationship, in that potential conflicts of interest might arise, especially if the interviewer is interviewing people under their direct supervision. Participants might feel they need to say what they believe the researcher wants to hear, or may not be completely open and honest with the researcher for fear of backlash. This is especially the case in a teacher/student interview relationship. Teachers as researchers must be vigilant of "status differences inherent in research interactions and work to minimize them" (Glesne, 2011, p. 127). One way to mitigate this situation is to avoid interviewing participants for whom you are in a 
supervisory role. As a teacher, I chose not to interview students for whom I had control over their grade or instruction. Seidman (2013) warned against this moral concern when he wrote, "a student can hardly be open to his or her teacher who has both so much power and so much invested in the situation" (p. 45), and also suggested that teacher/researchers should instead interview students "in some other setting with some other teacher who is using a similar method or curriculum" (p. 45). To this end, I asked three of my mathematics teacher colleagues who implement similar teaching strategies to recommend to me students who they believed were strong mathematics learners, and who would be interested in participating in the interviews.

\section{Participants}

The participants in this study were all high school seniors (aged 17) from three of the four high schools ${ }^{1}$ in Infinity School District, a school district in the Pacific Northwest. The school district I teach in was selected for convenience. To eliminate potential bias, the specific high school I taught in was not a part of this study. Three high school seniors volunteered to participate in the interview data collection. The selection process is described in the following section. My study was specifically interested in the development of Latinx high school students' mathematics identity, their motivation for self-empowerment, and their sense of agency to seek personal or corporate academic transformation; and whether district initiatives surrounding mathematics dialogue has aided in growing student mathematics identity, self-empowerment, and academic agency.

\section{Procedures}

${ }^{1}$ Infinity High School separated into four small schools 14 years ago through the Oregon Small Schools initiative with grant funding through the Meyer Memorial Trust and the Bill \& Melinda Gates Foundation. 
The following procedure was adhered to as a means of conducting the interview study. Each step had a critical importance in maintaining the authenticity of the research.

Participant recruitment and selection. Before I could invite participants to volunteer to be interviewed, I first was granted permission from the school district superintendent to collect data from students. Secondly, I received permission from the principals in each school to conduct the study. Once these "gatekeepers" (Creswell, 2014, p. 188) granted permission, I (in person) approached three of my math teacher colleagues (whose pedagogical practice was similar to mine) to assist me with creating a sampling group by recommening students they saw as students with strong mathematics identities. Creswell (2014) described, "The idea behind qualitative research is to purposefully select participants or sites (or documents or visual material) that will best help the researcher understand the problem and the research question" (p. 189). Once students were recommended to me, I contacted each student (via the school email system) and asked if they would like to meet with me to learn about the purpose and objective of my research. I explained to the student that their current mathematics teacher had identified them as someone who was a strong mathematics learner. I created a brief Google survey that used several questions based off of a survey created by the Portland Metro STEM Partnership (2018) that focused on how students personally view themselves as a mathematics learner. I modified the original survey from 51 questions to eight questions. I chose questions that focused specifically on how student perceive themselves - and how they are perceived by peers - as mathematics thinkers, if they feel they belong to the mathematics community (as a whole), and how useful they believe mathematics is in their lives. I asked each potential participant to fill out the survey. The 
survey tool was used to rank the students in order of those who most highly self-reported as a strong mathematics learner. After reviewing the survey results, I asked the highest self-ranking students if they were interested in participating in the three-interview series. The survey resulted in four potential participants. Of those four, three were interested in participating in the interview study. Only one of the participants was enrolled in an AVID elective class. I discussed the entire informed consent form (see Appendix A), and answered any questions of the potential participant. The informed consent form was available in both English and Spanish (see Appendix B), to honor the bilingual abilities of the students, and because the students were under the age of 18 and required parental/guardian permission. Having the document available in both English and Spanish for their parents/guardians demonstrated a level of respect, as some parents/guardians needed the document in their primary language for clarity of purpose. Once I selected the three students, and established informed consent from the students and parents/guardians, I began the interview series with each participant.

Interview sessions. As interview research is not about testing a hypothesis and reporting quantitative data, the data that was collected needed to represent the lived experiences of those being interviewed in "compelling enough detail and in sufficient depth that those who read the study can connect to that experience, learn how it is constituted, and deepen their understanding of the issues it reflects" (Seidman, 2013, p. 54). As such, through my role as the researcher, I became the learner. Glesne (2011) related, "Casting yourself as a learner correspondingly casts the respondent as a teacher...And when you are a learner, you get taught" (p. 122). The purpose of interview 
research is to become richly informed. The researcher taking the standpoint as the learner is critical in interview methodology.

Researchers who use interview methodology vary in their recommendation for the number of interview sessions. However, many (Bevan, 2014; Glesne, 2011; Seidman, 2013) suggested a series of sessions, specifically when regarding phenomenological interview research. For my research design, I followed Seidman's (2013) series of three specific interviews. Each participant was interviewed individually over a two to three week period, which was appropriate for my research questions, as the process of creating a counter-narrative took time to reach the targeted depth in conversation. The threeinterview structure allowed the participant to go into depth about their lived experience, as it pertained to the research question(s) (Seidman, 2013). Each of the three interviews carried a specific purpose. Seidman explained:

The first interview establishes the context of the participants' experience. The second allows participants to reconstruct the details of their experience within the context in which it occurs. And the third encourages the participants to reflect on the meaning their experiences holds for them. (p. 21)

Allowing participants the safe space to explore, build, and elaborate upon their lived experience throughout the interviews respected the nature of asking participants to be open and honest throughout the conversation.

Each of the three interviews took place in a location that was a comfortable interviewing location and that provided confidentiality, but was not secluded. The location was in an office space at the front of the school. This room offered privacy and had a window that made the meeting visible to others. Being visible to others was 
especially important as it increased the level of safety for the participant and the researcher. The interview length did not exceed 90 minutes, and with the exception of one interview, which was 82 minutes, did not exceed 60 minutes. All three interviews were completed within a three-week window of time, as permitted by the participant. I planned for approximately six weeks to complete all three interviews with all of the participants. This allowed for some flexibility if any of the participants needed to reschedule.

First interview session. The first interview focused on the life experiences that had built and shaped the students' mathematics identity, thereby building the context of the phenomenon. The students described specific experiences in their lives, inside or outside the classroom that had supported their mathematics development. This focused life history was about their development as mathematics learners. The purpose of this semi-structured interview was to allow the students to talk about their lived histories as learners of mathematics, up until the present time. Students talked about when they first identified as strong mathematics learners, how they saw themselves as learners of mathematics, and what pedagogy or supports were in place that helped engage the students in their mathematics learning. This focus spoke to my first research question, "In what ways does a select group of high-performing Latinx high school students describe the development of their mathematics identities?" From this foundational interview, the participants were able to build upon the details of their experiences in the subsequent interviews. The second and third interviews spoke to my second research question, "What pedagogical methods (ways of teaching) do high-performing high school students find the most meaningful as mathematics learners?" 
Second interview session. The second interview focused in-depth on the details of their lived experiences, and "aimed to reconstruct the experience with its relationships and structures" (Bevan, 2014, p. 138). Seidman (2013) wrote, "The purpose of the second interview is to concentrate on the concrete details of the participants' present lived experience in the topic area of the study" (p. 21). This interview encouraged the participants to provide and elaborate upon concrete examples of ways in which their mathematics identity led to self-empowerment. The interview explored specific details about the participants' math histories, the specific instances that supported the participants' mathematics identity, self-empowerment, and or academic agency. These instances linked to specific pedagogical practices, self-actualized incidents, peer interactions, family support, and conversation with a teacher, and so on. All of the details were used as building blocks for the third interview, where participants were asked to make meaning out of their lived experiences.

Third interview session. The purpose of the third interview was to reflect on the meaning behind the lived experiences. Seidman (2013) stated, "Making sense or making meaning requires that the participants look at how the factors in their lives interacted to bring them to their present situation" (p. 22). Students had the opportunity to critically analyze their past experiences: how and why specific experiences influenced them in such impactful ways; that shaped them into who they are presently. Another key aspect of the third interview "requires that [the participants] look at their present experience in detail and within the context in which it occurs" (p. 22). Interview questions guided students to make meaning out of their current mathematics identity, self-empowerment, 
and academic agency. Students made meaning out of current pedagogical practice, and their specific mathematics community.

Data collection and maintenance. I used a digital audio recorder to record each interview session. The audio recordings were kept in a locked cabinet. I, along with one fellow graduate student currently enrolled in PSU's doctoral program in educational leadership, transcribed the audio recordings. This graduate student was briefed in full on the expectations of participant privacy and confidentiality that accompany this study, and all audio recordings transcribed by this graduate student were limited to recordings that did not include participating student names or other directly identifying information. I used Express Scribe Transcription software to transcribe the interviews. Pseudonyms for each participant were used in my field notes and the within the typed transcription. I was the only person who had the key to identify participants. I secured the field notes in a locked cabinet while they were being unused. The field notes were also used as a data source during analysis.

\section{Instruments and Measure}

Because the goal of this research was to illuminate lived and current experiences that accentuate the development of student mathematics identity, the establishment of self-empowerment, and recognition of academic agency, I used interviews that focused on how the student developed as a mathematics learner. Within the in-depth interview structure, I conducted semi-structured interviews. The interview questions and conversations that flowed from the questions directly correlated to each of the research questions, and were tied to the specific structure of the three-tiered interview protocol (see Appendix C). Glesne (2011) expressed, “The questions you bring to your interview 
are not set within a binding contract; they are your best effort before you have had the chance to use them with a number of respondents" (p. 103). As interviews are meant to be relational, there was some deviation from the protocol in recognition that conversation is not always predictable, and participants offered insights and ideas that pulled the conversation in other directions, which offered new insights into the research questions.

\section{Role of the Researcher}

I believe that a researcher can gain knowledge though learning about lived experiences. Gathering data through making observations, conducting interviews, listening to and documenting stories offers room for evidences that are experientially linked. The importance of this type of knowing is that when researchers study populations that have historically been marginalized, I believe that it is a critical need to remove oneself from a purely objective standpoint.

I concluded that I could no longer view my teaching practice through an objective lens after evaluating my own position in education as an educated White woman (as the teacher population demographic within education is largely made up of White women). Intuitively, I lean more strongly toward objective research, preferring a dominant-culture construction of reason and understanding of what I interpreted to be a tangible and known reality, over a subjective way of researching, which is "generally conceptualized as the way research is influenced by the perspectives, values, social experiences, and viewpoint of the researcher" (Allen, 2017). However, as I think "How can I ensure my research matters?," I am more convinced that I need to have a more subjective viewpoint. This led me to qualitative research methodology, which incorporated an expectation for reflexivity. When part of the process as a researcher is to be transparent and to become 
metacognitive about results, researchers are forced to come to terms with who they are as researchers and what impact their research has (or can have) within the community (Guba \& Lincoln, 2005). In holding this reflexive mindset, researchers are forced to question themselves as much as they are questioning, observing, and interviewing participants. I believe that this reflexivity is an essential part of understanding what can be known. This reflective piece in research requires that we "interrogate each of our selves regarding the ways in which efforts are sharped and staged around the binaries, contradictions, and paradoxes that form our own lives" (Guba \& Lincoln, 2005, p. 210). I am convinced (as a researcher) that if I am going to act justly, transparency in who I am as a researcher will lead to a firmer grasp of knowing.

How a researcher goes about finding out what can be known, I believe, depends on the subject of research. There are different methodologies for a reason, which are all valid approaches to finding out what can be known. However, with that said, I do think that all research needs to done with care and understanding of who is being researched, for whose benefit, and for what purposes. One of my realities as a researcher is that I am an educated White American, and that I have unearned power and privilege as a result. Parker and Lynn (2016) expressly explained issues of participant exploitation tend to occur when researchers do not "honestly address the power struggles between researchers and their participants of color" (p. 145). It is essential to consider whose voices are being heard and whose voices are going to be left out when designing research methods. For this very reason, I chose interview studies as my methodology. This form of qualitative analysis elevated the voices of students of color. Their voices carry enormous weight for 
impacting positive and transformative change, especially in the current political actions toward of decrease of national funding for the public school system.

Because of the political nature of my problem of practice, I chose to take a transformative worldview approach (Creswell, 2014). The transformative worldview approach places the researcher as an advocate or ally within the community in which they are working/researching such that transformative change may occur within the community because of the research. Creswell (2014) stated, "Thus, the research contains an action agenda for reform that may change the lives of the participants, the institutions, in which individuals work or live, and the researcher's life" (p. 9). My problem of practice aimed to overhaul traditional ways of teaching mathematics, specifically in classrooms with a majority of Latinx students. Using a critical lens to examine my problem of practice seems most fitting. Parker and Lynn (2016) explained, "CRT narratives and storytelling provide readers with a challenging account of preconceived notions of race, and the stories are sometimes integral to developing cases that consist of legal narratives of racial discrimination" (p. 145). Narratives and storytelling give voice to people groups who have consistently been rendered voiceless. If I continue to look at my problem of practice with a binary, "black and White" lens, I'm not sure that I will be challenging the status quo to promote a transformational change in education. A transformational lens moves the researcher from merely interpreting the results to a "now what are you going to do about it" lens. My mind has shifted from a reasoned "what is happening" to "how can I inform change because of what is happening." Not just seeing that change needs to happen, but seeking out methods to bring about that change.

\section{Data Collection and Analysis}


Data collection and analysis are an essential component of meaning making within this research. Maintaining fidelity to the process will be essential, and I have outlined my anticipated steps in the section that follows.

Data collection. I audio recorded each of the student interviews using a digital audio recorder. I jotted down side notes, specific student responses or memories, or follow-up questions as needed, but wrote as little as possible during the interviews so that my full attention was given to the students. After the interview, I wrote a researcher memo of my wonderings and any pivotal ideas. I addressed both the field notes and my reflective comments and connections as a part of my general analysis.

After I collected the data from the student interviews, I, along with my aforementioned fellow graduate student, transcribed the interviews. Participants chose their own pseudonym. I used participants' pseudonyms in place of their real names in each student transcript, during member checking, and in place of the student's names in the final report. As each interview session was built upon the next, reviewing the transcripts was an aid in maintaining the authenticity of the semi-structured interview process.

Analysis. Analyzing an interview data set can follow a general process. Interview researchers Hycner (1985) and Seidman (2013) have suggested processes for interpreting interview data. In the proceeding sections, I highlight the different elements of the process that I followed.

Transcription of data. I, along with my fellow graduate student, transcribed the data using the Express Scribe Transcription software. As member checking is a crucial form of assuring validity in analysis (Hycner, 1985), my fellow graduate student and I fully transcribed each interview session before the subsequent interview. I read through 
each of the typed transcripts, made notes, and wrote follow-up questions in the margins. Before each interview, I reviewed the previous interview topics with the participant, and addressed my handwritten thoughts and questions before beginning the new interview questions. The participants clarified my questions, and added on to their previous thoughts when clarification was required. I discuss a more detailed description of how the themes developed in the following sections.

Bracketing. Once I transcribed an interview, I began the process of bracketing. First, I came "to the transcript prepared to let the interview breathe and speak for itself" (Seidman, 2013, p. 120). Bracketing, Hycner (1985) explained, "Means using the matrices of that person's world-view to understand the meaning of what that person is saying, rather than what the researcher expects that person to say" (p. 281). An important element of bracketing is for the researcher to clear their mind of what they expect the participant to say, and to listen for what the participant is actually saying. This is a foundational practice, as the researcher will be making efforts to avoid potential preconceived biases (Hycner, 1985).

Creating general themes. After listening to and re-reading through the transcripts, I began the process of looking for developing themes. I conscientiously analyzed the data for major themes or ideas that developed, and repeated statements, phrases, or words. Hycner (1985) explained, "This is a process of getting at the essence of the meaning expressed in a word, phrase, sentence, paragraph or significant non-verbal communication" (p. 282). I read through and marked the text with a highlighter, coding major ideas from the text (this process can be called "open coding"). I typed the open coding on the right-hand side of the transcript, such that the original transcript is on the 
left hand column, and the corresponding coding is in the right hand column. These themes and ideas were member-checked with each interviewee at the following interview. The purpose of the member check with the participants was to ensure that what I indicated as important ideas or developing themes were also what the participant deemed to be important.

Connecting themes to the research questions. I identified two themes in connection to my first research question, and three themes in connection to my second research question. My first research question, "In what ways do high-performing Latinx high school students describe the development of their mathematics identities?," had two major themes. These two themes were, (a) descriptions of external support systemsteachers and family/guardians, and (b) descriptions of participant introspection on mathematics learning processes. The two themes delve into the development of students' mathematics identities, and are driven by the funds of knowledge theoretical framework. I sought to understand how students saw themselves as a learner of mathematics inside the classroom, in their homes, and in the community. Additionally, I hoped to learn from students if they saw a transferability between what they were learning in school with what they were learning and experiencing outside of school, whether in their homes or in the community. This theme is foundational to my research because of my claim that a teacher using students' funds of knowledge to inform their pedagogy is asset-based and enriches the student's learning experience.

My second research question is, "What pedagogical methods (ways of teaching) do high-performing high school students find the most meaningful as mathematics learners?," in which I identified three key themes. The themes were, (a) intentional and 
supportive classroom structure and environment for learning, (b) structures for collaboration with classmates through mathematics discourse, and (c) teacher emphasis on mathematics literacy and relevancy. The themes relate to my second research question as they focus on pedagogical practices that foster self-empowerment and academic agency, and were driven by critical race theory — specifically within the realm of culturally sustaining pedagogy.

The first theme speaks to how classroom community can build students' confidence in sharing their learning of mathematics. This theme was foundational to my claim that building a caring community of learners can aid in creating an environment that supports students' ability to be vulnerable in sharing in their learning (and process for learning) with one another in both small group settings and in whole-class discussions.

The second theme I identified was specific to the pedagogical use of mathematics dialogue while collaborating with classmates, which is a focus within culturally sustaining pedagogy. This particular pedagogy highlights how students have used oral and written language to inform and enhance the depth of their understanding of mathematics concepts, all the while building self-confidence and increasing communication and leadership abilities. This reinforced my claim that mathematics dialogue can support students' self-empowerment and academic agency.

The third theme explored students' understanding of the relevancy of mathematics in their lives, and how mathematics had driven their idea of potential career choices, how they see themselves as leaders in their school mathematics community, with their family members, and within their community at large. This theme was foundational to my claim 
that students need to see a connection between what they are learning in class and their lived experiences outside of class, fostering self-empowerment and motivation to seek transformational change.

I identified the codes from the text, and then grouped the codes into categories across participants and studied them for further thematic connections. I used a hard copy of the transcripts to begin, and then I categorized the themes into a spreadsheet. These themes were member-checked with the participants so as to ensure validity.

Retaining confidentiality. As the students were speaking about their teachers and peers, I ardently worked to retain confidentiality throughout the data collection and analysis process. All information and data in this study was kept confidential and was not released. Transcripts, audiotapes, and documents were de-identified in a systemized manner and did not use names of individuals or institutions. Any personally identifying information provided by participants about other educators or students were de-identified to ensure privacy and confidentiality. My focus remained on the overall mathematics experience of the participants, and the growth and development of their mathematics identities, self-empowerment, and academic agency.

\section{Summary}

Throughout the history of educational research, many studies have been conducted about students with the intention of improving teaching practice, student engagement, and to inform curricular decisions. What is clearly missing from these educational research studies is student voice. As my research topic involves rethinking the way in which mathematics is taught in light of the ever-diversifying public school system, I thought it absolutely appropriate to hear from students about their needs as 
mathematics learners. Student voice is a critical element in breaking away from traditional mathematics pedagogy, which has historically best served students in the majority. Therefore, I chose to conduct interviews with students to learn from them about what teaching strategies best supported them as mathematics learners, how to better foster student engagement and self-empowerment (especially as it pertains to collaboration through mathematics dialogue), and lastly how to support students in actively seeking academic agency.

The three-interview series (Seidman, 2013) allowed me, as the researcher, to get to know the mathematics background of the student participants, as well as learn from them about their academic agency as it pertains to their leadership inside and outside of math class. The interview series focused on the development of the participants' mathematics identities by pinpointing key situations where their mathematics learning was enhanced by specific teaching pedagogies, through experiences in their homes, and from their experiences as members of the community at large.

The interview data shed light on the degree to which district initiatives surrounding mathematics dialogue has been successful in supporting students' mathematics achievement, and appreciation for and understanding of the mathematics in their life. I shared the participants' detailed responses with the school district, where it might become a conduit for pedagogical change. 


\section{Chapter 4: Findings \& Analysis}

Infinity School District has focused time and invested money in implementing initiatives related to collaborative teaching and learning practices. The research problem addressed in this study was whether the district initiatives surrounding collaborative teaching practices supported students in building their identities as mathematics learners, led to self-empowerment, and contributed to academic agency. The purpose the study, through phenomenological interviewing, was to highlight and give voice to several Latinx high school students identified by their math teachers as students who have strong mathematics identities. These students shared their lived experiences with collaborative learning in Infinity School District. Student voice is an important and often overlooked element in understanding how best to foster students' mathematics identity, selfempowerment, and academic agency. Additionally, student voice can provide essential feedback to my math teacher colleagues, school administrators, and the district office personnel (in the curriculum department as well as the superintendent) about particular teaching strategies that may be updated or enhanced to further support mathematics learning.

Because student voice - especially when the students belong to a historically marginalized group of people - is so rarely included when it comes to exploring how to improve mathematics education (Milner, 2015; Pizarro, 1998), the method I chose for learning about the development of student mathematics identity, self-empowerment, and academic agency was through interviews with several selected students. Through interviews, I learned directly from three students about their mathematics identity development. 
As described in previous chapters, interview studies can open up the opportunity for students to share their perspectives on their experiences, including their experiences with mathematics education. Learning directly from students about how their mathematics identities were cultivated and supported can profoundly impact the teaching profession. Rooted in this idea, the following research questions guided my study:

1. In what ways do high-performing Latinx high school students describe the development of their mathematics identities?

2. What pedagogical methods (ways of teaching) do high-performing high school students find the most meaningful as mathematics learners?

\section{Participants}

The students interviewed were Jamie (female), Leticia (female), and Abe (male). All three students were seniors in high school, had attended school in the Infinity School District for all 13 years of their formal education, were enrolled in one or more academically advanced classes, and were bilingual and biliterate (fluently read, write, and speak in more than one language).

Jamie's older brother was attending an in-state public university. Her older sister did not pursue any post-high school education. Jamie was legally emancipated from her mom, and her dad passed away when she was younger. At the time of our conversations, she lived with her sister, her sister's boyfriend, and her infant niece. She planned to attend an in-state public university in fall 2019.

Leticia is the eldest child in her family. After completing high school, she was on track to become a first-generation college student. She participated on the high school 
softball team, and helped with providing child care for her younger siblings in the evenings. She planned to attend an in-state private university in fall 2019.

Abe has two older brothers, one of whom graduated from college, and the other of whom is still in college. Abe plays guitar in his band (not associated with school), and was also a part of the Mariachi band at the high school. He planned on attending an instate university in fall 2019.

The thoughtful and heartfelt responses given by each of the three students guided my analysis and interpretation of the results. It is their powerful ideas and statements that breathed life into this study, and has brought forth several themes. In the following sections, I present my analysis, findings, and interpretation of the findings of the interview study.

\section{Analysis of Data}

My interview study was modeled upon Seidman's (2013) interview methodology. I asked my colleague to suggest several of their students who identified as Latinx and were seen by the colleague to have a strong mathematics identity. I emailed these students via the school email to ask if they were interested in participating in my research study. If they indicated interest, I set up a time to meet with them individually to provide an in-depth review of the purpose of the study, and to outline the requirements for participating in the study. Three of the students agreed. The two students living with their parents were granted parental permission to participate in the interview series, and the emancipated student signed for herself. I met individually with each of the three students three times over a four-week period of time. The first series of interviews took about an hour per interview. The second series of interviews took in between an hour 
and 80 minutes. The third series of interviews were all about 30 minutes long. The students each received a copy of the interview protocol (see Appendix C) prior to meeting for the first interview session. This interview protocol was available to parents/ guardians as well, as I gave each student a copy to take home with them to share with their parents/guardians. I used the school email system to set up a mutually convenient time to meet for each interview with each participant (as they were individually interviewed). On a of couple occasions, our meeting time needed to be rescheduled due to inclement weather conditions and sickness.

Each interview session was held in an office at the front of the high school. The office provided confidentiality, as the door remained shut during our meetings, but also provided transparency, as there was a window in the door. The principal and secretaries were also aware of each interview and when it was taking place, which added an extra level of transparency.

Before the recorded start of all of the interview sessions, I asked the students if they had any clarifying questions about the guiding interview questions from the protocol. I answered any questions that they had, and when they were ready, we started the recorded interview. Each student chose their own pseudonym to be used during the interviews and for all written documentation. During these interview sessions, I asked the students about the development of their mathematics identities, self-empowerment, and academic agency. The series of interviews progressed from recounting a background history of their past to current mathematics learning experiences, to exploring what role mathematics will play in their future lives. Throughout the interviews, in addition to the audio recording, I used a small notebook to capture key phrases that I knew I would want 
to revisit. This notebook was kept in a locked and secure location while it was not being used during the interview sessions.

As noted, I audio recorded each interview, and later transferred the recordings to a secured file on my computer. I uploaded the interviews to a transcription program, Express Scribe (NCH Software, Inc., 2019) to transcribe each interview. I also had the help of a fellow doctoral candidate with transcribing the interviews. I printed and read each typed manuscript of the interview session before each participant's following interview session. As a part of reading through the transcripts and the initial analysis of the data, I highlighted or underlined key ideas, and wrote follow-up questions in the margins. I emailed the students these follow-up questions a minimum of a day before our next interview session so that they could think through and be prepared for our following session. At the end of the final three interviews, I asked the participants if they would be willing to meet with me one more time before the end of the school year so as to member-check the initial analysis of the data.

Over the following four weeks, I read and re-read the data, coding and categorizing the data. My coding cycles followed the method described in Saldaña (2013). I used "Narrative Coding" (pp. 131-136) for the first cycle, and "Pattern Coding” (pp. 209-213) for the second cycle. I used the qualitative analysis program, Dedoose, (SocioCultural Research Consultants, LLC, 2019) to highlight noteworthy text and create codes within the data. Initially, the codes were key words or phrases from the main text of the interview that emphasized or captured the main idea being offered by the participant (Saldaña, 2013). As I read through the interviews on Dedoose, I coded sections of text, at times coding a phrase, and other times coding an entire section of text. 
After my initial round of coding, I had generated 49 codes. I created a table with the three columns to organize these codes. The first column was the code name, the second column had excerpts from the participants, and the third column was initial themes and ideas drawn from the participants' words. In the second cycle, I read back through the table, I highlighted key phrases and words, and wrote notes about the data in the margin, which later assisted with my increasingly refined data analysis. I went through the data several more times to re-code and merge similarly coded categories. Through this thorough process, 17 main codes remained. I include these codes in a table in Appendix D (Saldaña, 2013).

Once I completed this coding process, I contacted all three participants via the school email system to ask if they would be available to meet to go over the data. I member-checked with two of the three participants. The third participant did not respond to my inquiry about meeting to member-check. Member checking was a crucial part of the analysis because I wanted to ensure that I accurately understood their words and documented their thinking in a way that stayed true to their voices, therefore lessening my bias (Seidman, 2013). Highlighting students' voices is the backbone to my research; therefore, it was imperative to maintain their voices and messages. At the time of the member-checking, Jamie and Leticia only knew that each other was a part of the study, and Abe did not know the identities of either of the other participants. The participants read through all of my initial coding, which included the voices of all of three participants. They provided additional comments, clarified statements, and corrected or agreed with my synthesis of their statements. I took this additional information and added it to the table, noting where the students had added or commented on an excerpt. 
After re-reading through the updated table once more, I mapped each code onto one of the research questions. As I connected the codes with the research questions, I identified key themes from the data. Two essential themes developed from research question one, and three themes developed from research question two. I discuss the two themes from research question one in turn before moving onto the three themes in research question two.

\section{Findings}

I collected rich and meaningful data from the students as I actively listened to their thoughts and insights during the interviews. I followed up on emergent lines of inquiry, transcribed the interviews, read and re-read through the transcripts, and conducted member checking with the students. The students' narratives of their development as mathematics learners both encouraged and challenged me in thinking through the way that mathematics is currently being taught in Infinity School District, and in the ways in which I am teaching. I separately analyzed the two guiding research questions, starting with the development of students' mathematics identities, to be followed up with teaching practices that support mathematics identities, selfempowerment, and academic agency. To ground these analyses in the voices and experiences of the students with whom I spoke, while simultaneously extending the analysis beyond the unique perspectives of any one participant, I employed counternarratives as an analytic framework in presenting my findings. Counter-narratives are a critical element to my research because, "The incorporation of alternative scholarship situates knowledge and experiences outside of the dominant hegemonic discourse and can serve as an opportunity to rethink unquestioned assumptions about people, place, 
worth, and deservingness" (Blessett, Sherèe, Gaynor, \& Alkadry, 2016, p. 268). The compiled counter-narratives of my three participants can breathe life into a story that so often goes untold - the growth and development of one's own personal mathematics identity as seen from a first-person perspective, as one progressed through the $\mathrm{K}-12$ educational system. The participants' counter-narratives speak in direct opposition to the false notion addressed in Chapter 1 that students of color do not belong in advanced mathematics courses, and cannot perform at the same level as their White peers (Martin, 2009; Boaler et al., 2000). Their counter-narratives tell a story of a passion for mathematics, an enjoyment in learning mathematics, and detail their sense of belonging in the mathematics community.

I presented the counter-narratives with the students' own individually spoken words, taken directly from the interviews, so as to highlight each students' voice. All three interviews with each participant are represented under one or more of the themed sections. I merged the interview responses (from the three interviews, such that responses within the first interview might be coupled with responses from the second or third interview) to create comprehensive counter-narratives as spoken by each participant. I divided the major themes into sections, and for each section, and represented the students' voices individually, using the students' chosen pseudonym. In the analysis that follows, verbatim student responses are block-indented. Students did not always use scholarly language throughout the interviews, but I intentionally chose to leave much of their spoken responses intact, representing their authentic speech and thinking. I have edited some of their sentences and phrases for the purpose of readability, eliminating utterances such as "um" and "like," or redundancies through repeated words. 
I also added punctuation to assist with readability. When needed, I used brackets to add clarifying words or to give context to the sentence. Some parts of the interviews were omitted in building the counter-narratives because not all elements were directly linked to the research questions, such as formalities of introducing the interview session, relationship-building conversation, and parting words.

In the sections that follow, I address each of the themes that developed in response to Research Questions 1 and 2.

Research question one. The first research question is, "In what ways do highperforming Latinx high school students describe the development of their mathematics identities?" The participants described ideas and experiences that fell into two themes, which were, (a) descriptions of external support systems - teachers and family/guardians, and (b) descriptions of participant introspection on mathematics learning processes. The following are excerpts from the three participants over the course of the nine interviews, separated by the two key themes (external support systems and personal reflection) that I identified from the data. The themes are summarized at the beginning of each section before the participant excerpts.

The two themes I identified in response to research question one were developed from eight codes identified in Appendix D as salient modes of support for participants in the development of their mathematics identity. Research question one addressed the development of the students' mathematics identity. Students addressed this development in terms of external support - how their teachers and family have fostered their growth as mathematics thinkers, and internal support-how the students have internally cultivated their mathematics identity. 
Theme one: External support systems-teachers and family/guardians. Theme one developed as participants reflected on how they have been, and continue to be, supported by both their teachers and family/guardians as they developed their mathematics identities. The participants emphasized the importance of feeling a teacher's support, particularly as a student in mathematics. Teacher support looked and felt different for each participant, and each reflected on how teacher support has helped him or her in his or her journey as a mathematics learner. In addition, each participant's family supported the development and growth of the students' mathematics identities. Their mathematics identities really began in their homes, as children playing games, and in conversation with their respective families. Each participant had unique stories to tell of how their family members emphasized the importance of mathematics learning, even from a young age. The participants' responses reflect how these external support systems helped to cultivate and encourage mathematics thinking.

The discussions in theme one reinforced the idea that each student established a knowledge base as a young child from their home life and community. The children bring this knowledge base, their funds of knowledge (González et al., 2001; SmithMaddox \& Solórzano, 2002), with them into the classroom, building upon what they have already learned. The participants spoke to the value of their funds of knowledge as they reflected on the development of their mathematics identity. Their identities began to form in their homes and community, and grew as it was reinforced in the classroom, and continued to strengthen as participants learned more about themselves as learners both inside and outside the classroom. 
Additionally, all three participants' counter-narratives highlighted how both teachers and family/guardians have supported the participants in enrolling and thriving in higher-level mathematics courses, which is in contrast to the narrative that is so often told in this nation about Latinx students, families, and teachers. Additionally, the participants' counter-narratives speak against the dominant narrative and bias that suggests advanced mathematics is only for White men (Martin, 2009; Gutiérrez, 2008), and clearly depicts experiences that show otherwise. Participants never received the message (implicitly nor explicitly) that they did not belong in their advanced math classes. In contrast, each participant was chosen or encouraged by their teachers to participate in the upper level math classes throughout their middle and high school years. In addition, for Leticia and Abe, their families/guardians valued learning math facts, and affirmed them in pursuing mathematics. Jamie's counter-narrative tells of how she taught herself math concepts that her brother, who is two years her senior, was learning. I describe each student's narrative in turn.

Leticia's mathematics identity development. First, Leticia remarked on how her teachers have helped foster her mathematics identity. She reflected on how she has been impacted by her teachers who have spent extra time working with her and helping her to process the mathematics content, remarking:

I think the things that are important to help students learn math is having teachers be available to the students, even if it's really a dumb question. Being available to their students and doing intentional confidence building exercises for students so that they feel heard [has been really important to me and my classmates]. 
Delpit (2012) confirmed the importance of attentive and involved teachers in building empowered students when she noted, "[Teachers] were visible in the classroom. They held students' attention. They were explaining concepts and using metaphors to connect the knowledge students brought to school with the new content being introduced" (p. 75). Teachers' active involvement in their students' learning, connecting the classroom learning to students' lived experiences.

Furthermore, Leticia emphasized the importance of being held to a high standard both (a) individually, working toward a personal goal of accepting the challenge of the learning and to work her hardest, and (b) collectively, that the whole class was expected to learn and do well (specifically on assessments). She highlighted:

Holding the student up to a standard would help them want to get to the standard. Like if the teacher was like, "Oh everyone with a four ${ }^{2}$ on this test can do this or this," like just holding them to like an expectation I think is helpful.

Leticia's identity as a mathematics learner was supported through her teacher being available to work directly with her to answer her questions, building her confidence as a learner, and empowering her by holding her to high standards and expectations.

Leticia continued by explaining that she felt the most like she belonged in her advanced math class when she was placed at a higher level. She reflected:

We were selected [she and a few other students] to be in the advanced math class just because we demonstrated fast understanding, and so when I was in that class, I was like "Oh like I guess my teacher thought I was good at this," so I kinda saw

\footnotetext{
${ }^{2}$ Infinity High School grades on a four-point proficiency scale, where a four is "exceeds proficiency."
} 
MATHEMATICS IDENTITY

myself as a math student or someone who was like, who had a good understanding of it.

Leticia also detailed how her family supported her mathematics identity when she was growing up. She explained a game that she would play with her father and younger sister saying:

We had a times table, like a poster of the times table. My dad always like, as a game or like teaching thing, he would tell us that if we learned like part of the times table — like I'll learn this section, like the twos — and then [he] would give you a dollar. So we would do that and learn the times tables before he comes back so we could have a dollar.

Leticia's family, by way of games and mathematics posters, built her funds of knowledge and supported her identity as a mathematics thinker and learner. Her father relayed the importance of helping her and her siblings learn their multiplication facts by creating a game with prizes.

Learning from her father's example, Leticia highlighted how she supported her younger siblings with their math lessons when she said, "Yeah, now that my sister is in high school I help her. Or even when she was in middle school I helped her with things she didn't understand. And then my brother, I also helped him." Leticia's family established an expectation for learning mathematics as young children that has carried into young adulthood.

Abe's mathematics identity development. Next, in similar ways, Abe also described the supports from teachers and his family that he found memorable. In response to my question about how he most felt supported by teachers, Abe reflected: 
Building the relationship between [teacher and student] from the beginning [of the school year], just starting like a certain bond so once they walk into the classroom they feel that's like that comfortable environment. And then [students will] work themselves up little by little to get to that comfortable zone, and then from there they can just work on and get to working. [Building a relationship] helps [teachers] understand me more and we could work [together]. I guess the connection gets stronger, and the relationship that we build is much better because, well for one thing, they understand me. They [the teacher] understand me much more so we could just work better and more efficiently.

Abe continued his thought by reflecting on how a healthy and positive classroom environment supported his mathematics identity, saying:

I feel the best thing [for teachers] to do [is] not make [the students] feel like they're being a burden in the class. Make them feel that that [the teacher is] there to support you and make sure that you get to where everyone is at. If [the teacher] made me feel like we're all in it together-he's gonna help me, she's gonna help me- anything, like it gives me the motivation to actually want and try to learn, and like actually go and put in my a hundred percent effort. So I feel like that'd be a really good way to make sure students actually feel supported and a part of the class. It boosts their confidence up, not down. Any support that I can get really boosts my confidence and it actually makes me actually want to learn, gives me the desire to learn.

Building a strong relationship between student and teacher helped Abe to engage in a learning environment that supported his mathematics learning, and one way of doing 
that was through conversations. Conversations with his teachers challenged him to not settle for a basic understanding of what he was learning, and pushed him by maintaining high expectations. These conversations were also a way for his teachers to learn about him as a student and as a person. The more comfortable Abe became with his teachers, the more he felt seen and heard. His confidence strengthened as a mathematics thinker, and he began having new experiences with mathematics where he felt more like a risktaker, and was willing to experiment with mathematics, which fostered a stronger identity as a mathematics learner. Delpit (2012) wrote, "It is the quality of relationship that allows a teacher's push for excellence" (p. 86). A trusting relationship between teacher and student establishes the foundation for setting high standards for teaching and learning.

Abe also recounted three particular instances in his math classes where his teachers made a real impact on his confidence in learning. The first narrative was from first grade. Abe recounted:

I'd always struggle with, like, just counting in general. I hit first grade and then my teacher there, she would always help me and would stay there until I would know how to count, and like know how to work with numbers. I guess that just boosted my little self's confidence, and like ever since then, I guess I just started enjoying math, or any other subject, which is why it made me take the challenge of going and expanding my knowledge.

The second instance Abe recalled was when he was in eighth grade. He remembered: 
My eighth grade year was when one of the teachers there was actually like, he would push me to make sure that I would use everything that I have in my head, to make sure I could solve that problem. It just boosts my confidence so after, the more it boosts it, the more the stronger I get, and I feel like the smarter I get too. More things are opening [understanding of math is clearer] and my mind is working in ways that I haven't worked with yet, so I just like to experiment and like try new things. So I feel like that whole, like, pushing me gave me a different bump, like boosted in me to better myself in my math learning. He was really strict, but in a very positive way. It's not like he would get mad, instead of like dragging you down, he would make sure he's pushing you up and challenging you to get to the right place that he wants you to be in. And I feel like his determination of teaching really put a good place in me for me actually learn and put that effort in to try.

Abe's final narrative came from his freshmen year when he was in Geometry class. Abe recalled:

[My teacher] would explain [the math concept] to the point where it would just be easy to for you to go do it on your own. Everything would be explained, like there wouldn't leave no doubt in your head, and once you started working on it [the math assignment], you're like, "Oh this is what we covered! Oh this is what we covered!" and then you just put everything together that you learned and then you just solved it. And I feel like that's probably like the best teaching that I've had in all my years. 
Abe spoke specifically about his confidence as a mathematics learner and thinker increasing as a result of working with his teachers. His teachers built his confidence by offering guided instruction, and being in conversation with him about where he was struggling with a particular concept. The scaffolded teaching and learning allowed him to engage with the material, and feel agency and purpose to his learning. Abe reflected that his relationship with his teachers propelled him to continue studying mathematics.

Similar to Abe's teachers, his family also supported the development of his mathematics identity. Abe explained how board games and online mathematics games that he played with his older brothers supported his foundational understanding of basic math concepts when he said:

There are some websites that [my parents] would let me use, like cool math games or something like that, which would make me like have fun, but also at the same time, I would be able to learn too. We also played board games like Monopoly. I feel like that has some math to it too because it also involved money, and you have to make sure how much money you have, and you have to be like, "This is how much value there is," or something like that. Or like, "You won this amount of money." So, [my family] did put a part into [my early math learning], but it was also a struggle because they struggled with school. So, I guess I had to put more of my part into it than they kinda helped me. But, it was like the amount of help that I got from them was still very useful.

Along with games, Abe's parents and older brothers provided emotional support as he began to struggle with more difficult mathematics concepts in the advanced classes. In talking about his brothers, Abe mentioned: 
We [Abe and his two older brothers] all went through similar challenges, and each of us learned something different. And since I'm the youngest, [their support] was made much more stronger for me because they already went through it. In speaking about his parents, he reflected:

I started talking to my parents on like how much tougher math was from middle school, and I would let them know how I'd been struggling, like, "I don't know how I'm gonna get through it, but I'll try to get through it as much as I can," and thankfully, they're really understanding.

Abe continued to see himself with a strong mathematics identity as a result of having his family support him with an early and firm foundation in mathematics thinking and learning, and also by his teachers helping him to develop an identity as a mathematics thinker and learner. Abe's funds of knowledge continued to be built upon as his mathematics identity strengthened through both familial and teacher guidance and encouragement.

Jamie's mathematics identity development. Finally, Jamie's responses are related to both Leticia and Abe in that she also felt her teachers recognized her as a strong mathematics thinker, and that she felt supported by her teachers. In addition, she also played board games with her older brother at home. Her responses differed from the other two participants because she took it upon herself to challenge herself mathematically at home, whereas Leticia and Abe both had hands-on support from their parents.

Jamie explained how being recognized by her teacher as a strong mathematics thinker impacted her when she said, "One of my past teachers said I was "talented" in 
math, and I think words like those just boost my confidence in being able to be confident in myself."

She also reflected that one thing she felt was missing from her advanced classes was verbal affirmation from her teachers that she belonged in the advanced math class. Jamie emphasized, "Having the recognition [by a teacher that] you are capable is important. When you get to like higher levels, the teacher doesn't tell you anymore that, like you know, you [are a strong mathematics thinker and belong] in a higher level." For Jamie, having verbal acknowledgement from her teachers would have helped further support the increased growth of her confidence and mathematics identity.

Jamie emphasized that she did feel supported by her past and present teachers in her math classes. That support often came through her math teacher spending time in conversation with her about her learning. Her current math teacher asked questions to decipher where Jamie was struggling, and how to proceed from that specific point of confusion. She reflected:

I think maybe [my math teacher] saw why I didn't understand, and they saw what it took to get me to understand. I think they had to take a step further into understanding why I didn't understand and they had to look at the situation and maybe look at what was wrong with my understanding. They had to ask me a certain question, just ask me a question, and if I didn't know that question, then they would go back and then thoroughly explain the whole concept overall. And then after I understood the concept, I was able to understand, and the whole problem in the first place was that I didn't understand the concept in general. So them going back and explaining it, that helped me understand and maybe it helped 
them understand that they had to take a step back and address the situation, and then teach from there, instead of teaching from a point further where I wasn't at yet — going back to the original point and then moving forward. Just them being able to understand where I'm at. If anyone who is helping you does it where they can understand where you're at, they can go from there. I think that's what makes them a good teacher and it helps the student understand.

The teacher Jamie described offered support by learning where Jamie was in her learning process. Through conversation with her teacher, Jamie was able to gain a stronger understanding of the concept by asking that her teacher learn about her as a student, as a learner, and as a mathematician. Jamie was able to engage in the mathematics learning more intentionally when she felt this level of support from her teachers. Her teacher's use of asset-based teaching (Steele, 1997) resulted in Jamie's growth as a mathematics learner. Furthermore, Jamie felt supported was when her teacher identified her as a mathematics thinker and learner, and was addressed as though she was a competent learner and doer of mathematics.

At home, Jamie sought ways to challenge herself mathematically. She took it upon herself to learn the math concepts that her older brother was learning. She explained:

My brother was always very smart in science in math, and so I would always see him kind of challenging me to see what he knew, because he was two grades ahead of me, because he was older. And so when he would ask me a question and I didn't understand, I was like, "Well, I want to know too!" So I would go further to try to understand what he was doing at a higher level. Just so I could, not 
compete with him, but be on his level. So having a brother who was also interested and who was older kind of made me more interested [in math] than I would have been if I didn't have that person.

Jamie's older brother challenged her to understand the mathematics concepts that he was learning in school, which positively impacted Jamie's mathematics identity. She pushed herself to learn advanced concepts, which contributed to her continued interest in learning mathematics. Along with learning beside her brother, she also played board games that helped to reinforce basic mathematics concepts. Jamie recounted some of these experiences when she said:

We used to play family board games like Monopoly or Life. And so that had to deal with money, like, "Do you want to buy this property? Okay it's going to cost this much, this is how much you'll have left over."

These activities supported her development as a mathematics thinker and learner, and reinforced the learning that she was doing inside the classroom.

Theme two: Personal reflection on mathematics learning process. In considering the development of students' mathematics identities, theme two developed as participants reflected on themselves as mathematics students. This theme highlights student voice through personal reflection on participants' understanding of their own learning practices. Boaler (2016) wrote, "The most powerful learners are those who are reflective, who engage in metacognition - thinking about what they know" (p. 150) and advocating for their learning. In my research, the participants' process of reflecting on their own thinking helped them to recognize their strengths and opportunities as learners, and empowered them to critically analyze (a) how they viewed themselves as 
mathematics thinkers, (b) how they processed learning mathematics concepts, and (c) how they viewed their confidence level, and the ways it has changed over time. While each participant offered a similar set of ideas, there were noteworthy differences between each participants' narrative.

In theme two, the participants' narratives highlighted their metacognitive processes, their reflections over their struggles as mathematics students, and how they have worked to overcome feelings of insufficiency. My participants described discovering how to ask clearer questions, and learning what strategies worked best for them to access the mathematics topics. My participants told about not giving up when the concepts became more difficult, and instead saw themselves as capable mathematics learners, and pushed themselves to continue, resulting in a stronger academic agency. I describe each student's thinking on this topic in turn.

Jamie's metacognitive reflection. First, Jamie reflected on how her confidence wavered based on whether or not she felt like she was as capable as her peers of understanding a particular mathematics concept. She explained:

I'm just not [experiencing] the same [level of] understanding as everyone else. I think that's probably why I would say that maybe my confidence hasn't like been like as high. [When I had finished a class problem], I knew I was correct, but I think when you're just not certain on something, obviously you're not gonna want to say something out loud because it might be like wrong; or like you just don't have the best understanding so you're not gonna feel as like, "Oh I know what I'm doing." Then when you see other kids who are very sure of themselves, you're just like, “Oh, obviously I'm not like them." I mean I don't, I wouldn't 
say that other kids' succeeding decreases my confidence. I would just say it's my own reasoning that I'm not as confident. I would say like a lot of it is your own self, like understanding of something. But then again, I think also it's just like seeing other kids be like a hundred percent sure of themselves-it makes you question yourself and what you're doing.

Jamie also recognized that her irregular attendance played a part in her not understanding the mathematics concepts as a firmly as she wanted, and also impacted how willing she was to participate in whole classroom discussions. Jamie reflected:

I think like in the past years when I was doing better, not saying that I'm doing bad, but when I was there like every single day, and I really understood the concept — like I wasn't scared to like go up [to the board] and do something or say an answer out loud-because I knew what was going on.

Yet, she also recognized that her confidence could grow if she spent time working through and really learning the different concepts, and maintaining her own high expectations. She recognized that it was up to her to accept the challenge of learning, and through that, her self-confidence might grow.

I think it's really up to the student wanting to really practice through every problem, really want to get to those fours [the highest score in the school district] on the test. You know, it's up to the student to really want to like be successful in something in order to have better confidence. Ultimately, it's just like up to the student, what they want in life. So I think a lot of it is self-motivation and selfconfidence. 
Lastly, Jamie articulated her desire to change how she was asking questions in class. She reflected:

I need to understand what's going on before I can understand how to do it, because if I don't know what's going on, I'm not going to know how to do it. So when my teacher was able to explain every part, I was then able to move on, and it helped me understand that sometimes I need to maybe ask a different question, like maybe not "How do I do this problem; how do [I do] this concept?" Instead, ask like, "What's going on, why is this like this?" So for me, just knowing that sometimes I might need to just ask a different question, has helped me as a learner.

Her teacher (at the time of this interview) was able to support her learning more fully once she changed the way in which she communicated her confusion.

Leticia's metacognitive reflection. Next, Leticia's ideas are similar to Jamie's ideas in that she, too, reflected that her confidence as a mathematician had faltered as she advanced to higher-level classes. She felt like she was either below or at the same level of understanding as her peers, which made her feel less confident in herself as a math thinker than she did in previous math classes. As a learner who typically caught on quickly to mathematics concepts, she struggled with remaining confident in herself as a math thinker when she no longer saw herself at the top of the class, explaining:

Before when [I was] ahead of other students [I felt] more confident. I think [I] just [didn't] feel like, you know, the smartest person. I think of myself as kind of like an underdog in the classroom now, since sometimes, well like, I don't get it as fast [as my peers]. 
Carol Dweck (2008), in her research on intellectual abilities, attributed this type of thinking to a "fixed mindset," (p. 2) where the student believes their intelligence level cannot be changed or improved, in contrast to a student with a "growth mindset," (p. 2) who believes their intelligence is not static and can continue to develop. While Leticia felt her confidence falter, she also acknowledged that she was not doing everything possible to help her feel more confident, such as doing her homework. Leticia reflected further:

I don't think of myself as a much as a mathematics learner now as much as I used to, because recently I haven't been doing the things that I should be doing, like all of my homework. Doing all the homework is good to build confidence because it's practice. I like that [math is] challenging. And I can still learn, and study to get better, just by doing all the homework and all the practice.

Leticia enjoyed the challenge of learning math, and knew she was a capable learner. Continuing this thought, Leticia remarked:

If I really am really challenged, I learned how to ask for help when I need it. In any problem I try to solve it myself first. Like seeing what would work and what wouldn't. And then when I do get stuck I ask either a group member or peer, and then I ask my teacher for help. I do like to challenge myself, but it's also kind of stressful when I don't get it.

Learning math can be stressful for Leticia when she does not fully understand the concept. However, she learned when and how to ask for help when she needs it from both her teacher and her peers. Leticia felt frustrated when she struggled with harder 
topics, but knows that she has a support system of her teacher and peers to help her when she is confused.

Leticia believed that it is up to the student to make sure that they are understanding the material, and that each student is responsible for improving their understanding of a concept and changing the behaviors that are harmful to the learning process. Reflecting on these changes, she said:

A lot of it just has to do, like the changes just have to be made by the [student] themself, and just the [student] wanting to really understand everything.

Leticia ended her thoughts emphasizing how important math is to her and her life, that it is an ingrained part of who she is, remarking, "[Math] is like a lifelong like thing inside of me, not just now."

Abe's metacognitive reflection. Lastly, similar to both Jamie and Leticia, Abe noted that as the higher-level classes increased in rigor, his struggle to understand the concepts was greater, and became even more critical for Abe to accept help from his teacher and peers. Abe highlighted that he needed to:

...not have that pride of not receiving help just because you think you don't need it. As you work up [to higher levels of math], I guess it's just gonna be tougher, but I don't recommend giving up as much, cause after you do it, it just doesn't feel right. It feels like something is off, and like you just don't, you probably won't even feel the same way that you did when you did not give up, you know? Abe addressed the struggles that he has encountered over the last few years in his upper division math class when he remarked: 
Once you get into a struggle, make sure to go out and ask for help instead of really limiting yourself with the resources that are given to you. I think I'm very committed to finding solutions and finding a way to make it work. So, I think after struggling through something, just getting the reassurance [from my teacher] that I can do it is really great.

He was committed to continuing his learning even when the concepts got increasingly more difficult, and getting affirmations from his teacher that he was able to work through the harder concepts reassured him and boosted his confidence.

Research question two. Building from the ideas explored in research question one, I turn to research question two, "What pedagogical methods (ways of teaching) do high-performing high school students find the most meaningful as mathematics learners?" This question remains important to consider, as Infinity School District has invested significant effort, time, and funding into a strong focus on implementing collaborative learning initiatives, and also connects back to critical race theory (Delgado et al., 2012; Ladson-Billings, 2016), as it explored how students saw themselves as mathematics leaders, and understood how math impacted their world outside the classroom.

Boaler (2016) noted, "There are many strategies for encouraging students to become more aware of the mathematics they are learning and their place in the learning process" (p. 151). In response to this research question, the three themes that I identified from the responses of my participants were, (a) intentional and supportive classroom structure and environment for learning, (b) structures for collaboration with classmates through mathematics discourse, and (c) teacher emphasis on mathematics literacy and 
relevancy. I developed three themes from nine codes identified in Appendix D as salient modes of support for the participants in regard to teaching and learning in mathematics. The following are excerpts from the three participants over the course of the nine interviews, separated by the key themes that I identified from the data. I summarized the themes at the beginning of each section before the participant excerpts.

\section{Theme one: Intentional and supportive classroom structure and environment}

for learning. Theme one developed as a result of the participants' reflections on how teachers were successful in their work with students, and ways teachers might better support, engage, and empower students in their learning, both inside and outside the classroom. The common factor noted by each participant related to the structure of classroom systems and routines. The participants relayed specifically their thoughts surrounding teaching methods, working with peers in table groups, unwritten (or hidden) classroom rules, and how teachers might better build students' confidence. Participants explored how they felt when working with groups, and offered insights for how to improve the classroom environment to make it more of a comfortable and inviting learning space. Participants' counter-narratives told of how they worked to feel more comfortable in their math classes by promoting working with many classmates, and not only sitting with the people that they knew. Participants expressed a desire to create a classroom community that built a collaborative working environment. I address the insights of each of the three participants in turn.

Abe's reflection on classroom structure and environment. First, Abe highlighted how important collaboration with his peers was to him as he wrestled with rigorous 
mathematics concepts. He emphasized that the classroom environment can directly impact how students work, or do not work, with each other.

Abe reflected that the seating arrangement does not always create the most supportive learning environment. He explained:

There's times where we're put in table [groups] where we don't really know the person. Yeah we could get to meet them and stuff, but it won't be as effective as if you were with someone you really know and you know that they're willing to learn.

He thought that students should be able to choose the location and group members that would best support the student's learning, admitting, however, that students do not always make the best decisions when it comes to who they sit next to. Abe explained: I feel like it would be much better if they [teachers] allow you to pick who you work with. But, there's times also where I feel like students should know what [location in the room] and who is good for you (and who is bad for you), because there's times where they let you pick who you wanna be with, but it turns out to be much more of a disaster than it is helpful for you because it's just a distraction. So what I what I usually do is partnering myself up with someone that I know that has the capability, cause everyone has the ability to do what they want in class. Abe reflected that it is hard for all students to get their questions answered, as the classroom is full, so making time and space for students to collaborate with each other could provide the extra help needed, especially when students are working through more difficult problems. 
The important piece for Abe was that students need to feel comfortable learning with and talking to the peers that are a part of the table group. Getting to know one another, and learning how to talk about math with his peers helped Abe to feel like he belonged to the group, and felt more at ease when sharing his ideas.

If you're stuck and everyone in your table is stuck, there's kind of that awkward part where you're just like, who do I ask for help cause it's just like you don't I mean you don't really know anyone else like yeah there's different people in the class but you're not used to going up and just like talking to them. So you don't know how they will react or if they're actually willing to talk to you because they're not comfortable with you yet. So any more, [in] any classroom, whole classroom projects would be much better to have I guess. It would really boost confidence and be more comfortable.

Abe reflected that it can be intimidating to share ideas when it feels like there's a competition going on between students when he related:

I feel like sometimes it feels like sort of competition, and instead of pushing each other up, we're just dragging ourselves down. Maybe like getting more familiar with your classmates, [so] if you have a question you can go somewhere else. That might help.

Gay's (2002) research on culturally responsive teaching supported Abe's thoughts on classroom competition when she noted CRT, "questions the integrity and viability of persistent individualistic and competitive learning” (p. 622). Student competition can destabilize positive classroom community because of the individualism that it promotes. Gay (2002) suggested instead to emphasize cooperation and collaboration in classrooms 
as, "a great deal of cooperation and collaboration are involved in virtually every learning situation whether it is acknowledged or not" (p. 622). This was precisely what Abe proposed.

Abe suggested changing the seating chart, and doing more activities that got the students up and moving and talking to each other. The better students know each other, the easier it would be to work collaboratively and participate in mathematics conversations. He offered:

Like, maybe switching [seating arrangements] every week or something-just making it more like you can move around, or just getting to know your class better. I think when we're in table groups we only know the people in our groups. It's best that you create friendships, or just relationships, and so you know you have the support — not just from you, not limiting yourself to just your table or your group, you can expand to the whole class and then you could rely on any of 'em.

Abe proposed that collaborating with peers on the more rigorous problems could give students the opportunity to try out their ideas in a safe environment, and help them to feel more confident in their ability to solve the more difficult problems. He said:

The first ones are always the easier ones, and as it gets down though the problems, then it gets tougher. And if you don't practice those hard ones, then you're just really setting the students up for failure because they get home and they haven't, they're not used to it. Any just sort of communication between students that are trying to get to the same destination or the same solution makes me feel much more comfortable and allows me to engage much more easier. I 
know that I'm not left out, and I know that if I get stuck there's someone that will know. Any form of communication, any form of socializing with everyone in that class to get comfortable [building a positive and healthy classroom environment] since day one. It would just lead up to success for the rest of the year. That would really be cool!

Also, Abe recognized that because class sizes are larger than his previous math classes, having time for his peers to help answer questions and work through several leveled examples of problems would help to support his learning, when he expressed:

I feel like the usual thing is, "Here's a set of problems, come back with questions the next day." And there's like, it ranges from like twenty to like thirty kids in a regular class. And if everyone has different questions, there's not going to be enough time to go through every single one. And [work on] all the harder are done ones in class. Because you actually have, you could work stuff out with students, come up with different techniques, and like you have the teacher there to confirm if the technique you're doing is correct or what flaws you're having to so you can perfect it.

It was hard for all students to get their questions answered, as the classroom is full, so making time and space for students to collaborate with each other could provide the extra help needed, especially when students are working through more difficult problems.

Abe believed students need to be taught how to have academic conversations with each other, but before that can happen, students need to feel comfortable talking with each other and sharing ideas. Building working relationships between classmates could 
increase student involvement in academic conversations, empower students to work collaboratively, and help to boost students' confidence in mathematics.

Jamie's reflection on classroom structure and environment. Next, some of Jamie's responses coincided with those of Abe, and she also added an emphasis on how visual aids have helped her to see why and how mathematics works. She began by touching on what she sees as an unwritten rule in classrooms, which is that students are not always allowed to move around to collaborate with peers outside of their table groups. She commented that she felt she would be reprimanded for working with peers outside her table group when she explained:

I think that [the classroom is] not very like inviting. I feel like there's no, like, nobody says that you can go to another group. No one says that. You think that you're just stuck to your own group. Like that's how I always have felt. Like wherever you [are seated in a seating chart], that's where you're placed-you can't move around. It's very inclusive to just your table group. I think that might take away from like talking to someone else who might help you better. I don't think we get the opportunity often to talk to someone who might help us just better. So when you want to go somewhere else, you think you have ask the teacher if you can move. It's just not very like, an inviting thing to do. It's like, "Don't do it [move around the room]; you'll get in trouble." Jamie suggested that it would be helpful if the room felt more inviting to move around. She believed that being able to collaborate with other peers would enrich and deepen her learning, as she would be able to make connections with peers who might be able to support her better. Jamie recognized that students learn in different ways, and 
some students need the teacher to be able to explain the concept using multiple methods, one of those methods specifically being one-on-one conversations. She noted:

Making sure the teacher is able to explain something in many ways can help the students, because not every student is the same, and not everyone's gonna learn the same way. And so making sure there's different ways available of explaining what's happening, what the problem's saying. Making sure that [the teacher] can explain something in different ways helps again with like the comprehension and how much [the students] know about a subject. Also, providing one-on-one conversations between the students and teacher would be helpful.

Making space for students to ask questions and have conversations with their teacher further supports the student's understanding of what is being learned.

Jamie also emphasized the importance of having time in class to work through concepts with her classmates, and underscored the importance of being able to work with a variety of students in the class. It took time to process the content and make sense of the math. Creating time and opening up space in the classroom for the students to collaborate with peers aside from only their groupmates further supported student growth as mathematical thinkers and learners. She explained:

I think since, if it's a full class, then sometimes like the people who already know the concept already kind of answer the whole thing for everyone, and then that doesn't, it doesn't leave space for people who actually want to learn, or like still don't get it. 
In addition to these suggestions, Jamie also explained how visualizing the math that she was learning about supported her understanding of the concept. She expressed this saying:

In first grade, one thing that helped me was visualizing what was going on. The teacher asked us to create a pattern, any pattern, with shapes, and I couldn't really think of any to do. So then she gave me a sheet that showed me an example of a pattern. And so after seeing what she was referring to visually, I was able to do it. After seeing what was going on, I was able to do it myself. So visuals helped when I was younger.

Leticia's reflection on classroom structure and environment. Finally, Leticia's responses echoed the sentiments of both Abe and Jamie. Leticia voiced the importance of using visual aids as a means for demonstrating the relevance of the math concepts, and also the need for students to be more cohesive as a mathematics community of learners. Leticia reflected that she and her peers tended to sit together in class if given the choice, instead of integrating with the students from the other small schools ${ }^{3}$. She explained, "Well, since we're kind of separated into four schools this year, we kind of go to our [own school] peers, I guess since we're more comfortable with them, instead of like other peers."

She appreciated when the teacher created a seating chart that allowed students to get to know classmates from the other schools, remarking, "Now we kind of moved around table groups since he [the teacher] changed our seating chart. So we're kind of not segregated anymore. So it was helpful to have the forced integration."

\footnotetext{
${ }^{3}$ Some advanced classes have crossover between two or more of the schools.
} 
Also, Leticia enjoyed collaboratively solving problems in her table group. She felt more confident when everyone was participating in the conversation. Building in team problem solving practice with integrated table groups helped to improve the learning environment and confidence in learning mathematics. She noted, "I also think peers should help each other out like having table groups so they can solve problems together or solve problems as a class, having everybody participate to increase your confidence."

As a part of that confidence building, Leticia suggested that teachers provide many different types of leveled questions. Practicing with the basic problems to learn the concept is important, but being able to work through the tougher problems would help to give context to the math that she was learning. She expressed the need for teachers to:

Give lots of examples. Staying at the basic level is not super helpful. I think like in general there can be more examples of other, like maybe an easy example, medium example, and maybe a really hard example, so students can see how that same math can apply to all three.

Leticia also appreciated when she could see why she needed to understand the foundational principles as she was working through the harder problems, and had time to work on understanding the concept before moving on. She expressed the wish that teachers were, "Making sure that students are able to practice something more than one time will help the student really get familiar with the subject." Being exposed to the differing levels of math problems, and spending multiple days on one idea was helpful for her in gaining a better understanding of the concept as a whole. 
In addition, Leticia valued combining visual representations of the mathematics concepts with talking about what she was noticing. For Leticia, the pairing of these two methods fosters a more in-depth understanding of the concepts, which supported her overall comprehension of the topic. She explained:

I feel like manipulatives are really helpful. Visually learning, like having things in front of you to demonstrate what's going on in a math concept, versus just like stating what's going on - like actually showing how it works - is important and beneficial. I feel like you get to comprehend it better, like what's going on. It sometimes works better to have a visual and a verbal [explanation] so you could combine them and make better understanding of it.

\section{Theme two: Structures for collaboration with classmates through mathematics}

discourse. The second theme that I identified focused on how participants' mathematics identities and confidence as mathematics learners were developed further and strengthened through participating in collaborative exercises and mathematics discourse with their peers and teachers. Participants' narratives counter traditional classroom teaching, highlighting how they and their peers joined together in learning by supporting and listening to each other, and increasing their knowledge and understanding of mathematics. Participants felt working with their peers unified the class in learning, and generated stronger understanding of the mathematics concepts. I introduce each student's thinking in turn.

Jamie's reflection on collaboration and mathematics dialogue. To begin, Jamie focused on different elements of collaboration that have helped her become a stronger math student. Collaboration in her group has allowed for intentional dialogue between 
her and her peers. This dialogue not only benefited her as a learner, but has also assisted her peers. She explained:

I kinda just comprehend [math] better with a group, like you get everybody's input in how to solve a math problem. Or it could be vice versa, you can give them input also. Having to work with others helps with communication skills. So, instead of explaining to just your teacher, or like to yourself, you have to explain to others. [Collaborating to work through] something that you don't understand is helpful. Maybe another student can be like, "Oh! This is how you do it!" and you're right there; you just learned something you didn't know and you got to work through it from there. I think it is beneficial in that way. I think group work would just help make sure that students see in different ways, like whether it be like having to explain it in different ways, because there would be like a group, so not everyone is gonna get the answer the same way. So having a group might help like expand on that, like be a way to help with the different ways of solving and stuff. [Collaboration] forces my skills in math, and I feel kinda of useful because I'm helping someone, or they're helping me, and I'm getting better as well as they're also getting better by teaching me. Yeah, I think it's just learning more math together.

Jamie used multiple mediums to deepen her understanding of mathematics concepts, specifically through visual representation, talking about the concept with peers, and writing about her process and further connections. She expressed:

One thing I think is really important is showing how something actually is happening, how it's working. I think learning in more than one way how to do 
something; like showing it, saying what's going on, and writing what's going on. Having different ways to explain something I think is important.

Jamie's understanding of different mathematics concepts was deepened as she worked to explain her thinking process and conceptual understanding. Being able to explain her thinking cemented her learning, and enabled her to hold onto ideas and concepts. She expressed:

And when you have to think about how to explain it in another way yourself, instead of only the teacher having to explain the different ways [the mathematics] concept works. When you have to explain it in different ways, I think that means you really understand it. And, if you're not able to make everyone kind of understand, maybe you really don't understand it. So, if you're in a group and you just only know it your way, I think that shows that you might not have the greatest understanding. I like talking about [math problems] out loud because when you talk through them, you understand it better. Like they say: If you can't teach someone else, you don't know how to do it yourself. So, if you can't explain what you're doing or how you're doing it, you really probably don't understand it because you can't explain it. So I think making students talk about it out loud helps see their understanding of something.

Talking out loud with her peers gave her the opportunity to hear herself think, which helped to clarify ideas and clear up misunderstandings. She was able to work through tougher problems with a team, and share different methods for solving.

Jamie realized that often there was more than one way to understand and solve a problem, and hearing from multiple peers about their processes helped her to more deeply 
understand the topic. Jamie felt supported by her peers through the collaboration process, and was able to return that support when her classmates were frustrated with a concept. She reflected:

It might be helpful if every student did talk about their work in a group, and then try and understand other students' struggles at the same time. Classmates come and ask me for help if there's something they don't understand and I already got through it. So yeah, building that peer support helps to build that confidence, helps you to see yourself more as more comfortable in that mathematics-thinking role.

Along with deepening her understanding of mathematics through dialoging with her peers in collaborative table groups, she also saw an increase in her confidence as a result of working so closely with her classmates. The more they worked together, the more comfortable she became with sharing her ideas with the whole class. Incorporating more collaborative activities in small groups might make speaking aloud in class discussions less intimidating because she already will have had the practice of dialoguing with her peers.

Abe's reflection on collaboration and mathematics dialogue. Next, similar to Jamie, Abe described what a collaboration process might sound like in the classroom. He highlighted needing individual think-time, and the need to make sure that everyone in the group was involved in the process and has an opportunity to voice their thoughts. As he reflected, he though:,

If it's a much longer problem it's going to be a lot of talk and moments of silence to just process the information and put it to use. I feel like it's important to listen 
to everyone's point of view because you never know what someone has in their head. I make sure that [everyone in the group] put a part in, cause if we're a group, we all have to put our own part in to make sure that we get to what we want to be, cause if it's basically like one person doing it, then it's not really a group; it's just one person.

After relating how important it is to hold his teammates accountable for positively contributing to the collaboration process, Abe continued his thought on why he valued collaborating with peers when he stated:

[Collaborating with peers] forces my skills in math and I feel useful because I'm helping someone, or they're helping me, and I'm getting better as well as they're also getting better by teaching me. Yeah, I think it's just learning more math together. I feel like the conversation between students valuable and you learn much more than if you do it all on your own. Then, the confidence of students would be much better if they know that they will be able to work out the harder problem with each other, instead of having to deal with it alone. Then you get comfortable with the harder problems, so then it will be so much easier to do it on your own, and then get in more depth to the harder problems. It's just like you just do the harder ones, and then once you get used to them, you do them at home. Abe reflected that working with groups helped him to think through the math problems differently, because he and his peers would work individually first, and then come together with ideas for solving. This helped Abe to push himself to be an active participant in his table group. He related: 
We all do it separately and then talk about it, like if someone gets a different answer, then we all try to solve it together to see what each person did; first talking about something with your group, and then going in a new group, and then talking about it again with different people. I think the more ideas there are better.

Abe knew that his work and how he was problem solving were important to the group because his knowledge helped to build a greater communal understanding of the concept. Likewise, Abe recognized the importance of listening to his peers think aloud about their process. The team members can help each other understand the concept more thoroughly, break down any points of confusion, and build each other's confidence as they rely on each other to share in the learning experience. Their understanding could be enhanced, while refining their problem-solving skills. Abe explained: I understand [the mathematics concepts] much more, because if we work it out ourselves, it makes it more meaningful, but also it challenges you to partner up with other people and work together to get to the solution of the problem. And that could actually help you with not even just math-related stuff, but like liferelated stuff. Like if you become a problem-solver and like it starts boosting yourself up in a way that you didn't think you could be boosted up in. So, I feel like math also can bring you a boost, not just that subject related; it could also impact in your life.

Abe's confidence in his ability to solve rigorous math problems increased through collaborating with his peers and dialoging about their thinking processes. Collaborating with his teammates helped him to build valuable life skills. He realized that the critical 
thinking that was demanded of him in math class were the same skills that are required in working through tough situations in his life. The skills learned surrounding collaborating with his peers in talking through how to solve math problems positively impacted the way he approached resolving situations that came up in his life.

Leticia's reflection on collaboration and mathematics dialogue. Finally, Leticia's responses resonated with those of both Abe and Jamie. Authentic collaboration strengthened her understanding of the mathematics concepts, and supported her by providing her the opportunity to become comfortable discussing math with her peers. She found that talking through her problem solving proved to be helpful in that it clarified some of her misconceptions, and strengthened her ability to communicate her ideas.

Having to work with others helps communication skills; so, instead of explaining to just your teacher or to yourself, you have to explain to others, so like communicating. Also having like knowing that your teacher is willing to help you if you're struggling, that you can always ask for help, as well as asking your peers for help. You just had to look at [the math problem] in another way. So, I think when were able to talk to others we get to see things in more ways. Working collaboratively with others created a supportive peer group where she felt like more of a team member who played an important part.

Leticia was encouraged by her teammates, and could return the support by sharing her ideas. She explained:

[Collaborating about math processes] is helpful since everybody has different brain processes. People solve problems differently and it's kinda useful. I could 
have solved it [one] way, and you can learn an easier or different way to solve a math problem. All of us [in her group] have to participate to get the answer. So that allows us to all go up [to the front of the classroom] and solve the problem. It took the three of us to kinda comprehend. So yeah, we just had to like work through it and eventually we did get the answer. [Collaboration] makes me feel good. I'm helping you, but I'm also learning myself, like refreshing my memory, and I kinda just comprehend [the math concept] better [when collaborating with peers]. With a group, you get everybody's input in how to solve a math problem. Or it could be vice versa; you can give them input also. I think [math discourse and collaboration] is helpful because it's kinda the same thing as me thinking about it, pronouncing [verbally explaining out loud] my work. I start explaining, and then it just enforced my skills.

Listening to her peers as they described their process and conjectures helped Leticia to think differently about the concepts, and deepen her understanding. The process of working together with her peers supported her confidence, as she was able to solve more difficult problems and learn new ways of solving that strengthened her self-perception as a mathematician.

Lastly, Leticia believed that collaborating and sharing in math discourse could improve her level of confidence in mathematics more because she was building the skills to communicate her thoughts aloud, and became increasingly comfortable sharing in whole-classroom discussions. She explained:

If you talk about it with others then maybe you would be more comfortable talking about it like as a whole class, maybe that would happen. Just like little by 
little, like gaining a better understanding would make you want to just say it out loud I guess. I think the little steps are helpful to create a bigger step.

Working in small groups provided the safe space to build her confidence in speaking about math, which eventually led her to become more comfortable with sharing her ideas with the whole class.

Theme three: Teacher emphasis on mathematics literacy and relevancy. Theme three highlighted the participants' desire for the math that they are learning in school to be more connected and relevant to their lives. Teaching math in a way that brings students into the learning process and helps make connections between what is being learned in class with how the content can be used to problem-solve in the world might encourage students to continue pursuing higher levels of mathematics. All three participants addressed specifically their desires for continued study in a STEM-related field.

The participants also remarked on the critical need to learn basic mathematical concepts in a way that allows them to maintain and build upon these foundational principles. Their narratives highlighted the inequity that comes from being behind gradelevel peers. An emerging understanding of basic mathematics makes learning higherlevel mathematics difficult and contributes to a disconnection between what is learned in class with how students see mathematics in the world, which can also result in weakening students' identities as mathematicians. Each participant's lived experiences have been voiced in relation to these ideas in turn.

Jamie's reflection on mathematics literacy relevancy. First, Jamie understood mathematics to be the foundation upon which everything in life is based. She 
commented on the vastness of mathematics, that it is more than just a set of numbers. Jamie recognized the intricacies of mathematics, and rigorousness of the higher-level concepts. She felt that the difficulty of the higher-level mathematics class prepared her for future college classes, and she chose to continue with her study of mathematics because she is interested in learning more about how it connects to other parts of her life. Jamie reflected about tying her love of math and art together in her future plans saying: I like both art and math a lot, like probably more than most subjects. I think I'm excited for bringing them together and showing how they can be used together, because so many people think that math students can't be good at art, art students aren't good at math. So, showing how they are actually related, like through architecture, I think is what I'm looking forward to.

Jamie thought more about how her math classes have prepared her for her future by remarking:

I'm thinking more clearly about what school I wanna go to, and what classes I'm going to have to take. And I'm thinking if I didn't take this math class [upperlevel math class that she is currently taking], I don't think I would've been like as prepared. I'm glad I'm taking it even when it's hard because I think it willtowards my career specifically—help. I'm very interested in the bigger picture. Math just never stops. There's never gonna be a certain amount, like you don't get to a certain level and just stop. There's always gonna be more and more and it gets tougher and tougher. And there are different people that would just give up because they don't think of the bigger picture. Students I talk with just feel or 
think that math is pretty useless after like Algebra 2, so they just don't want to do it anymore.

Jamie took to heart the importance of advancing in mathematics and being mathematically literate. She pondered this concept while describing two interactions with two of her friends. Jamie explained:

I was working through [a math problem] with my friend, and the problem came when he couldn't do like two minus negative four, and he was a junior in high school! And I think that's when I realized it's the basic math that people don't understand, and then people expect them to do like higher math. If they're not understanding the basics, they're not gonna move through math, and I think that happens like so often. Maybe it's like they didn't understand, but they were carried along and they keep not understanding. And then they're four steps backwards, you know? And maybe that's where the problem is. I think mostly it's like they were dragged along to understand.

Jamie struggled with understanding why her friend seemed to have a lower level of understanding basic mathematical principles than Jamie might have anticipated. She commented that it seemed as if some students were being passed on from class level to class level without actually understanding what they had learned in the class prior to the one in which they were currently enrolled.

In the second interaction with one of her friends, focused on an outside-of-school scenario, Jamie described:

I was thinking about how she has a year contract [to a gym], and she probably didn't think like mathematically about how that's gonna affect the whole year. Or 
maybe like how much she has to drive. Maybe it's because she didn't have that math understanding. I don't know if there is any correlation between thinking about your life and math and things like that. I dunno if it's just a coincidence that the ones who like do things like that [referring to the above situation], not saying they don't think about things, but like maybe not thoroughly. Maybe if they had more math understanding, their actions would be different.

Jamie's suggestion is for teachers to make real-life mathematics connections more often. She believed this would lead to increased engagement in their classroom studies and mathematics literacy, and would help students make better-informed decisions in their lives. Corroborating her thoughts, Delpit (2012) elaborated:

The urgent need for demanding critical thinking of our students exists in all subject areas. Only those who are authentically and critically literate can become the independently thinking citizens required for society's evolution. The opportunity to achieve such levels of literacy is even more critical for those whom the larger society stigmatizes. (p. 128)

Jamie recalled a time when her teacher was able to help her and her classmates see how the mathematics content was applicable to their lives. The students were more engaged in what they were learning, and were even able to see their use of mathematics in their daily lives.

Someone [in eighth grade] was like, "Why is math even like, why are we doing this?" And [my teacher] was like, "Well, for example, when you're at the grocery store..." and ever since then I'm like, "Wow! She's so right!" Because of her, I think about [math] a lot in everyday life because of what she said. 
She continued her thought expressing:

I also think we can do world related problems, because I hear some kids who are like, "Oh, when am I ever going to use this in real life?" So maybe applying itmath to real life - and having us problem solve a situation like that would kind of force them to be like, "Oh, maybe I do need this in real life." I mean sometimes, I myself think like, "Oh, when am I going to use this math? All I really need is simple math." So yeah, kind of doing those activities to kind of see that would be helpful.

Real-life connections might help students become more interested in their mathematics learning, increase their mathematics literacy, and find mathematics to be relevant in their lives.

Leticia's reflection on mathematics literacy relevancy. Like Jamie, Leticia also chose to continue learning mathematics because of the challenge it brings, how it sparks her curiosity, and how it will help her with her future studies and career. She noted:

I think when you know more, your knowledge is just, there's more opportunity to go further into more things. I was just more curious about how everything in the world does relate to math. And before I didn't really think about that because I didn't have a lot of things to base it off of. So as I learned more, I was more curious because [I was] like, "Oh now I know this, so what else does it apply to?" When talking about her future, Leticia mentioned how the challenge of her mathematics class has prepared her for the college classes that she will be taking in the fall. She commented: 
Challenging myself and working through problems applies to my life. Being able to take a challenging course will prepare me for other challenging courses, even when it's hard. If there's a difficult situation, I just have to work through it. I try to solve the problem or make it better. Right now I'm still undecided on what I want to [do as a career], but I do know that I want to focus on math and science. I want to focus on something around those fields or involving both of them. Maybe a type of engineering, I'm not sure, or pharmacy.

Broadening and deepening her understanding of how mathematics plays a role in the world encouraged Leticia toward a STEM-centered career.

Leticia discovered that not all students felt as connected to math in the same way that she did. She explained:

Some [students] think, “Oh, I'm not good at math" because they don't get it as easily as others. Or like they don't see how it would apply to their daily lives, or what they're going to do in the future.

Leticia remarked on her peers' seemingly less-robust math identity as a result of not seeing the connection between what they are learning in class and their lives in the community. She suggested that her peers also struggled to connect what they were learning in class with how they will use math in the future, whether directly as a part of their chosen profession or as a part of their day-to-day living. Leticia emphasized the criticality of making mathematics real and relevant to students. She believed if mathematics were more applicable to students' lives, they would be more likely to continue pursuing mathematics courses. 
Abe's reflection on mathematics literacy relevancy. Finally, Abe agreed with Jamie and Leticia that helping students to become critical and literate mathematics thinkers will help them to see the relevance of mathematics in their lives. Abe emphasized that students compartmentalize how they understand or use math when he remarked:

The real world - a lot of students just think of it as like numbers or just shapes. They don't see like shapes in their everyday life. When they come to school, they don't think about the building they're in, or how they get to school. They don't think about like how far they travel, things like that.

Abe believed students tend to keep their learning of math inside the classroom and struggle to find the meaning behind the mathematics in relation to their lives. He explained further:

I think that maybe it would help like if people knew why we're even learning what we are, and finding why it's meaningful. I feel that would be beneficial and it would create more interest in the subject. Sometimes people just lose motivation because it gets too hard and you feel like there's no way of making it better, and sometimes there are different people that would just give up because they don't think of the bigger picture.

As the mathematical concepts increase in difficulty, students could lose their motivation to continue to learn because the learning has not felt relevant. Abe believed that supporting students in finding the meaning behind what they are learning would create a greater sense of need and interest in continued learning of mathematics. In many cases, 
students are willing to work hard if they can see how the learning will benefit them in the long-term.

At the same time, Abe felt like the advanced math classes were less interactive and engaging when he said:

Everything [in the advanced math class] became more about notes and like an example problem. Nothing from that day forward [in the upper level math classes] was interactive, it wasn't like anything like visual.

Supporting learning with interactive lessons, visual aids, and relating the learning to his life engaged and empowered Abe in his academic pursuits. As an example, he described a time in Geometry class when he made a connection between what he was learning in class with what he was experiencing outside the classroom:

You see shapes, or sometimes you even encounter them in person. So it just adds fun. Because for me personally, like when I'm out and I see a certain shape that I'm learning, or like measuring or something, I'm just like, “Oh! I'm looking at that in class!" Any whole classroom projects would be much better to have I guess, to have as um, it would really boost confidence and be more comfortable. Making those connections between what was learned in the classroom with what he was seeing in his daily life were exciting for him, as he was able to see how the math he was learning in the classroom correlated to the events in his life.

Lastly, Abe reflected that having a strong background in mathematics would give him a leg up over any competition in the job market when he remarked:

I mean [math literacy] will put me to a better advantage than someone who doesn't [also have math literacy]. I feel like if [an employer] is looking for 
someone that like has the certain, I guess certain assets, like [the employer is] looking for someone to hire, they'd chose someone that it has high knowledge in math, over their competition who doesn't. [Being math literate] just helps you understand the basic concepts of math. You're already at a bigger advantage than someone that lacks in it. Math is just part of your knowledge—and just your knowledge in general is what helps you survive in this world — cause if you didn't have knowledge at all then you're, I mean, the whole the saying of like the survival of the fittest.

He believed that potential employers intentionally seek math-minded individuals. As he is interested in pursuing a career in business, being math-literate will help him to have a deeper understanding of business principles and practices. Abe viewed mathematics as a critical part of his life, as it guides his understanding of how mathematics is used in the world. He saw math literacy as a tool to help him become successful and lessens the possibility of being taken advantage of by others.

\section{Interpretation of Results}

In this section, I expand upon the five aforementioned themes in response to the two research questions. The first research question is, "In what ways do high-performing Latinx high school students describe the development of their mathematics identities?" The two themes from research question one were, (a) external support systems-teachers and family/guardians, and (b) personal reflection on mathematics learning process. The second research question is, "What pedagogical methods (ways of teaching) do highperforming high school students find the most meaningful as mathematics learners?" The three themes from research question two were, (a) impact of classroom structure and 
environment on learning, (b) student collaboration through mathematics discourse, and (c) emphasizing mathematics literacy and relevancy. I address each theme in consecutive order.

Research question one. The first research question was, "In what ways do highperforming Latinx high school students describe the development of their mathematics identities?" The following discussion examines the two key themes that developed from the data through my interpretation of the responses of the three participants. The participants were asked specifically about the different ways their mathematics identity development was supported as they grew up. Theme one details how participants' mathematics identity developed through the support of external systems, specifically through their teachers and family/guardians. Theme two delves into how participants' mathematics identity developed through their own reflection on their personal growth as mathematics thinkers.

Theme one: External support systems-teachers and family/guardians. The participants all focused on the development of their mathematics identities in terms of how their teachers and families/guardians supported their interest and pursuit of studying mathematics. Participants concentrated on how the different systems of support helped to build their confidence as mathematics thinkers. In particular, students focused on how teachers set and maintained high expectations for each student, listened to students as they described their point of confusion, were available to students outside of class, and built professional relationships with their students. These supports furthered the development of their mathematics identity because the participants felt listened to and 
cared for as learners, and they used this support to move forward as stronger mathematics thinkers.

In addition, the participants reflected that their families/guardians supported the development of their mathematics identities by playing games, and by the families/guardians engaging with them in conversations about mathematics. The conversations surrounding math differed based on each participant, but the participants all commented that conversations about mathematics were encouraged and supported at home. Like their experiences at school, the conversations and focus on math games at home reinforced their learning at school, and further supported the development of their mathematics identities.

Theme two: Personal reflection on mathematics learning process. In considering research question one, which states, "In what ways do high-performing Latinx high school students describe the development of their mathematics identities?", participants focused on how their confidence in their ability to easily solve math problems and understand more complex topics had become less stable as they advanced into the higher-level mathematics courses. They reflected that in the past, as younger students, they had been at the top of their classes, and that understanding the mathematics concepts came easily for them, which boosted their level of confidence as mathematics thinkers. As they advanced into the upper division math courses, they felt like they were no longer at the top of the classes, and that the concepts were no longer easily understood. This caused the participants' confidence to waver. However, the participants also recognized what they needed to do to regain their self-assuredness. The participants began asking more focused questions in class of their teachers and peers, and 
realized the need to do their homework to help reinforce the ideas that were being presented in class.

Learning how to ask meaningful questions in class was a big step for the three participants. In their previous math classes, they had not needed to receive much help from their teachers - they were independently capable of working through the concepts. As the rigor and level of demand increased, the students not only needed to learn how to ask questions in class, but how to ask the right kinds of questions to clarify their points of confusion. For students who had never really depended on asking questions of their teacher or classmates, this took courage to seek out help. However, students realized how beneficial it was to struggle through a problem, and to work with their peers and teachers along the way. Participants took ownership of their learning, and worked toward regaining their confidence as mathematics thinkers.

Research question two. The second research question is, "What pedagogical methods (ways of teaching) do high-performing high school students find the most meaningful as mathematics learners?" The following discussion examines three key themes that developed from the data. I asked participants were asked specifically about what conditions for learning, and what teaching methods, best supported the development of their mathematics identity at school. Theme one addressed classroom structures (routines) and classroom environment, and how these two elements affect learning. Theme two discussed how intentional collaboration and the use of mathematics discourse enhanced their learning experience, and increased their understanding of different concepts. Theme three emphasized the importance of making mathematics relevant for students, and supporting students' mathematics literacy. 
Theme one: Impact of classroom structure and environment on learning. The participants commented on classroom structures and routines that both supported and hindered their growth as mathematics thinkers. All three students desired for there to be more activities that united the class, so that all students felt comfortable working with each other. The participants honed in on the importance of building a classroom community that invited students to work with their peers around the classroom, because as the participants grew to be more comfortable working with their classmates, their comfort level with sharing their ideas and their struggles increased, and assisted in building the participants' confidence as mathematics thinkers.

Participants desired to have opportunities to move around the classroom during their work time to work with other members of the class, not just those that they were originally grouped with in accordance to the teacher's seating chart. The participants recognized that if they only sat with people that they knew, and did not challenge themselves to work with other classmates, they might continue to feel uncomfortable in whole-classroom discussions. Building relationships with their peers in the classroom made it less intimidating to share their thoughts and ideas. My participants also recognized that sometimes partnering up with classmates that they felt very comfortable with yielded a less-than productive work time, so having the expectation that the students would work with everyone in the classroom helped to minimize distractions, and maximize their productivity.

All three participants claimed that one of the most helpful ways to support students with building strong academic relationships with their classmates was through collaborative activities. Students were able to learn from and with each other by talking 
through the mathematical concepts. It was through this learning process that students built trusting relationships with their classmates, and created a less-intimidating classroom environment. Leticia, Abe, and Jamie all felt that their confidence was higher when they were able to struggle through math problems with their peers, which also contributed to a positive classroom learning space.

Theme two: Student collaboration through mathematics discourse. Participants relayed the value of collaborating to work through difficult math problems. Intentional collaborative exercises helped students voice their thoughts about the mathematics concept that they were learning. Working collaboratively did not simply mean that they were working in groups, but that they were actively solving problems together by listening to each other's ideas, recording thoughts and possible ways of understanding the problem, explaining their process in solving, and justifying why their process and answer made sense with respect to the concept. Through these exercises, students were learning with and from each other. This support from peers in class helped students to understand the concepts better because they were asked to use their mathematics vocabulary and academic language to support their claims. As students supported each other with the learning process, they sharpened their problem-solving skills, and became more comfortable openly sharing their ideas with their classmates. Students encouraged each other when they were struggling, and learned how to voice any continued confusion.

Collaboration was a key teaching method that allowed students to voice their own confusion with a math concept within a small group of their classmates, and opened the door for students to learn how to work with different groups of students around the room. Unveiling their mathematical frustrations in a small group setting supported students with 
becoming more comfortable with talking through the mathematics. Once students were feeling more at ease with sharing their questions with a small group, students felt more empowered to share in large-group discussions with the whole class.

Jamie, Abe, and Leticia mentioned that it was just as important to listen to their peers, as it was to be listened to. Listening to their classmates talk through mathematics concepts also helped the participants to see mathematics in many ways, which deepened their overall understanding of the topic. This mutual respect helped to create a stronger sense of self in the classroom as a mathematics thinker, which likewise led to an increased confidence in seeing themselves as strong mathematics students.

Theme three: Emphasizing mathematics literacy and relevancy. Learning the relevancy behind the mathematics being taught, and emphasizing mathematics literacy were poignant points made by each of the participants. Leticia, Jamie, and Abe had each, at some point, felt some degree of disconnect to what they were learning in their mathematics classes, especially in in the higher-level mathematics classes. The three participants stayed in the advanced classes because they enjoyed learning, and desired to work in a STEM field in the future, but often struggled to find the connection to what they were learning with how it impacts their daily life. While visual aids did not necessarily contribute to making real-life connections to the math they were learning, the participants felt strongly that using visual aids of any kind helped students to better understand where the math was coming from, and why it was important for them to be learning it. The more the students could picture the "how" and "why" behind the concepts they were learning, the more they were interested in learning it, and the better they understood the concepts and could connect it to their lives. Visual aids built a 
deeper understanding and connection to the mathematics, which increased their interest in learning mathematics and their desire to learn more about how mathematics was relevant in their life.

Participants relayed their concern for their peers who were not as likely to advance into the advanced classes as a result of not being able to make connections to their life. Both Jamie and Leticia expressed concerns with what they perceived to be the low level of basic mathematics reasoning and literacy of some of their peers. Without making meaningful connections, the participants believed that those who did not see themselves with strong mathematics identities might not desire to continue learning math, and that this was an inequity. Abe specifically spoke to the importance of understanding mathematics as someone who is looking for a job. Hiring committees, he believed, would hire someone with more confidence in and skills with mathematics than one who struggled with mathematics. Participants thought students compartmentalize how they are learning math, such that what they learn at school stays at school and does not transfer to their lives outside of the mathematics classroom. Changing teaching methods to increase the focus on guiding the students to see the relevancy behind what they are learning, and to make the learning meaningful, might strengthen students' mathematics identities in every mathematics classroom.

\section{Limitations of the Study}

The purpose of this research was to give voice to underrepresented studentsthose who belong to a historically marginalized racial identity. Student voice was at the center of my research because student learning is at the heart of teaching, and who better knows about student learning than students themselves? Therefore, I chose to conduct a 
series of three consecutive interview sessions with three Latinx high school seniors. In this section, I review three main limitations of this study. The three main limitations are (a) the focal school demographics are largely Latinx, (b) only students who acknowledged having a strong mathematics identity were interviewed, and (c) student voice was largely missing in the question creation and analysis of the data. I will address each limitation in turn.

Homogeneous school demographics. The demographics of Infinity High School are reflective of the demographics of the local community at large, which has a majority Latinx population. As such, many students in this district share similar backgrounds, cultural norms, and racial profiles, and have had teachers at every school level (elementary, middle, and high school) that speak their primary language. This is atypical in comparison to the rest of the nation. In many cases around the United States, students of color are in classes with peers who do not look like them, who do not share similar upbringings, and mainly have teachers who are White (U.S. Department of Education, 2017). This is a limitation to my study in that the students that I interviewed did not regularly feel a sense of being discriminated against because of their race. The participants remarked:

Leticia: I don't really think about me being a Latina or a female or anything; I just kind of think of myself as a math learner.

Abe: Here in this town, it's been really, really supportive because the percentage of Latinos is really high. I've never felt that I that I don't belong. But, that's just here. 
Jamie: I feel like growing up, I feel like it has been pretty equal, at least where I'm coming from. I don't think I've ever seen separation, but I'm also surrounded by many like me, so it's hard to really like see the difference. In [Infinity Town], I feel like it's pretty equal opportunity.

While it is truly wonderful that the participants felt a sense of belonging among their peers and teachers, if I were to reproduce this study in a White-dominant school district, I question if my results would have yielded the same responses. This limitation does not negate any of the lived experiences of my participants, but instead offers the opportunity for further study in areas surrounding this school district where the Latinx population is not as prominent.

I believe that it was critically important to highlight these participants' voices from their perspective as Latinx youth about the development of their mathematics identity. Abe, Leticia, and Jamie saw purpose for, and were in support of the district's focus on collaborative teaching and learning, and provided keen insights into what changes need to be made to support Latinx youth. The participants also painted a picture of how their personal funds of knowledge were constructed from childhood, and built upon at school. It was important to hear Leticia, Jamie, and Abe's voices because their stories as Latinx youth can open doors for more Latinx youth to contribute to the continued research of mathematics education. Their stories run counter to the tale that has been so often painted of Latinx youth in this nation, and it is vital to share their successes to encourage and empower other Latinx youth to share their narratives, and work to bring about transformational change in our national educational system. 
Participants with strong mathematics identities. I designed my research study specifically to interview students who have strong mathematics identities. The purpose of this decision was to learn from students the ways in which their mathematics identities have been fostered and supported, and which teaching practices most greatly cultivated self-empowerment and academic agency. The experiences, both inside and outside the classroom, contributing to their mathematics identity development help to shine a light on how teachers can better serve and grow the next generation of mathematicians. However, only hearing from students who have a strong and positive association with mathematics is a limitation to the study. The stories and lived experiences of students who have never had a strong mathematics identity, or those who previously had a strong mathematics identity and no longer do, are equally important. If the goal of math teachers is to help foster the development of mathematically literate individuals, we must also learn from students who do not see themselves as strong mathematics learners, to better identify the ways in which teachers and families could better support students' identity and growth as mathematics thinkers. A continued study focusing on these students' voices could bring rich dialogue to mathematics education researchers and teachers about why some students do not positively identify as mathematics learners, and what teaching strategies could be improved upon to increase students' development of their mathematics identity.

Missing student voice from question creation and analysis. I intentionally chose to interview seniors in high school because they have spent the longest time in the K-12 school system, and therefore have had the longest time to reflect on their mathematics identities. The interview series began in late February, and ended right before spring break in March. My study design left the question posing and analysis of 
the data up to me, as the researcher, and included member checks to ensure the interpretation of the data was in line with the participants' meaning. As a White, adult female, I see this as a limitation. Although I engaged in member checks with my participants, my voice dominated the types of questions asked and left me alone to construct interpretation and meaning from the data.

In future research, student voice should be part of the research design, including the questions asked and the analysis of the data. Pizarro (1998) addressed this same concern, saying, "The fundamental innovation of recent methodological discussion on interactive research is the suggestion that researchers include participants both in the formation of questions and in the interpretation of results" (p. 58). Limitations in time also did not allow for students to participate in multiple member checks. The initial round of data analysis ended in early June, and as my participants were seniors, they were not able to meet with me again before graduation. Member checking occurred after graduation, and participants provided valuable insights. Had the participants been able to be a part of the analysis, their voices would have been carried through the entirety of the study. 


\section{Chapter 5: Discussion and Conclusion}

Infinity School District has implemented several different initiatives focused on collaborative, student-discourse-focused teaching practices, spending a sizeable amount of time and money in preparing teachers to implement these strategies in their classrooms. The specific research problem addressed in this study investigated whether the district initiatives surrounding collaborative teaching practices supported students in building their identities as mathematics learners, led to self-empowerment, and contributed to academic agency. The purpose the study was to elevate the voices of Latinx youth identified as strong mathematics learners.

A substantial and starkly noticeable lack of student voice and perspective has been absent in educational research, especially in mathematics education. As previously noted in Chapter 1, but is worth repeating here, Milner (2015) stated, "In my experience, I have found that we-researchers, teachers, principals, counselors, parents, policy makers - often spend time talking about students and not enough time talking and listening to them" (p. 70). Students know best how they learn, and can detail their experiences as learners better than any adult. Of his research with Chicana/o students, Pizarro (1998) related, "I know that interactive research had the possibility of providing both more detailed understandings of the school experiences of Chicanas/os and, in turn, ideas as to how we might make change for these students" (p. 59). If we, as educational researchers, really desire to know how to improve our teaching, we need to involve our students as active participants in the teaching and learning process.

This is precisely why I chose interview studies as my research methodology. Students can offer valuable insight into the effectiveness of teaching practices, and can 
give suggestions for how to better support students with their learning experiences. For this reason, I chose to conduct my research study through a series of interviews with students. I based my interview model on the interview process detailed by Seidman (2013). I interviewed three students three separate times over the course of a four-week period of time. The focus of the interviews was guided by the following research questions:

1. In what ways do high-performing Latinx high school students describe the development of their mathematics identities?

2. What pedagogical methods (ways of teaching) do high-performing high school students find the most meaningful as mathematics learners?

In this chapter, I synthesize the findings related to these research questions within the larger context of the problem of practice, purpose of the study, and literature. I focus the synthesis of my findings on the development of students' mathematics identity. Next, I draw upon the synthesis of my findings to address implications for professional practice, including the ways my findings can inform the development of students' mathematics identities; the importance of building a caring community of learners within the math classroom; using collaborative, student-discourse-focused teaching strategies to build student academic engagement, and self-empowerment; and emphasizing mathematics literacy and relevancy. I conclude by suggesting next steps for research, to extend and build upon the work I offer herein.

I identified two key themes in relation to research question one, and three key themes developed in relation to research question two. The participants' thoughtprovoking interview sessions led to several key conclusions surrounding the development 
of students' mathematics identity, and teaching practices that first scaffold, and then led to and encouraged self-empowerment and academic agency. I address my conclusions in the following section.

\section{Synthesis of Findings}

The participants provided rich and meaningful data throughout the interview series. I situated this work and my findings within the context of my school district, which has a majority population of students who identify as Latinx. The school district has spent the last decade on focusing on initiatives that specifically incorporate collaborative, student-discourse-focused teaching strategies in attempt to increase academic engagement. The school district adopted the AVID program to support teachers in changing their pedagogical structures and routines. The Common Core State Standards Initiative (2020) for mathematics also have a specific focus on communicating reasoning through validating and justifying ideas, processes, and solutions. My research ties to these core ideas and constructs through examining how participants' mathematics identity developed both inside and outside the classroom environment, and examining specific teaching strategies and practices that support the growth of self-empowerment and academic agency.

In Chapter 2, through critical race theory, I examined the need to reform teaching practices to incorporate culturally sustaining pedagogies. Researchers, such as Steele (1997), Ladson-Billings (1995), and Gay (2002) emphasized asset-based, reflective teaching as a foundational approach to teaching students of color. Students' racial identities critically factor into their mathematics identities, and therefore should be forefront when reforming pedagogy. Teaching with equity and social justice has been 
foundational to reforming mathematics teaching practices (Ladson-Billings, 1995;

Gutiérrez, 2013; Valero, 2004). I drew from Ladson-Billings' (1995) work on building students' critical consciousness, wherein she remarked, "Building those individual characteristics of academic achievement and cultural competence, students must develop a broader sociopolitical consciousness that allows them to critique the cultural norms, values, mores, and institutions that produce and maintain social inequities" (p. 162). It was through building this critical consciousness that students could begin to build selfempowerment to better analyze, challenge, and build active lives to inspire transformational change in society. My research hightlighted on how three Latinx youth have become reflective, empowered citizens. Their lived experiences illuminated different methods for approaching collaborative learning that increases students' confidence, mathematics identity, self-empowerment, and academic agency.

Additionally, another major idea from Chapter 2 highlighted how each student comes into the classroom with their own unique set of academic attributes - funds of knowledge (González et al., 2001; Smith-Maddox \& Solórzano, 2002) — that teachers and the classroom community as a whole can draw from. Students' funds of knowledge have been constructed in their home and within their community, and should be accessed by teachers in the classroom as a tool to learn about their students' lives, and engage students in their learning (González et al., 2001). Teachers who accesses their students' funds of knowledge have been better equipped to teach with an asset-based approach. An asset-based teacher understands their students' background and lived experiences, and uses those experiences to increase relevancy and personal connection to their learning (Paris \& Alim, 2014). My research connected to these ideas through the participants' 
reflections on how their mathematics teachers supported the development of their mathematics identities. Each participant described building supportive relationships with their teachers built on trust and respect, and a genuine desire for the teacher to get to know their students. Through relationship with their mathematics teachers, Abe, Leticia, and Jamie felt engaged in their learning, and encouraged to continue in higher-level mathematics, and supported by the amount of extra time and care given by their teachers. In this section, I further detail my conclusions based on the analysis and interpretation of the previous sections.

Research question one. Research question one focused on the development of the participants' mathematics identity. The two themes developed from the data for the first research question were (a) external support systems - teachers and family/guardians, and (b) personal reflection on mathematics learning process. I discuss my interpretation of the participants' interview responses one by one.

Theme one: External support systems—teachers and family/guardians. My participants advocated for systems that support building and maintaining their confidence levels. I noticed that the participants mentioned they were most confident when their teachers and peers recognized them as strong mathematics thinkers. Jamie, Abe, and Leticia suggested building in specifically designed confidence-building exercises, and to have teachers specifically working one-on-one with students to increase students' selfperception. This is a good place to start, but I believe the conversation needs to be shifted to address the underpinning issue that students are viewing mistakes and a healthy struggle as an indication that they are no longer a strong mathematics thinker; "They think it means they are not a math person because they have been brought up in a 
performance culture" (Boaler, 2016, p. 12). On the contrary, Boaler (2016) remarked, "If we believe we that we can learn, and that mistakes are valuable, our brains grow to a greater extent when we make a mistake" (p. 13). The fear of making mistakes is paralyzing for a student. Teaching students the power of mistake-making through a growth mindset can increase students' confidence and self-empowerment.

Along with confidence building exercises, participants remarked on the positive impact of having an encouraging relationship with their teacher (Ladson-Billings, 1995; Gay, 2002; and Gorski, 2013). Leticia, Jamie, and Abe commented that a positive relationship strengthened their sense of belonging, and was especially important at the advanced levels of mathematics. Building this teacher/student relationship helped the participants to feel comfortable asking questions and being in conversation with their teachers about what they were learning. When teachers build positive rapport with their students, students are more likely to feel comfortable engaging in academic conversations. Being in conversation with students allowed the student to feel heard, and helped the teacher to know how the student was processing the content, where the student might be struggling, or learn from the student about their own unique way of understanding the mathematics. Conversations with students not only built students' sense of belonging, but also increased the teacher's ability to know and understand their students' learning processes. Ayers (2004) thoughtfully conveyed:

Teachers must know their students, reach out to them with care and understanding in order to create a bridge from the known to the not-yet-known. Teaching is more than incidental, more than accidental, demands sustained empathetic regard. Teaching is initially the art of invitation, and it is virtually impossible to invite 
people to learn if they are strange or inscrutable to you. Good teachers find ways to know and understand learners. They observe and record students at work and at play. They create dialogue. They inquire. They map social and cultural contexts. Odd or unfamiliar contexts place a straightforward demand upon teachers: Become a student of your own students as a prerequisite to teaching them. (p. 25)

Students also remarked that they felt supported when their teachers would set and maintain high expectations for learning. Asset-based teaching practices (Steel, 1997; Ladson-Billings, 1995; Milner, 2011) have been foundational for setting and maintaining high expectations for students. Students have aimed for the bar that was set for them, and know when the bar was set low. When teachers set and maintained high expectations for their students, the students were more apt to try to reach those expectations with the support of the teacher. The participants wanted to know that their teachers believed them to be capable of learning the challenging material, and that they were being held to high standards. These were all elements of culturally relevant, responsive, and sustaining teaching practices (Alim \& Paris, 2014; Gay, 2002; Ladson-Billings, 1995; Paris, 2012;). Additionally, Abe, Leticia, and Jamie recounted how they were supported in learning mathematics at home. Interestingly, playing games was a major part of all three participants' narratives. The participants mentioned how they would play games with their siblings, and in some cases with their parents/guardians. The parents/guardians valued spending time together learning. The parents/guardians supported the participants in learning and talking about mathematics as much as they were able. The act of learning was incredibly important within these families. The students were supported in their 
learning by the parents/guardians and siblings. Each family unit expected that the participants would do well in school, that graduation from high school was not an option, which were like to the high expectations set in the classroom.

Leticia's experience was striking in that her father created a multiplication times tables game for her and her siblings to play and learn their multiplication facts. Leticia enjoyed this aspect of competition, and even mentioned later in several interviews that she did enjoy certain facets of competition that she encountered in school. Leticia's enjoyment of competition in learning might have stemmed from her positive experiences learning her times tables with her family. Jamie and Abe also enjoyed friendly competition with their siblings. However, neither enjoyed competition in the classroom. I talk more to this point in the second research question.

Theme two: Personal reflection on mathematics learning process. The participants recounted that their confidence levels wavered as they advanced into the higher-level mathematics classes where the content became increasingly more difficult. Students based the ways they viewed themselves as mathematics thinkers on how quickly they were able to solve a problem. Therefore, when the concepts increased in rigor and difficulty, and the participants began to struggle with solving, their self-perception as a mathematics thinker declined. If this is the case for students who have strong mathematics identities, how much more is it felt for a student beginning with a less strongly developed mathematics identity?

Abe, Leticia, and Jamie did remark that they knew they would have felt like stronger students if they had done their homework assignments and spent more time studying. Before the upper division classes, the participants were able to achieve high 
grades without needing to do every homework assignment. However, the conceptual rigor of the higher-level classes required the extra effort. The participants needed to learn how to organize their time better to allow for this new expectation, and learn the material all at the same time. Helping students to learn study skills early on may help alleviate some of the stress of the upper division courses while increasing their confidence as mathematics thinkers.

Along with learning study skills, Jamie, Abe, and Leticia also reflected on changing their classroom habits; namely, how they learned to ask meaningful questions. With the increase of difficulty in the higher-level classes, asking questions became a lifeline. However, the participants realized that they needed to be able to articulate the specific area of their confusion to gain clarity. The types of questions that they were asking needed to change to define their misunderstandings more accurately. Social justice mathematics (Gutstein, 2009), culturally sustaining pedagogy (Paris, 2012; Paris \& Alim, 2014), culturally relevant pedagogy (Ladson-Billings, 1995, 2011, 2016, 2017), and culturally responsive pedagogy (Gay, 2000) speak to the absolute importance of supporting students in learning how to think critically, to dig deeply into what is being taught and why, to question their results, and to find purpose and meaning in their learning. Aiding students with building stronger study habits and teaching students how to ask powerful and meaningful questions academically empowers students and strengthens students' confidence, all the while simultaneously increasing their academic agency.

Research question two. Research question two focused on teaching methods that promoted a positive learning environment, collaborative learning opportunities, and 
emphasized making the learning relevant. The three themes developed from the data related to the second research question were (a) impact of classroom structure and environment on learning, (b) student collaboration through mathematics discourse, and (c) emphasizing mathematics literacy and relevancy. The participants reflected on the how their mathematics classes helped them to develop better understandings of how to communicate and work with different members in their classroom through collaborative teamwork and using mathematics dialogue. Participants felt empowered to take their learning to a deeper level by reframing the way they were asking questions in class, persevering in working through more difficult problems, and advocate for support from their teacher and groupmates. I discuss my interpretation of the participants' interview responses in turn.

Theme one: Impact of classroom structure and environment on learning. The main points mentioned by the participants were that they wanted the classroom environment to be one in which all the students in the class were comfortable working with each other, and that there needed to be more use of visual aids to increase their understanding of the mathematics concepts (instead of depending on a traditional way of teaching). The participants wavered between wanting to be placed in groups where they knew all the group members, to wanting to get to know and work with their other classmates. The participants' main struggle was in assessing how productive and comfortable they felt in the class. Abe commented that a student would be more effective working with someone they knew well, but then also reflected that it was important to switch seating arrangements so that the students could get to know each other better. 
This is a real struggle for students - and teachers - and an important one to try to understand. Students want to stay seated with students with whom they know and feel comfortable. Students are more willing to be vulnerable with classmates with whom they have built trust. It takes courage to share ideas and thinking, and admit confusion and frustration. However, by not moving into different seating arrangements or participating in collaborative activities to experience shared learning experiences with more of their peers, it is less likely to push against the dominant culture's social structures that hamper student academic growth (Martin, 2011; Valero, 2004). As to classroom power, Martin (2011) said, "Knowing what the culture of power actually is, how it works, and how power can be achieved are important competencies for students' success in the classroom, and again, teachers should help students in their development and knowledge of that culture" (p. 68). Balancing the power in the classroom can be an extremely vulnerable act for a teacher, as they are releasing their structural hold and entrusting the students to negotiate the power balance to create a functioning classroom.

The participants pointed out that the more they were comfortable working and talking with all their classmates, the more they were willing to participate in whole classroom discussions. One way to gain comfort with working with all classmates was through the teacher regularly changing the seating arrangement. When that did not happen regularly, Jamie and Abe took it upon themselves to move around the room to work with other classmates. Both students exhibited elements of self-empowerment as they sought out a way to support their learning by building their connectedness (Wedekind, 2011) with their mathematics community. Leticia, however, was more hesitant to move to work with other classmates. She expressed that she would gain 
valuable learning experiences from working with students that she did not know as well, but depended on the teacher to move her into a group that was away from the people around whom she felt most comfortable. It was possible that Leticia felt uncomfortable moving from her assigned seat to talk with other members of her class because of the implicit power structures within a classroom (Milner, 2011). I did not specifically ask Leticia if these power structures were inhibiting her from moving around the classroom, so I could not resolutely say for sure.

In the end, Jamie, Abe, and Leticia concluded that they would benefit as mathematics learners if they were able to work with different groupings of students throughout the school year. All three students reflected on the impactful nature of working in table groups. They recounted how working cooperatively with their tablemates, especially on the more difficult problems, increased their understanding of the mathematics concepts and their overall confidence as mathematics thinkers. They did not feel isolated or alone, and saw their tablemates as a helpful resource. These students benefitted from working with different groups of students, as it fostered deeper confidence in the students.

Additionally, it was important to recognize that the participants mentioned how they appreciated being able to work individually from time to time. They benefitted from thinking through the mathematics on their own, and reflecting on their process for solving. This individual think-time allowed students to dig into the concepts and work at their own paces, without feeling any pressure to share their thoughts about a concept without having first taken the time needed to do their own thinking. Creating a space for 
students to have individual work time is just as important as incorporating time for groups to work together.

The second consideration participants mentioned involved making mathematics more visual, especially in the upper division courses. Leticia, Abe, and Jamie explained that their interest in learning a mathematics concept was elevated when they were able to visualize the how and the why behind the mathematics that they were learning. Their ability to visualize mathematics directly connected to understanding its relevance, and fostered a deeper understanding and clarity. For example, when teachers used or asked students to use mathematics manipulatives (e.g., pattern blocks, negative/positive tiles, algebra tiles), drawings, demonstrations, or projects, participants could see the mathematics principles, which enhanced their understanding of the concept. Abe, Leticia, and Jamie clarified that the more they were able to picture mentally and envision the mathematics concepts that they were learning, the deeper they were able to understand topic.

Boaler, Chen, Williams, and Cordero (2016) researched the positive impact of visualizing mathematics. Recent scientific discoveries surrounding the ways in which our brains understand mathematics through visual representation support their work. The science indicated, "When we work on mathematics, in particular, the brain activity is spread out across a widely-distributed network, which include two visual pathways: the ventral and dorsal visual pathways" (Boaler, Chen, Williams, \& Cordero, 2016, p. 1). Boaler et al. (2016) suggested, "The problem of mathematics in schools is it has been presented, for decades, as a subject of numbers and symbols, ignoring the potential of visual in mathematics for transforming students' mathematical experiences and 
developing important brain pathways" (p. 4). The evidence shown by neuroscience researchers at Stanford University suggested our brains desires to think about mathematics through visual aids, and that, "Building students' mathematical understanding doesn't just mean strengthening one area of the brain that is involved with abstract numbers, it means strengthening the connections between areas of the brain and strengthening the visual pathways" (youcubed, 2019). Visual aids empower students, and teachers alike, to see and experience mathematics in new ways, promote multiple methods for problem solving, and "inspire students and teachers, to see mathematics differently, to see the creativity and beauty in mathematics and to understand mathematical ideas" (Boaler et al., 2016, p. 4). Students can build their mathematics understanding and engagement in their learning through the use of visual aids. Promoting the use of visual aids in math class by teachers and students alike can further strengthen a student's mathematics identity, self-empowerment, and academic agency.

Theme two: Student collaboration through mathematics discourse. Jamie, Leticia, and Abe uniformly described how the collaborative teaching model supported their understanding of mathematics, and strengthened their ability to use academic language. Collaborative learning allowed participants to discuss the mathematics concept, elaborate on areas of confusion, recognize different methods for solving a problem, reflect on their own thinking process, and offer support to their classmates. Collaboration provided the opportunity to learn in a different way, and allowed participants to critically think, analyze, ask questions, listen, and reflect with their peers. Students were able show how they made sense of and persevered in solving a mathematics problem, and critically analyzed processes and solutions. These specific 
practices are also a part of the Common Core State Standards Initiative (2020): Standards for Mathematical Practices.

Additionally, collaboration offers students the opportunity to voice their thinking and own their learning. As previously stated in this study, student voice "provides insights for teachers but also creates the type of environment that encourages students to be active participants in the kind of education they receive, deserve, and aspire to experience" (Milner, 2015, p. 70). Students capture more out of their learning experiences when they are actively involved in creating the learning. Students grow and become empowered learners as they take more responsibility for their learning (Gutiérrez, 2013).

Jamie realized that the process of thinking, speaking, and reflecting improved her overall understanding of mathematics concepts. Jamie's awareness relates to Vygotsky's (1978) zone of proximal development. Jamie began to realize what she can understand as she transformed how she thought about and reflected on her mathematics practices. Interestingly, she remarked that collaboration helped her classmates because everyone's voice could be heard - their ideas and struggles alike—-but that at times, classmates asked for her explanation of the concept because she had already worked through the problem. There could be collaboration in solving in this particular case, but true collaboration occurs when classmates work together by bringing their own thinking to the discussion (Panitz, 1999). A common misconception, by teachers and students alike, is that collaborative learning and cooperative learning are one in the same. What Jamie is describing is cooperative learning, where she is explaining to a peer one way of understanding how to reach the solution to a problem. Both collaborative and 
cooperative learning strategies are useful and important techniques for supporting the use of academic language and mathematics dialogue, but do serve different end purposes. However, Jamie's point was that she was able to work with her classmate, and through their conversation, she strengthened her understanding of the concept through describing her process for solving, while simultaneously helped her peer to resolve their area of confusion.

Abe also responded positively about being able to work together with his classmates, emphasizing that working as a group allowed everyone to have a voice, and forced him to be an active participant in the math conversations. Talking through the math processes with his groupmates supported him because he felt like his ideas were being heard, and he was able to learn from the different ways his peers approached a math problem. Collaboration with his group made way for deeper conversations about the math concept, and built his confidence in solving, especially with the harder questions. However, as Abe mentioned earlier, this level of conversation can only really happen when students feel comfortable sharing their ideas with their group. Relating back to critical race theory and culturally responsive teaching, Gay (2010) emphasized the importance of "creating caring learning communities where culturally different individuals and heritages are valued" (p. 31), and "mediating power imbalances in classrooms based on race, culture, ethnicity, and class" (p. 31). Sharing ones' ideas is a deeply vulnerable act, and requires trust and relationship with peers. Abe felt at times like his peers were more competitive than collaborative, which resulted in Abe feeling intimidated more than supported. It is clear-from Abe's perspective- that working in collaborative table groups is a supportive and confidence building learning strategy, but 
that building up trust in peer relationships needs to come first. From my personal experience, aiding students in building these core relationships has helped with comfort for students in opening to share ideas, and is grounded in culturally responsive teaching (Gay, 2010). Sharing thinking is an incredibly vulnerable act; it shows how and what a person is thinking, including errors in thought. I know and understand the importance of sharing thinking with others, even (and especially) errors in thought and points of confusion, which makes it doubly important for teachers to guide students in building a caring and trusting learning environment that helps to establish relationships with their peers.

Abe also related the experience of working in his group in math class to working with his family and friends outside of class when problems arose. This connection ties directly to the funds of knowledge framework (González et al., 1995; González et al., 2001) addressed in Chapter 2. Abe saw that he used the same thinking skills to problem solve with his parents as he used to critically think through a math problem. Seeing how the skills transferred to his life outside of class also worked to build his confidence. This transference of critical thinking skills is the exact principle teachers desire their students to apply to their lives (Paris \& Alim, 2014). Aiding students to understand how to apply the thinking skills fostered in math class directly supports students as they make important life decisions.

Leticia agreed with all that Jamie and Abe contributed and added that collaboration reinforced her understanding of a concept because she was actively talking about the mathematics throughout the solving process. She responded that working with her peers allowed her to hear different ways of looking at a math problem, and expanded 
her understanding of a concept. Leticia related that she is naturally shyer than her peers, and working aloud with her peers has helped her to build stronger communication skills. Just like Abe, she was able to see how the skills she was learning in math class could relate to important life skills. She also added that working in different groups helped her to build confidence and feel more comfortable sharing her ideas as a part of a whole classroom discussion. Again, the more students recognize themselves and their classmates as a community of learners, the more likely it is for students to participate in whole classroom discussions.

Teachers of Jamie, Abe, and Leticia recognized them as strong mathematics thinkers. Since all three participants were strong mathematics thinkers to begin with, I wonder if group collaboration was more comfortable for them. All three suggested that collaboration was beneficial for their learning and added that it took time to feel comfortable with sharing their ideas and thoughts about math. But does their collectivist epistemology hold true for students who have less developed mathematics identities? Something for teachers to consider is how students with differing levels of developed mathematics identity might affect their experience with collaborative work. All three participants made one thing clear: a supportive classroom environment, built on trust and relationship, makes collaborative learning more inviting and less intimidating.

Theme three: Emphasizing mathematics literacy and relevancy. Abe, Leticia, and Jamie all saw themselves as strong mathematics learners, they believed that they belonged in upper division math classes, they could see how mathematics related to their lives outside the walls of the mathematics classroom, and they all desired for mathematics to be a part of their chosen careers. As the participants moved up through 
the different math levels, they noticed that there was less of a focus on making sense of what they were learning as it related to their lives. Because these students enjoyed learning math and wanted to continue in the higher courses, they did not give up once the relevancy for what they were learning became less intuitive. Abe, Leticia, and Jamie did feel that advanced classes needed to be tightly linked to relevant aspects of their lives. The participants struggled to connect the math concepts to relevant experiences in their lives in any recognizable ways. Leticia, Jamie, and Abe each repeatedly remarked that mathematics relevancy and literacy needed to be emphasized in every single math class. Relevancy and literacy are the aim of culturally sustaining pedagogy (Paris, 2012; Paris \& Alim, 2014).

The participants' advanced mathematics classes were not the only ones that reflect that type of disconnected-from-life teaching and learning. As a veteran mathematics teacher, I know I could have, and should have, spent more time helping my students to discover the connections between what was being learned and how they could see and use the information in their daily lives. Teachers can reposition the focus of mathematics classrooms to promote mathematics literacy and highlight the mathematical relevance of the concepts being taught, engaging "critically with young people about the impact of their words and the full range of their funds of knowledge and create third spaces that take on both the liberatory and the restrictive" (Paris \& Alim, 2014, p. 95). It takes time and conscious effort to intentionally add in time for students to go deeper into their learning. However, increasing the depth of learning also increases the relevance of the mathematics.

The participants pressed on the idea that more students would be interested in 
continuing in mathematics if they could see how it applied to their lives. Jamie recounted through several different examples that her friends had low mathematics literacy (i.e. unable to make sense out of basic mathematics concepts) and did not see the purpose of using mathematics to guide their monetary choices. Jamie explained that these friends did not feel like they were strong math thinkers and did not feel like they belonged in higher-level math classes (or that they wanted to be there in the first place).

Both Leticia and Abe wondered if students with seemingly less-robust mathematics identities struggled with seeing how what they were learning in class directly related to how they think and live outside the classroom, and how they will use math in their lives post-high school. They emphasized that students tend to compartmentalize what they learn in mathematics class in such a way that the critical thinking and problem-solving skills do not permeate into their day-to-day living and decision making. Again, the call is for teachers to help students see how math is relevant and needed in their lives.

Finally, Abe concluded some of his thoughts about why mathematics was important to him by remarking that knowing mathematics would give him a leg up in acquiring a job over someone who has less math sense. While his comment went directly against his thoughts about the nature and importance of collaboration in work, he was not incorrect. Abe specifically desires to work in the business industry, which while has some elements of collaboration, is also very competitive. I believed this was a perfect example of the importance of culturally sustaining pedagogy (Paris, 2012; Paris \& Alim, 2014). Paris and Alim (2014) posed the question, "What if, indeed, the goal of teaching and learning with youth of color was not ultimately to see how closely students could 
perform White middle-class norms but to explore, honor, extend, and, at times, problematize their heritage and community practices" (p. 86)? As teachers, we are called to teach our students in ways that invite students into the learning, that train them to be critical thinkers, that hold them to high expectations, and make the learning culturally relevant and responsive. In addition, we are called to make sure our students are equipped to be successful living among the dominant culture. So yes, it absolutely is a competitive world, but how we are preparing our students to be prepared for life outside the classroom does not need to reflect that competitive nature. It would be a disservice to my students if they graduate unprepared for the world that awaits them post-high school.

\section{Situated in a Larger Context}

In the 2018-2019 school year, Infinity School District had an enrollment of approximately 5600 students k-12, where $83 \%$ of these students identify as Latinx (Oregon Department of Education, 2020). The research and findings presented in this study have direct impacts for all teachers and learners within Infinity School District. It is imperative to take a system-wide approach to (a) learn about and use students' funds of knowledge to enrich learning, (b) employ an asset-based frame of mind to guide teaching, and (c) enact a culturally sustaining pedagogy, which is needed not only to strengthen students' awareness of and ability to thrive in the White dominant culture, but also "to ensure access and opportunity" (Paris \& Alim, 2014, p. 89) for all of our students.

In Chapter 1, I began to frame a problem of practice that focused on learning from Latinx high school mathematics thinkers about the development of a person's mathematics identity, and what teaching strategies foster, support, and grow their identities as mathematics learners. Through a series of nine interviews, three high school 
student participants painted a picture of their mathematics journey. Leticia, Abe, and Jamie, while interviewed separately, all carried the same message. Their message, represented by the themes introduced in Chapter 4, ties directly to the theoretical frameworks addressed in Chapter 2.

The participants opened their hearts to share how mathematics had been every bit as much a part of their growing up lives as had sports and reading. Jamie, Abe, and Leticia all had shared experiences of how their families/guardians supported them in learning mathematics through playing games, cooking, going shopping, and talking about their days together, and by being lovingly challenged to become critical thinkers. Their families/guardians had established the expectation that dropping out of school was not an option, and held them to that high standard. Leticia, Jamie, and Abe walked into the school building with their own rich and complex funds of knowledge (González et al., 1995; González et al., 2001; Smith-Maddox \& Solórzano, 2002) from which they could draw to make connections between their lived experiences and their classroom learning. Clearly, teachers need to access their students' funds of knowledge to make connections between students' lived experiences in their homes and what they learn in the classroom.

As mentioned in Chapter 2, the more teachers understand about the cultural background of their students, the lived experiences of their students, and practice a culturally sustaining pedagogy, the better teachers will be equipped to combat having a deficit mindset. The participants each reflected to me that they never felt implicit or explicit bias by their teachers. I realize that it is possible that the students may have at some time felt either implicit or explicit bias from their teachers, and did not feel comfortable sharing with me. However, the participants' candid, thoughtful, and honest 
remarks throughout the interviews about their teachers does speak to how much the teachers in the Infinity School District do to get to know the surrounding community and their students. However, it again is important to note that each of these participants were seen by their math teachers as having a strong mathematics identity, and as people who were able to make a noteworthy series of connections between what they learned in class and where they saw math in the community. I wonder if the same would be true for those students who are viewed by their teacher as having a seemingly less-robust mathematics identity.

The participants clearly believed that more needed to be done to support students who struggle with identifying strongly as a mathematics thinker. Leticia, Abe, and Jamie emphasized the necessity of placing a focus on relevancy in mathematics. The relevancy of math should not be a secret held by the teacher. All learners should know the relevance of mathematics, because it is relevant to all learners. As Abe pointed out, those who have strong math literacy and can think critically tend to be more successful in the world, and I believe he is correct. As stated in Chapter 1, taking advanced mathematics courses is not necessarily indicative of success in higher education, but "the role of higher-level mathematics is increasingly significant in paving the way to post-secondary and workplace success" (McCormick \& Lucas, 2011, p. 9). When teachers employ a culturally sustaining pedagogy in their classrooms, teachers can support students better in bridging what is learned in school to their lived experiences with mathematics in the world (Gutstein, 2009; Paris, 2012; Paris \& Alim, 2014). It is known that mathematics knowledge and literacy contribute to college readiness, an increase in college graduation rates, and can provide opportunities higher paying jobs (McCormick \& Lucas, 2011). As 
explained by McCormick and Lucas (2011), “The understanding of mathematics bridges all subject areas, as well as the globalizations of today's society, and provides measures to effectively interpret, critically analyze, and evaluate data in both numeric and visual presentations" (p.10). It is a grave disservice to graduate students from high school illiterate in mathematics. Teaching through a culturally sustaining lens can equip students with relevant knowledge, power, and resources to successfully navigate in the dominant culture while preserving their heritage.

As a high school mathematics teacher of 12 years, and additionally as evidenced by this interview study, I know that teaching with a culturally sustaining pedagogy, it is possible to foster, support, and nurture strong, literate mathematics thinkers. Abe, Leticia, and Jamie cultivated their mathematics identities and critical consciousness (Ladson-Billings, 2017; Paris \& Alim, 2014) by questioning, analyzing, reflecting, and applying their leaning. They took ownership of their education, and transferred their learning inside the classroom to their lives lived off campus. Their actions show beyond a doubt that their narrative does not mimic the historical mathematics hierarchy (Martin, 2009) society desires to believe. Latinx students can, do, and will continue disrupt this punitive and archaic narrative by constructing counter-narratives that demonstrate resilience, empowerment, and agency.

\section{Implications}

I believe the initiatives implemented by Infinity School District are in an effort to improve mathematics pedagogy such that more students identify as having strong mathematics identities, take advanced classes, and graduate with a solid grasp of mathematics. However, there is room for growth in this district, and I discuss several 
implications resulting from the research.

Building an academic community of learners. How students view themselves in a classroom of learners matters; their academic mindset matters. Abe, Jamie, and Leticia contributed responses that elicited a charge for teachers to help build a community of academic belonging. The participants suggested moving students into different groups often, starting at the very beginning of the school year, so that the students could begin to build trust and relationship with each other. Sharing ones' ideas, processes, points of confusion, and understanding is very sensitive. Students become vulnerable when sharing their thoughts about mathematics. Building this community of learning, fostering a sense of belonging within this community among their peers, is absolutely essential. Students are comfortable sharing their thoughts and questions with their teachers one-on-one because, usually, the teacher spends time and energy getting to know the students in the class. The same time and energy needs to be given to the students to get to know each other. Only then will students be more likely to open up about their learning in small groups, and ultimately with the whole class. Jamie, Abe, and Leticia all remarked that they felt more comfortable, or would feel more comfortable, sharing in a whole group discussion once they built relationships with the larger class. Building this community of learners can help to foster a sense of belonging in the academic community.

Cooperative versus collaborative learning. Both cooperative and collaborative learning are critical elements of driving students to be the leader of their learning. Yet, it is important to note the differences in teaching techniques. Cooperative learning is a process where students work together to jointly come to one end product or conclusion. 
Collaborative learning is a process where students work together to bring their own ideas, evaluate their ideas, and form new ideas based off of the conversation and engagement with peers. I think that many times "collaborative" and "cooperative" are understood to be synonymous terms. I believe this because while participants were able describe some specific collaborative exercises, a few times during the interviews, what they were actually describing were cooperative exercises. Mathematics discourse was still very much a part of their experience, and the participants were academically strengthened through the process. However, I would advocate for further professional development in the district for teachers to better understand the nuanced differences between collaborative and cooperative learning. It is clear from the interviews that the participants felt deeply that collaborative learning enhanced their knowledge of the mathematics concepts, and they ways in which they were able to use academic language to describe the processes they used, and the justification for their results. This is an important implication because collaborative work pushes students to evaluate their own thinking apart from their peers, and leads more fluidly into patterns of inquiry and investigation, which heightens students' critical thinking skills.

Increase mathematics literacy and relevance. Abe, Leticia, and Jamie reflected on several of their peers chose not to advance in mathematics past the required amount of credits, and they noted how some of their peers had drastically less confident mathematics identities, less mathematics literacy, and fewer critical thinking skills. One of the root causes for this, they conjectured, was because some students have a harder time visualizing, and finding purpose and relevance of mathematics, and feel less confident in using mathematics. The participants remarked less time was spent in class 
for students to understand a concept deeply and meaningfully, and there were less projects, models, and visual aids to help students make meaning from the math in the higher-level classes. One major implication of their assertion is that more of an emphasis needs to be placed on meaning-making, building confidence, and critical thinking skills. All three participants remarked that their engagement levels increased, as they were able to visually understand how the mathematics concept was applicable to the world, and to their lives. Projects allowed participants to dig deeper and explore topics, and created time and space for more in-depth conversations with their peers. Finding ways to make mathematics more relevant and engaging to students, while maintaining high expectations for outcomes and the level of rigor, might increase students' confidence, interest, and literacy in mathematics.

\section{Future Considerations and Recommendations for Additional Research}

I believe much more can be learned about Latinx students' mathematics identities, and I believe that interview studies may be an important means to this end. This research study only began to scratch the surface of understanding how to more fully support the development of students' mathematics identities. It is imperative that more students have the opportunity to share their lived experiences as mathematics learners, and are granted the opportunity to work with a researcher in analyzing and interpreting their data. Therefore, I offer the following future consideration and recommendation for further research.

Interview students with seemingly less-robust mathematics identities. One future consideration is to interview students who self-identify with seemingly less-robust mathematics identities. There is an urgent need to interview students who do not see 
themselves as having a strong mathematics identity, as there is much to be learned from students with seemingly less-robust mathematics identities about additional teaching and learning strategies and supports that have not yet been discussed. Students with a seemingly less-robust mathematics identity may have a unique perspective regarding the development of their mathematics identity, and there is a clear need to study the contributing factors to a seemingly less-robust mathematics identity in Latinx students. The concern of the participants was viscerally felt for their friends with what the participants perceived to be less-robust mathematics identities. Teachers, kindergarten through high school, need to know how to foster and sustain strong mathematics identities in their students so as to grow their self-empowerment, and cultivate academic agency.

Youth participatory action research. One recommendation stems from my belief that student voice should be included in every part of research. Learning from the participants through the interview series was not only insightful for me as a teacherresearcher, but also inspired the youth to look deeper into their understanding of their own learning strategies, patterns, processes, and needs. However, my participants were not involved in the coding, data analysis, or interpretation. Involving the participants in this part of the research could have brought further insights, and while the research as currently presented attempts to reflect their voices and experiences as accurately as possible, their inclusion in the latter phases would have had the potential to further ensure this was the case. Youth participatory action research (YPAR) encourages youth to become more actively engaged in their academics as students and as researchers. In essence, "YPAR is a formal resistance that leads to transformation—systematic and 
institutional change to promote social justice" (Cammarota \& Fine, 2008, p. 2).

Importantly, youth who have been traditionally marginalized, learn that "conditions of injustice are produced, not natural; are designed to privilege and oppress; but are ultimately challengeable and thus changeable" (Cammarota \& Fine, 2008, p. 2). Students are encouraged to understand how they can foster change in a system, giving value to their identity. The research is a collective process, where the students and adult(s) involved are actively researching the same questions together, "engaging in ongoing conversation and reflection with other, across generations, similarly poised to inquire and act" (Cammarota \& Fine, 2008, p. 5). This type of transformative research has an end goal of creating actionable changes in the lives of the participants (Creswell, 2014).

YPAR invites youth to investigate their lived experiences, revealing, "how life experiences are malleable and subject to change, and the students possess the agency to produce changes" (Cammarota \& Fine, 2008, p. 6). Students are encouraged to use their voices as powerful instruments in seeking social, societal, and systemic change. The study described in this paper, while humble in scope and bounded by the limitations noted above, represents an attempt to offer a platform for exactly this amplification of student voice and experience, with the goal of sparking meaningful, authentic, youthdriven change within the world of high school mathematics education.

\section{Conclusion}

I began this doctoral journey in search of answers. I wanted to know more about systemic inequalities in the public education system, and how they directly impacted my students who are a part of a racial group who has been historically marginalized. I wanted to understand my role as their mathematics teacher better. I wanted to challenge 
myself to become vulnerable in learning how to critically analyze and reflect on my teaching pedagogy. What I learned as a result of my research study blew me away.

As I was learning about different research methodologies, I could not help but be pulled toward interview studies. My research questions focused on further understanding the development of students' mathematics identities, and the teaching strategies that best fit the needs of students. Students themselves hold the answers to these questions. Interviewing Jamie, Leticia, and Abe not only allowed me to learn from them about the development of their mathematics identities, but it allowed an opportunity for these students to be candid and open about their successes and challenges as learners, and what they hoped for themselves in the future. Their voices affirmed the importance of incorporating collaborative activities in the classroom, highlighted the need for creating a caring community of learners and including more mathematically linked confidencebuilding exercises, and encouraged teachers to help students to see the relevancy of mathematics thinking.

The thoughts and reflections of Leticia, Abe, and Jamie have forever changed my practice, and opened my eyes to see the need for more students to voice their lived experiences. Students are the change agents that will transform education. Let their voices rise. 
MATHEMATICS IDENTITY

References

Advancement Via Individual Determination. (2018). Do your students control their educational destiny? Retrieved from https://www.avid.org/student-learning.

Allen, M. (2017). Research reports, subjective. Retrieved from http://methods.sagepub.com/reference/the-sage-encyclopedia-of-communicationresearch-methods/i12327.xml.

Ayers, W. (2004). Teaching the personal and the political: Essays on hope and justice. New York: Teachers College Press.

Bevan, M. T. (2014). A method of phenomenological interviewing. Qualitative Health Research, 24(1), 136-144.

Black Panther Party Platform and Program. (1966). The Black Panthers: Ten point program. Retrieved from http:/www.blacklivesmattersyllabus.com/wpcontent/uploads/2016/07/BPP_Ten_Point_Program.pdf.

Blessett, B., Sherèe, T., Gaynor, M.W., \& Alkadry, M. G. (2016). Counter-narratives as critical perspectives in public administration curricula. Administrative Theory $\&$ Praxis, 38(4), 267-284, doi:10.1080/10841806.2016.1239397

Boaler, J. (2016). Mathematical mindsets: Unleashing students' potential through creative math, inspiring messages and innovative teaching. San Francisco, CA: Jossey-Bass.

Boaler, J., Chen, L., Williams, C., \& Cordero, M. (2016). Seeing as understanding: The importance of visual mathematics for our brain and learning. Journal of Applied and Computational Mathematics, 5(5). doi:10.4172/2168-9679.1000325 
Boaler, J., \& Greeno, J. (2000). Identity, agency and knowing in mathematical worlds. In J. Boaler (Ed.), Multiple perspectives on mathematics teaching and learning (pp. 171-200). Westport, CT: Ablex.

Boaler, J., William, D., \& Zevenbergen, R. (2000). The construction of identity in secondary mathematics education. 3-12, Paper presented at the International Mathematics Education and Society Conference, Montechoro, Portugal.

Cammarota, J., \& Fine, M. (2008). Youth participatory action research: A pedagogy for transformational resistance. In J. Cammarota \& M. Fine (Eds.), Revolutionizing education (pp. 9-20). New York, NY: Routledge.

Common Core State Standards Initiative. (2020). Standards for mathematical practice. Retrieved from http://www.corestandards.org/Math/Practice/

Creswell, J. W. (2014). Research design: Qualitative, quantitative, and mixed methods approaches. Los Angeles, CA: SAGE.

Delgado, R., Stefancic, J., \& Harris, A. (2012). Critical race theory: An introduction (2nd ed.). New York, NY: New York University Press.

Delpit, L. (2012). "Multiplication is for White people" raising expectations for other people's children. New York, NY: New Press.

Dweck, C. (2008). Mindsets and math/science achievement. The Opportunity Equation. Retrieved from http://www.growthmindsetmaths.com/uploads/2/3/7/7/23776169/mindset_and_m ath_science_achievement_-_nov_2013.pdf 
Englander, M. (2012). The interview: Data collection in descriptive phenomenological human scientific research. Journal of Phenomenological Psychology, 43(1), 1335.

Farber, D., \& Sherry, S. (2016). Telling stories out of school: An essay on legal narratives. In E. Taylor, D. Gillborn, \& G. Ladson-Billings (Eds.), Foundations of critical race theory in education (2nd ed.) (pp. 310-333). New York, NY: Routledge.

Franke, M. L., Kazemi, E., \& Battey, D. (2007). Mathematics teaching and classroom practice. In F. K. Lester, Jr. (Ed.), Second handbook of research on mathematics teaching and learning (pp. 225-256). Charlotte, NC: Information Age Publishing.

Fowler, F. C. (2013). Policy studies for educational leaders: An introduction. Boston, MA: Allyn \& Bacon/Pearson.

Gay, G. (2000). Culturally responsive teaching: Theory, research, and practice. New York, NY: Teachers College Press.

Gay, G. (2002). Culturally responsive teaching in special education for ethnically diverse students: Setting the stage. International Journal of Qualitative Studies in Education, 15(6), 613-629.

Gay, G. (2009). Preparing culturally responsive mathematics teachers. In B. Greer, S. Mukhopadhyay, \& S. Nelson-Barber (Eds.), Culturally responsive mathematics education (pp.189-205). New York, NY: Routledge.

Gay, G. (2010). Culturally responsive teaching: Theory, research, and practice (2nd ed.). New York, NY: Teachers College Press. 
Giorgi, A. (2012). The descriptive phenomenological psychological method. Journal of Phenomenological Psychology, 43(1), 3-12.

Glesne, C. (2011). Becoming qualitative researchers: An introduction (4th ed.). Boston, MA: Pearson.

González, N., Andrade, R., Civil, M., \& Moll, L. (2001). Bridging funds of distributed knowledge: Creating zones of practices in mathematics. Journal of Education for Students Placed at Risk, 6(1-2), 115-132. doi:10.1207/S15327671ESPR0601-2_7

González, N., Moll, L., Tenery, M., Rivera, A., Rendon, P., Gonzales, R., \& Amanti, C. (1995). Funds of knowledge for teaching in Latino households. Urban Education, 29(4), 443-470. doi:10.1177/0042085995029004005

Gorski, P. (2013). Building a pedagogy of engagement for students in poverty. Phi Delta Kappan, 95(1), 48-52. doi:10.1177/003172171309500109

Guba, E., \& Lincoln, Y. (2005). Paradigmatic controversies, contradictions, and emerging confluences. In N. K. Denzin \& Y. S. Lincoln (Eds.), The SAGE handbook of qualitative research ( $3^{\text {rd }}$ ed.) ( $\left.\mathrm{pp} .191-215\right)$. Thousand Oaks, CA: SAGE.

Gutiérrez, R. (2008). A" gap-gazing" fetish in mathematics education? Problematizing research on the achievement gap. Journal for Research in Mathematics Education, 39(4), 357-364.

Gutiérrez, R. (2013). The sociopolitical turn in mathematics education. Journal for Research in Mathematics Education, 44(1), 37-68. 
Gutstein, E. (2009). The politics of mathematics education in the US: Dominant and counter agendas. In B. Greer, S. Mukhopadhyay, A. B. Powell, \& S. NelsonBarber (Eds.), Culturally responsive mathematics education (pp. 137-164). New York, NY: Routledge.

Howard, T. C. (2003). Culturally relevant pedagogy: Ingredients for critical teacher reflection. Theory Into Practice, 42(3), 195-202. doi:10.1353/tip.2003.0031

Hycner, R. H. (1985). Some guidelines for the phenomenological analysis of interview data. Human Studies, 8(3), 279-303.

Klopfenstein, K., \& Thomas, M. (2009). The link between advanced placement experience and early college success. Southern Economic Journal, 75(3), 873891.

Ladson-Billings, G. (1995). But that's just good teaching! The case for culturally relevant pedagogy. Theory Into Practice, 34(3), 159-165.

doi:10.1080/00405849509543675

Ladson-Billings, G. (2011). Yes, but how do we do it. In J. Landsman \& C.W. Lewis (Eds.), White teachers/diverse classrooms: Creating inclusive schools, building on students' diversity, and providing true educational equity (pp. 33-46). Sterling, VA: Stylus.

Ladson-Billings, G. (2016). Just what is critical race theory and what's it doing in a nice field like education? In E. Taylor, D. Gillborn, \& G. Ladson-Bilings (Eds.), Foundations of critical race theory in education (2nd ed.) (pp. 15-28). New York, NY: Routledge. 
Ladson-Billings, G. (2017). The (r)evolution will not be standardized: Teacher education, hip hop pedagogy, and culturally relevant pedagogy 2.0. In D. Paris \& H. Alim (Eds.), Culturally sustaining pedagogies (pp. 141-146). New York, NY: Teachers College Press.

Litowitz, D. (2016). Some critical thoughts on critical race theory. E. Taylor, D. Gillborn, \& G. Ladson-Billings (Eds.), Foundations of critical race theory in education (2nd ed.) (pp. 293-309). New York, NY: Routledge.

Martin, D. (2009). Researching race in mathematics education. Teachers College Record, 111(2), 295-338.

Martin, D. (2013). Race, racial projects, and mathematics education. Journal for Research in Mathematics Education, 44(1), 316-333.

Martinez, A. (2017). Pew: Despite flat growth rate, Hispanics account for more than half of the US population growth. Retrieved from http://latinousa.org/2017/08/14/pewdespite-slow-growth-rate-hispanics-account-half-us-population-growth/

McCormick, N. \& Lucas, M. (2011). Exploring mathematics college readiness in the United States. Current Issues in Education, 14(1). Retrieved from http://cie.asu.edu/ojs/index.php/cieatasu/article/view/680

Merriam, S., \& Tisdell, E. (2016). Qualitative research: A guide to design and implementation (4th ed.). San Francisco, CA: John Wiley \& Sons.

Milner, H. R. (2011). But good intentions are not enough: Doing what's necessary to teach for diversity. In J. Landsman \& C. W. Lewis (Eds.), White teachers/diverse classrooms: Creating inclusive schools, building on students' diversity, and providing true educational equity (pp. 56-74). Sterling, VA: Stylus. 
Milner, H. R. (2015). Rac(e)ing to class: Confronting poverty and race in schools and classrooms. Cambridge, M: Harvard Education Press.

NCH Software, Inc. (2019). Express Scribe [Software]. Available from https://www.nch.com.au/scribe/index.html

Nord, C., Roey, S., Perkins, R., Lyons, M., Lemanski, N., Brown, J., \& Schuknecht, J. (2011). The nation's report card: America's high school graduates (NCES 2011462). U.S. Department of Education, National Center for Education Statistics. Washington, DC: U.S. Government Printing Office.

O'Brien, V., Martinez-Pons, M., \& Kopala, M. (1999). Mathematics self-efficacy, ethnic identity, gender, and career interests related to mathematics and science. The Journal of Educational Research, 92(4), 231-235. doi:10.1080/00220679909597600

Oregon Department of Education. (2010). The instructional core. Retrieved from https://www.ode.state.or.us/wma/teachlearn/commoncore/5.-instructional--corediagram.pdf

Oregon Department of Education. (2020). At-a-glance school and district profiles. Retrieved from https://www.ode.state.or.us/data/reportcard/reports.aspx Oughton, H. (2010). Funds of knowledge - a conceptual critique. Studies in the Education of Adults, 42(1), 63-78. doi:10.1080/02660830.2010.11661589

Panitz, T. (1999). Collaborative versus cooperative learning: A comparison of the two concepts which will help us understand the underlying nature of interactive learning. Retrieved from https://files.eric.ed.gov/fulltext/ED448443.pdf 
Paris, D. (2012). Culturally sustaining pedagogy: A needed change in stance, terminology, and practice. Educational Researcher, 41(3), 93-97. doi:10.3102/0013189X12441244

Paris, D., \& Alim, H. S. (2014). What are we seeking to sustain through culturally sustaining pedagogy? A loving critique forward. Harvard Educational Review, 84(1), 85-100.

Parker, L., \& Lynn, M. (2016). What's race got to do with it? In E. Taylor, D. Gillborn, \& G. Ladson-Billings (Eds.), Foundations of critical race theory in education (2nd ed.) (pp. 143-153). New York, NY: Routledge.

Passel, J., \& Taylor, P. (2009). Who’s Hispanic? Retrieved from http://pewhispanic.org/reports/report.php?ReportID=111

Pizarro, M. (1998). “Chicana/o power!” Epistomology and methodology for social justice and empowerment in Chicana/o communities. International Journal of Qualitative Studies in Education, 11(1), 57-80. doi:10.1080/095183998236890

Portland Metro STEM Partnership. (2018). Common measures. Retrieved from https://www.pdxstem.org/projects-1/2018/7/12/common-measures

Rios-Aguilar, C., Kiyama, J., Gravitt, M. \& Moll, L. (2011). Funds of knowledge for the poor and forms of capital for the rich? A capital approach to examining funds of knowledge. Theory and Research in Education Journal, 9(2), 163-184.

Saldaña, J. (2013). The coding manual for qualitative researchers (2nd ed.). Thousand Oaks, CA: SAGE.

Seidman, I. (2013). Interviewing as qualitative research: A guide for researchers in the social sciences (4th ed.). New York, NY: Teachers College Press. 
Smith-Maddox, R., \& Solórzano, D. G. (2002). Using critical race theory, Paulo Freire's problem-posing method, and case study research to confront race and racism in education. Qualitative Inquiry, 8(1), 66-84. doi:10.1177/107780040200800105

SocioCultural Research Consultants, LLC. (2019). Dedoose Version 8.2.27 [Software]. Available from https://www.dedoose.com

Steele, C. (1997). A threat in the air: How stereotypes shape intellectual identity and performance. American Psychologist, 52(6), 613-629.

Swetz, F. J. (2009). Culture and the development of mathematics. In B., Greer, S. Mukhopadhyay, \& S. Nelson-Barber (Eds.), Culturally responsive mathematics education (pp. 11-41). New York, NY: Routledge.

Tate, W. F. (1995). Returning to the root: A culturally relevant approach to mathematics pedagogy. Theory Into Practice, 34(3), 166-173. doi:10.1080/00405849509543676

U.S. Census Bureau. (2018). 2017 national population projections tables, table 4: Projected race and Hispanic origin. Retrieved from https://www.census.gov/data/tables/2017/demo/popproj/2017-summarytables.html

U.S. Department of Education. (2014). 10 facts about K-12 education funding. Retrieved from https://www2.ed.gov/about/overview/fed/10facts/index.html

U.S. Department of Education. (2017). Characteristics of public elementary and secondary school teachers in the United States: Results from the 2015-16 
MATHEMATICS IDENTITY

national teacher and principal survey. Retrieved from

https://nces.ed.gov/pubs2017/2017072rev.pdf

Valero, P. (2004). Socio-political perspectives on mathematics education. In R. Jorgensen

(Ed.), Researching the socio-political dimensions of mathematics education: Issues of power in theory and methodology (pp. 5-23). Boston, MA: Springer.

Vogt, W. P., Gardner, D. C., \& Haeffele, L. M. (2012). When to use what research design. New York, NY: Guilford Press.

Vygotsky, L. (1978). Interaction between learning and development. Readings on the development of children, 23(3), 29-36.

Weaver, D., \& Dick, T. (2009). Oregon mathematics leadership institute project: Evaluation results on teacher content knowledge, implementation fidelity, and student achievement. Journal of Mathematics and Science: Collaborative Explorations, 11, 57-84.

Wedekind, K. (2011). Math exchanges: Guiding young mathematicians in small-group meetings. Portland, ME: Stenhouse.

youcubed. (2014). Visual mathematics. Retrieved from https://www.youcubed.org/resource/visual-mathematics/ 
Appendix A

\section{English Informed Consent Form}

Dear Students and Parents/Guardians,

Thank you for considering this request for your student to participate in a study focused on mathematics identity, self-empowerment, and internal motivation for academic success. I am a math teacher at the Academy of International Studies (AIS, one of the Woodburn high schools), as well as a doctoral student at Portland State University. As a way to learn more about student experiences in mathematics, I am conducting interviews with several students as a part of my research for my doctoral program, under the instruction of Dr. Anita Bright.

\section{What will I have to do?}

The interview study will take part in three sessions, directly after school. Each interview session will a maximum of 90 minutes long, scheduled at the convenience of the student. All three interviews will be completed within a three-week window of time.

\section{What are the risks?}

There are no major risks associated with participation in this study. The questions that will be asked as a part of the interview will focus on mathematics experiences, and the degree of discomfort, or the level of risk for your child should not exceed that of regular day-to-day conversation. You child's name or other identifying information will not be included in the final written analysis, and all audio recordings of the interview sessions will be destroyed at the conclusion of this study. Participation in this study will not influence grades or academic standing in any way.

\section{What are the benefits?}

Our school district has spent time and money preparing teachers in specific ways to teach mathematics. As a teacher, I would like to learn from your child if the teaching methods we have been using in mathematics are supporting your child's personal academic goals, and what teachers of mathematics might to better to strengthen students' sense of self as learners of mathematics. Your child's voice is an important and valuable part of this research.

\section{What are the rights of the participant?}

Your consent for your child, and the consent of your child, to participate in this study are entirely voluntary, and you may withdraw your consent at any time during the course of the study with no penalty to your child. If you have any questions at any time, please contact me, Brea Cohen (503-980-6100, cohenb@pdx.edu), or my professor, Anita Bright (503 395 4372, abright@pdx.edu).

I have received approval of this project from our superintendent, Chuck Ransom, as well as individual school principals. If your child is younger than 18 years old, your 
permission must be granted for him/her to participate. I ask for your permission to conduct the three interviews with your child.

Your signature below indicates that you have read and understand the above information and agree to take part in this study.

Signature of student participant Date

Print name of student participant

Signature of parent or guardian Date

Print name of parent or guardian 
Appendix B

\author{
Spanish Informed Consent Form
}

Queridos Estudiantes y Padres/Guardián(es),

Muchísimas gracias por su consideración en la participación de estudiantes en una investigación parte de mis estudios graduados bajo la tutela de la Dr. Anita Bright. La investigación se enfoca en la identidad matemática, autoempoderamiendo y motivación interna del rendimiento académico del estudiante. Soy maestra de matemáticas en una escuela pública localizada en Woodburn, OR, llamada Academy of International Studies (AIS por sus siglas en inglés). Adicionalmente, soy una estudiante en el programa doctoral del departamento del Currículo e Instrucción en Portland State University. Mi interés en esta investigación es aprender en más detalle cuales son las experiencias de los estudiantes mientras aprenden matemáticas. Durante la investigación estaré conduciendo entrevistas con varios estudiantes.

\title{
¿Durante las entrevistas que se puede esperar?
}

Este estudio consiste en tres entrevistas las cuales serán durante un periodo de tres semanas. Las entrevistas ocurrirán después del día escolar. Cada entrevista durará un máximo de 90 minutos, y serán previstas a conveniencia del estudiante.

\section{¿Hay algún riesgo en participar de las entrevistas?}

No hay ningún riesgo asociado en la participación de este estudio. Las preguntas parte de la entrevista se enfocarán en las experiencias de los estudiantes en las matemáticas. El grado de incomodidad o nivel de riesgo de su hijo(a) no excederá mas allá de una conversación que usualmente suele ocurrir diariamente en el salón de clases. El nombre de su hijo(a) o cualquier otro tipo de identificación no será incluido como parte del análisis escrito de este estudio. Adicionalmente cualquier grabación de audio obtenido durante las entrevistas serán destruidos al final de la investigación. La participación de este estudio no influirá de ninguna forma notas o rendimiento académico del estudiante.

\section{¿Cuales son los beneficios de participar?}

Nuestro distrito escolar asigna tiempo y dinero en la preparación de maestros en la enseñanza de las matemáticas. Como maestra me gustaría aprender más de como el material didáctico de las matemáticas están ayudando a su hijo(a) a obtener sus metas académicas, personales y profesionales. Adicionalmente, me gustaría aprender como los maestros de matemáticas pueden ayudar y fortalecer el sentido de identidad de los aprendices de las matemáticas. La voz de su hijo(a) será muy importante en esta investigación.

\section{¿Cuales son los derechos del participante?}

Su consentimiento y el consentimiento en la participación de su hijo(a) en este estudio es completamente voluntaria. En cualquier momento usted puede abandonar su consentimiento en la participación de este estudio. Abandonar el consentimiento de la 
participación de este estudio no afectará a su hijo(a) de ninguna forma. Si usted tiene alguna pregunta favor comunicase conmigo, Brea Cohen (503-980-6100, cohenb@pdx.edu) y también puede comunicarse con mi profesora, Anita Bright (503395-4372, abright@pdx.edu).

Este proyecto a sido aprobado por el superintendente Chuck Ransom y también por cada principal de escuela. Si su hijo(a) es menor de 18 años, la participación de su hijo(a) requerirá su consentimiento. Le pido cordialmente su consentimiento en conducir tres entrevistas con su hijo(a).

\section{Su firma abajo indica que ha leído y entiende la información comunicada en la parte de arriba. Adicionalmente su firma también indica que esta de acuerdo en la participación de este estudio.}

Firma del estudiante participante Fecha

Nombre en letras de imprenta del estudiante participante

Firma del padre o guardián Fecha

Nombre en letras de imprenta del padre o guardián 
Appendix C

Interview Protocol

The following interview protocol will be used as guidance in each of the three interviews. The protocol will be followed closely, but it is not a word for word script.

\section{Interview Session 1}

- Review the purpose for the study, expectations, and parameters of participation in the interviews. Participants will be given an opportunity to ask questions.

- The participant's mathematics autobiography will be comprised of the different elements of the student's mathematics history.

1) When you describe yourself as a mathematics learner, what kinds of words come to mind?

2) How have your teachers described you or seen you as a mathematics learner?

3) How have your peers described or seen you as a mathematics learner? Is there overlap?

4) How are you defining your current mathematics identity?

a. Tell me about a time as a younger child that helped support your mathematics learning, whether it was an experience inside or outside the classroom.

b. What roles did your family play in building your math identity? What types of activities would you participate in that grew you as a math learner?

c. Tell me about some other experiences that you had in the community that supported your mathematics identity? 
5) Finish this sentence, "When I think about mathematics, I feel..."

6) How have your feelings about mathematics changed as you have gotten older?

7) What do you like most about mathematics?

8) Describe a time when you strongly identified as a mathematics learner.

9) Your teacher said mathematics has been great for you. What are some things that make mathematics "great" for you?

10) Teachers can learn from students' interpretations of mathematics concepts. Can you tell me about a time that your teacher has learned from your interpretation of a mathematics topic, or from a connection that you made to a concept?

a. How did this experience support you as a mathematics learner?

11) Communities can be a healthy support system for building your mathematics learning. Do you feel connected to your community?

a. If yes....tell me about an experience with math that you have had in your community that you have liked? Why was this experience memorable?

b. If no... what changes would you suggest for your community that might make it more supportive of your mathematics learning?

12) Describe your most memorable experience in learning math inside the classroom. Why was this experience memorable?

13) In our district, we spend a lot of time on mathematics dialogue. I want to know if students see this as an important piece of their learning and ability to connect with mathematics. Is it doing what it is intended to be doing?

a. Describe a mathematics community that fostered your personal growth as a mathematician. What did it look like? What did it feel like? What was 
your part in that community? How did you respond to others in that community?

b. Describe how your best teacher taught/supported you in class?

c. How has your confidence as a mathematics learner developed over time?

\section{Interview Session 2}

1) Briefly review the purpose of the study and parameters of participation in the interviews. Participants will be given an opportunity to ask questions.

2) Detailed explanation of key concepts

3) Tell me more about what you meant when you said (excerpt from the previous interview).

4) What are some of the ways that your teacher/classmates have helped to shape your mathematics identity within the classroom community? Do these same characteristics carry over to your lived experiences outside of the classroom?

a. What kind of things do your teachers do to help you learn math?

b. How does talking about math help you as a mathematics learner?

i. How does mathematics dialogue (intentional conversations with classmates about the mathematics concepts being learned in class, metacognition, and individual reflection) affect Latinx students' mathematics identity and agency?

c. How do your experiences working with your peers support your mathematics identity? 
d. As you have progressed to higher math classes, what specific teaching practices have most supported your mathematics identity? What teaching practices are most helpful or effective for you in your math class?

5) How can teachers better support students in building positive mathematics identities, as well as student agency?

a. How can teachers better support students' development of their mathematics identities?

b. What are the reasons students may not have a positive mathematics identity?

\section{Interview Session 3}

1) Briefly review the purpose of the study and parameters of participation in the interviews. Participants will be given an opportunity to ask questions.

2) Tell me more about what you meant when you said (excerpt from the previous two interviews).

a. What type of things do you think are important to help students learn math?

b. What inspired you to take higher-level math classes?

c. How do you envision using mathematics in the future?

d. How do you think mathematics is important in order to better understand the world outside of school?

e. What are the (immediate and/or future) benefits of taking a higher-level math classes? 
Appendix D

Coding Scheme

\begin{tabular}{|c|c|c|}
\hline Code & Interview Response & Theme/Synthesis \\
\hline \multirow[t]{4}{*}{ Collaboration } & $\begin{array}{l}\text { "all of us have to participate } \\
\text { to get the answer. So that } \\
\text { allows us to all go up and } \\
\text { solve the problem" }\end{array}$ & \\
\hline & $\begin{array}{l}\text { "I also think peers should } \\
\text { help each other out like } \\
\text { having table groups so they } \\
\text { can solve problems together } \\
\text { or solve problems as a class } \\
\text { um having everybody } \\
\text { participate to increase your } \\
\text { confidence." }\end{array}$ & $\begin{array}{l}\text { Confidence building when } \\
\text { working with team } \\
\text { members }\end{array}$ \\
\hline & $\begin{array}{l}\text { “...like having expectations } \\
\text { again for like what should } \\
\text { be done and like like if you } \\
\text { don't have work done like } \\
\text { they're gonna see obviously } \\
\text { you didn't use your time to } \\
\text { do it but if you're not } \\
\text { expecting anything } \\
\text { afterwards if you're just like } \\
\text { oh we're gonna that's it like } \\
\text { you're there's no } \\
\text { like...accountability }\end{array}$ & $\begin{array}{l}\text { Accountability and } \\
\text { expectations for what } \\
\text { should result from the } \\
\text { collaboration work. }\end{array}$ \\
\hline & $\begin{array}{l}\text { “...something that you } \\
\text { don't understand maybe } \\
\text { another student can be like } \\
\text { oh this is how you do it and } \\
\text { you're then right there you } \\
\text { just learned something you } \\
\text { didn't know and you got to } \\
\text { work through it from there I } \\
\text { think it is like beneficial in } \\
\text { that way but again like if no } \\
\text { one maybe no one knows } \\
\text { how to do it I don't think } \\
\text { that's beneficial it depends I } \\
\text { guess [laughs] on what the } \\
\text { outcome is and what people }\end{array}$ & $\begin{array}{l}\text { Learn from peers } \\
\text { Expectations } \\
\text { Accountability }\end{array}$ \\
\hline
\end{tabular}




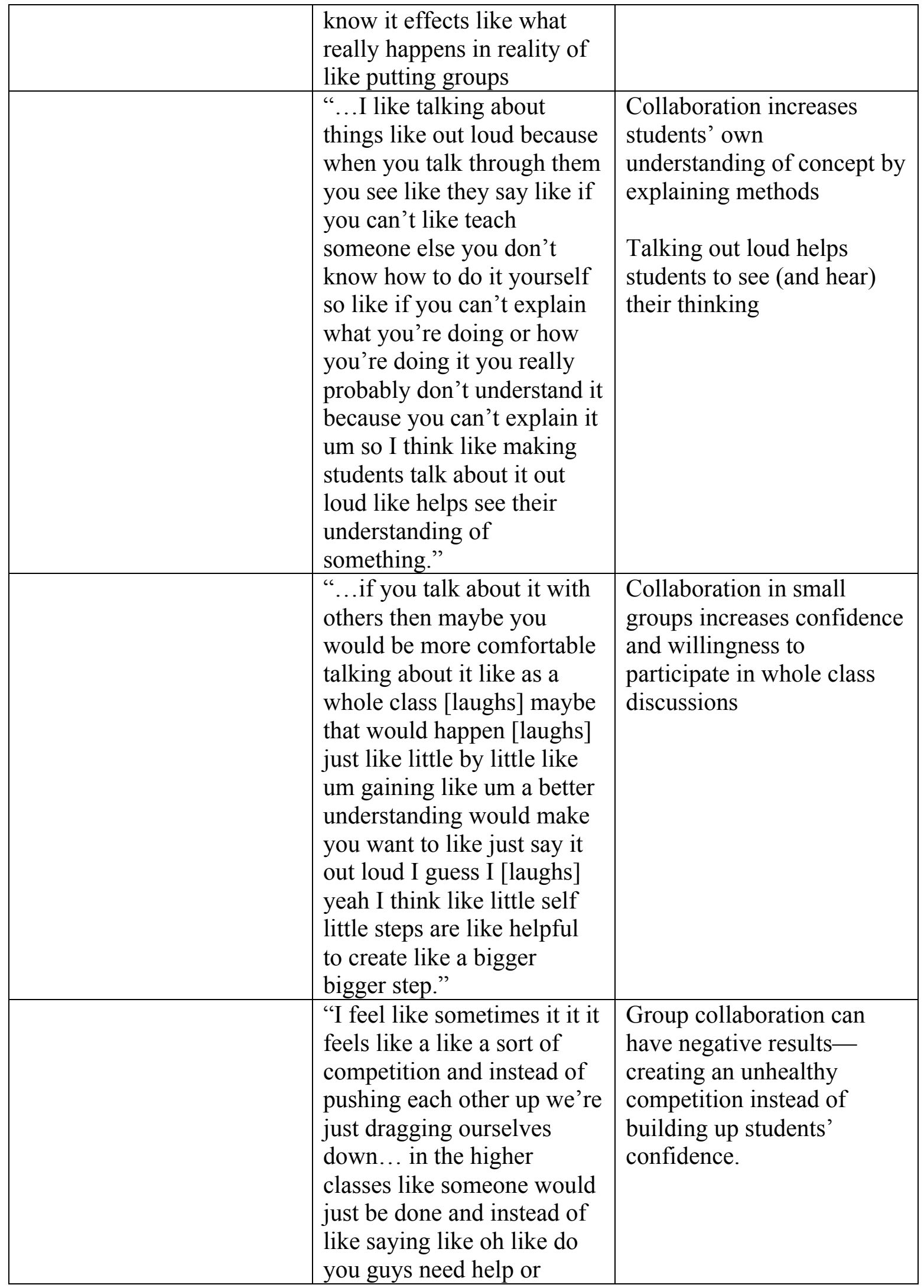




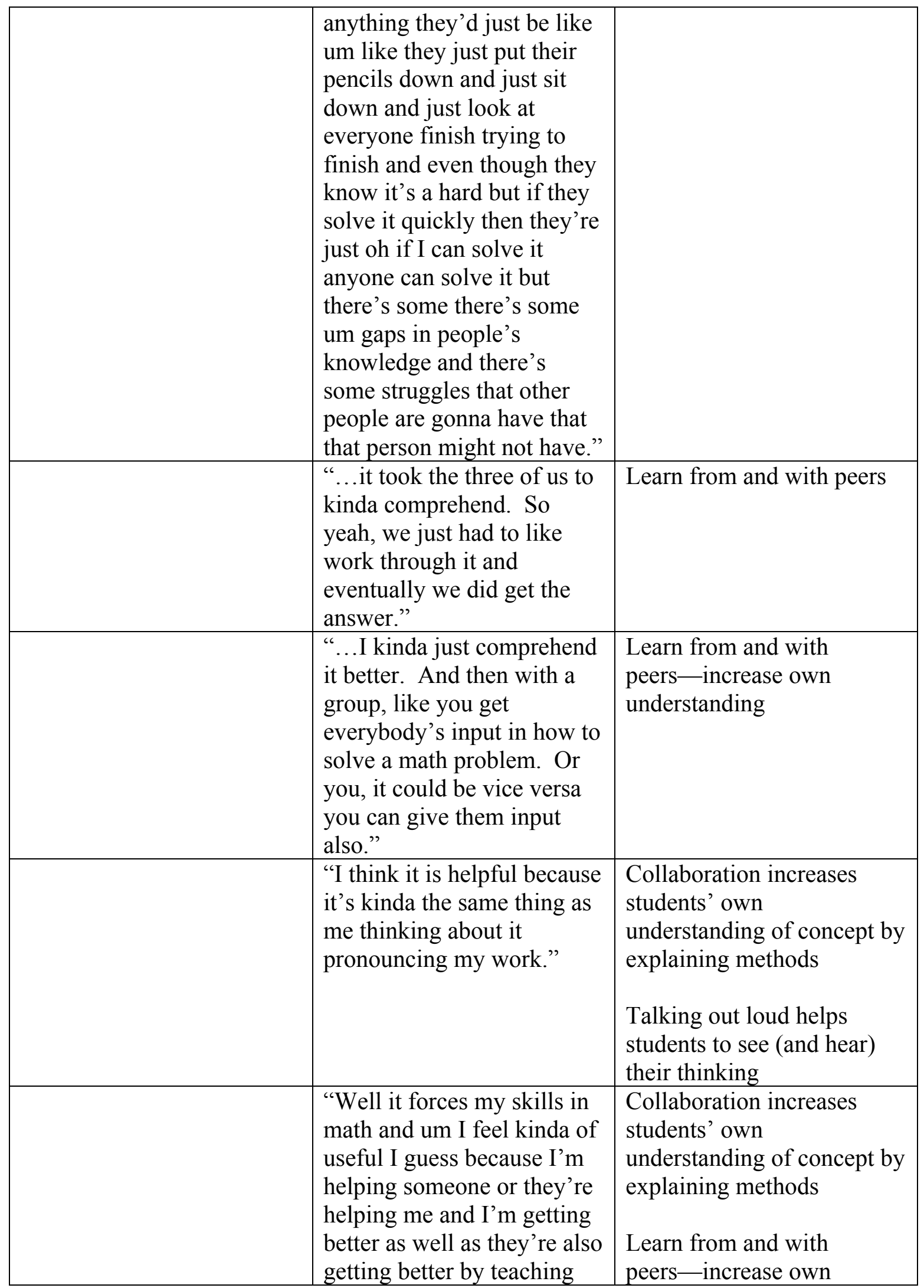




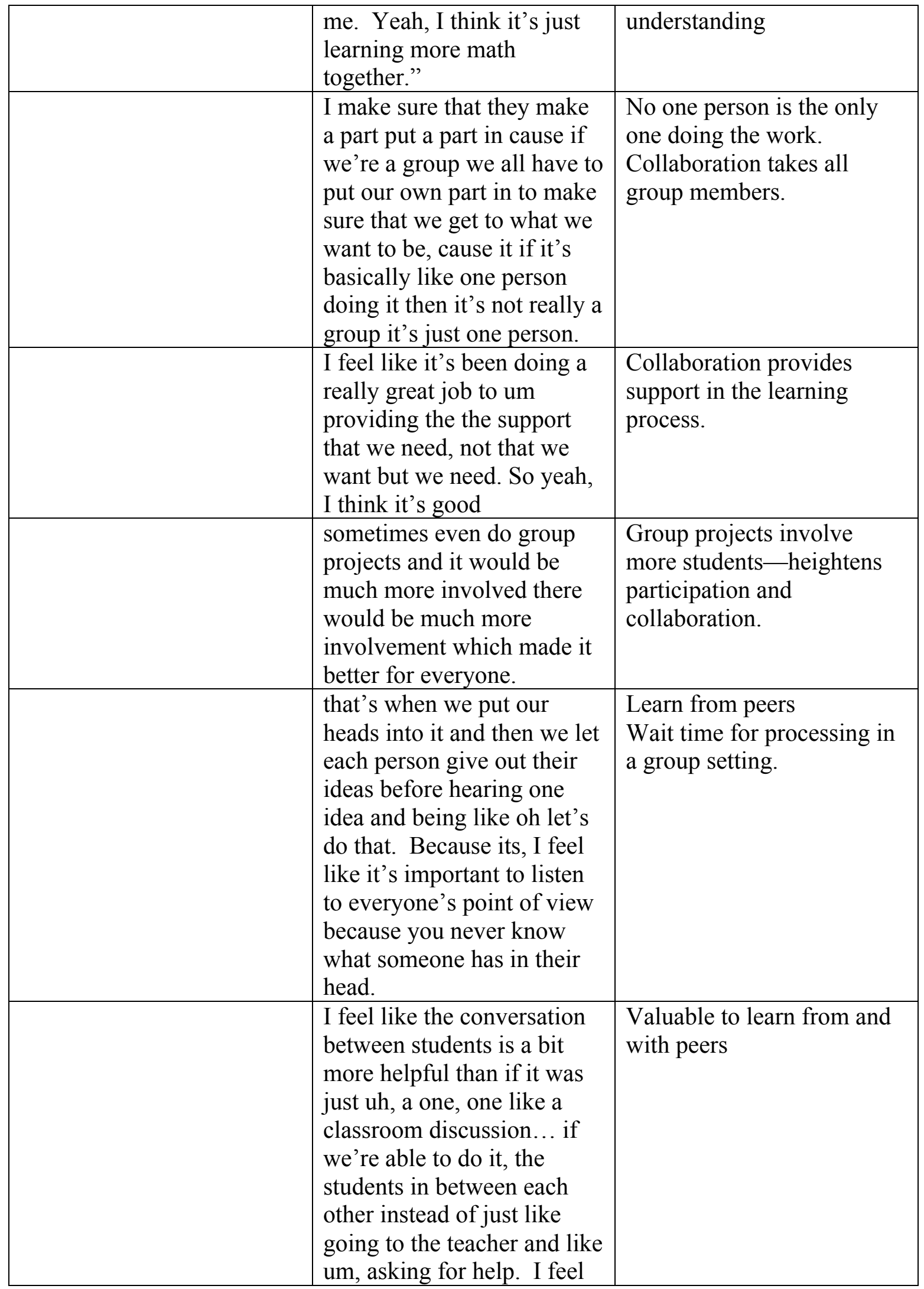




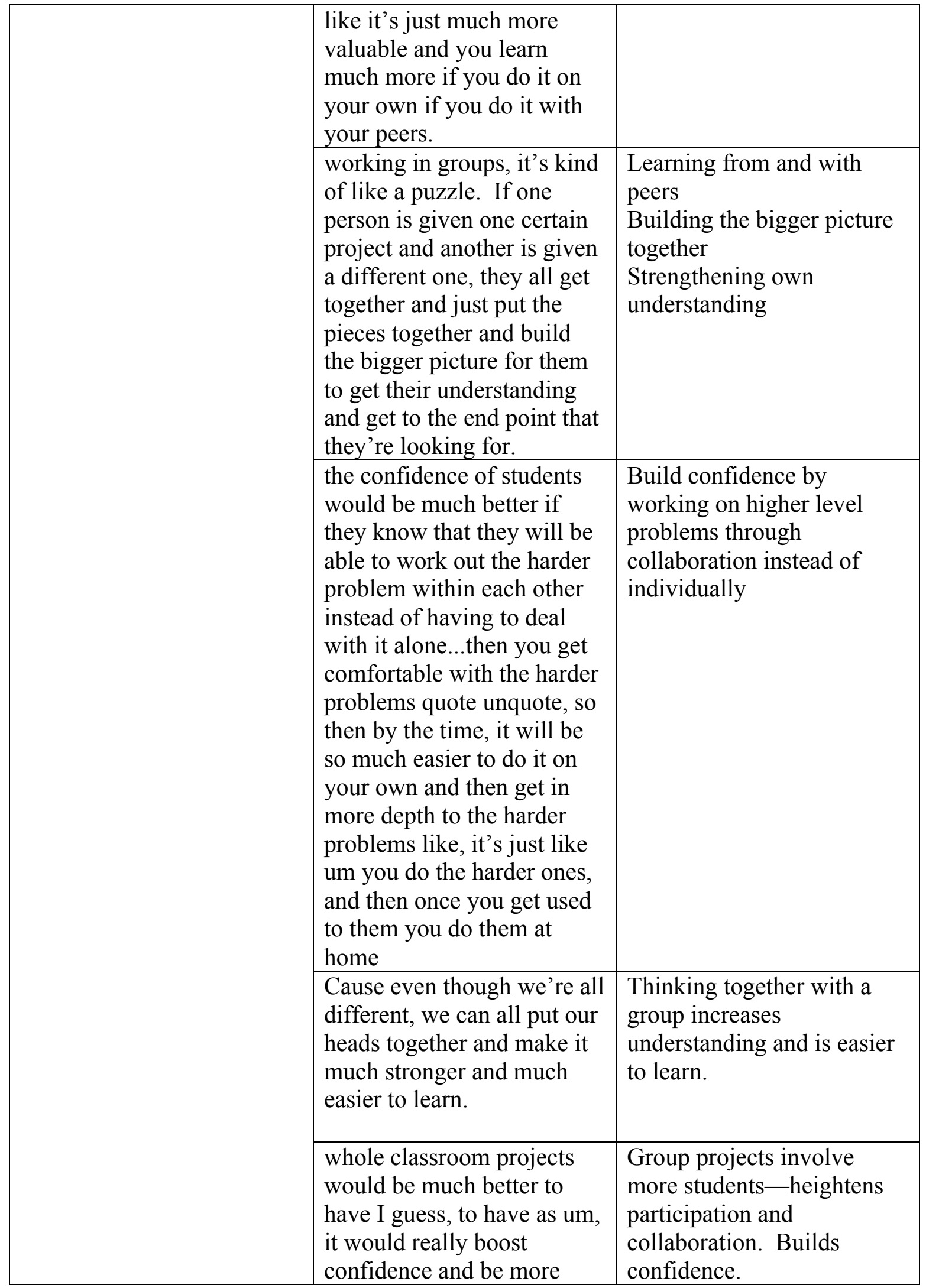




\begin{tabular}{|c|c|c|}
\hline & comfortable. & \\
\hline \multirow[t]{5}{*}{ Bigger Picture } & $\begin{array}{l}\text { I do actually wanna do } \\
\text { architecture so now I'm } \\
\text { thinking more clearly about } \\
\text { what school I wanna go to } \\
\text { and what classes I'm going } \\
\text { to have to take and I'm } \\
\text { thinking if I didn't take like } \\
\text { this math class I don't think } \\
\text { I would've been like as } \\
\text { prepared... Even when it's } \\
\text { hard because I think it will } \\
\text { like towards my career } \\
\text { specifically will help }\end{array}$ & $\begin{array}{l}\text { STEM career } \\
\text { Advanced math class } \\
\text { helpful }\end{array}$ \\
\hline & $\begin{array}{l}\text { I'm very interested in the } \\
\text { bigger picture }\end{array}$ & $\begin{array}{l}\text { Interested in mathematical } \\
\text { bigger picture ideas }\end{array}$ \\
\hline & $\begin{array}{l}\text { I think that just goes back to } \\
\text { me looking at every way } \\
\text { there is to look at a problem } \\
\text { and being able to } \\
\text { comprehend it really well. } \\
\text { And the teacher might have } \\
\text { thought that I had previous } \\
\text { experience. }\end{array}$ & $\begin{array}{l}\text { Analyzing math from all } \\
\text { angles_-deeper } \\
\text { understanding }\end{array}$ \\
\hline & $\begin{array}{l}\text { The reason I'm interested is } \\
\text { because I enjoy math. } \\
\text { When I think of math I } \\
\text { think of the world, you } \\
\text { know, I don't think about } \\
\text { numbers necessarily. } \\
\text { They're involved, they're } \\
\text { like a little part, but again it } \\
\text { makes up the bigger } \\
\text { picture... So just seeing it } \\
\text { in every day makes me } \\
\text { interested to know about it. }\end{array}$ & $\begin{array}{l}\text { Math is more than } \\
\text { numbers-life applications }\end{array}$ \\
\hline & $\begin{array}{l}\text { I was just more curious } \\
\text { about how everything in the } \\
\text { world does relate to math. } \\
\text { And before I didn't really } \\
\text { think about that because I } \\
\text { didn't have a lot of things to } \\
\text { base it off of. So as I } \\
\text { learned more I was more }\end{array}$ & $\begin{array}{l}\text { Interest beyond just } \\
\text { learning a math process, } \\
\text { extends to deeper } \\
\text { conceptual understanding } \\
\text { and life application }\end{array}$ \\
\hline
\end{tabular}




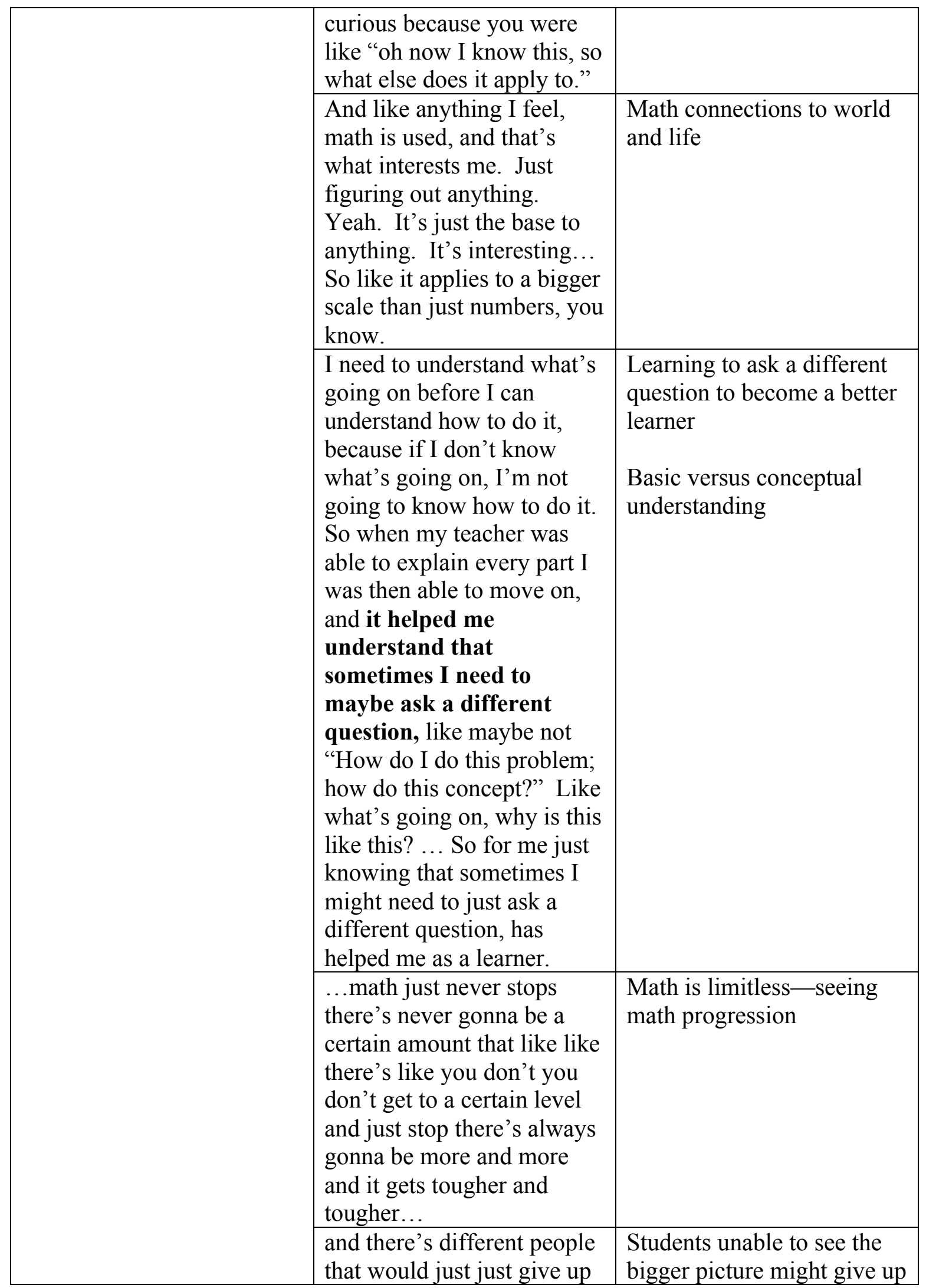




\begin{tabular}{|c|c|c|}
\hline & $\begin{array}{l}\text { because they don't think of } \\
\text { the bigger picture }\end{array}$ & understanding math \\
\hline \multirow[t]{6}{*}{ Accepting the challenge } & $\begin{array}{l}\text { a lot of it just has to do like } \\
\text { the changes just have to be } \\
\text { made by like the person } \\
\text { themselves um and just the } \\
\text { person wanting to really } \\
\text { understand everything }\end{array}$ & $\begin{array}{l}\text { Willingness and } \\
\text { understanding that learning } \\
\text { is hard work }\end{array}$ \\
\hline & $\begin{array}{l}\text { being able to like not have } \\
\text { that pride and of not } \\
\text { receiving help just because } \\
\text { you think you don't need it } \\
\text { you need you like once you } \\
\text { once you get into a struggle } \\
\text { like make sure like to go out } \\
\text { and ask for help instead of } \\
\text { really um limiting yourself } \\
\text { with the resources that are } \\
\text { given to you }\end{array}$ & $\begin{array}{l}\text { Part of accepting the } \\
\text { challenge of learning is } \\
\text { being willing to accept help } \\
\text { from peers and the teacher }\end{array}$ \\
\hline & $\begin{array}{l}\text { if I really am really } \\
\text { challenged I learn how to } \\
\text { ask for help when I need it. }\end{array}$ & $\begin{array}{l}\text { Part of accepting the } \\
\text { challenge of learning is } \\
\text { being willing to accept help } \\
\text { from peers and the teacher }\end{array}$ \\
\hline & $\begin{array}{l}\text { in any problem I try to solve } \\
\text { it myself first. Like seeing } \\
\text { what would work and what } \\
\text { wouldn't. And then when I } \\
\text { do get stuck I ask either a } \\
\text { group member or peer, and } \\
\text { then I ask my teacher for } \\
\text { help. }\end{array}$ & $\begin{array}{l}\text { Individual work time } \\
\text { beneficial }\end{array}$ \\
\hline & $\begin{array}{l}\text { challenging myself and } \\
\text { working through problems } \\
\text { applies to my life if there's } \\
\text { a difficult situation kinda I } \\
\text { just have to work through it } \\
\text { as a family. Uhhh, yeah } \\
\text { kinda try to solve a problem } \\
\text { or make it better. }\end{array}$ & $\begin{array}{l}\text { Overlap between problem- } \\
\text { solving skills being } \\
\text { reinforced in the classroom } \\
\text { and those being used in life } \\
\text { situations. }\end{array}$ \\
\hline & $\begin{array}{l}\text { I know that in everything } \\
\text { like there's always gonna be } \\
\text { a challenge cause nothing is } \\
\text { given to you easily like } \\
\text { there's always gonna have } \\
\text { to be something that you're }\end{array}$ & $\begin{array}{l}\text { Accepting challenges boosts } \\
\text { confidence in being able to } \\
\text { work through the difficult } \\
\text { problems-opens the mind } \\
\text { to accepting other } \\
\text { challenges. }\end{array}$ \\
\hline
\end{tabular}




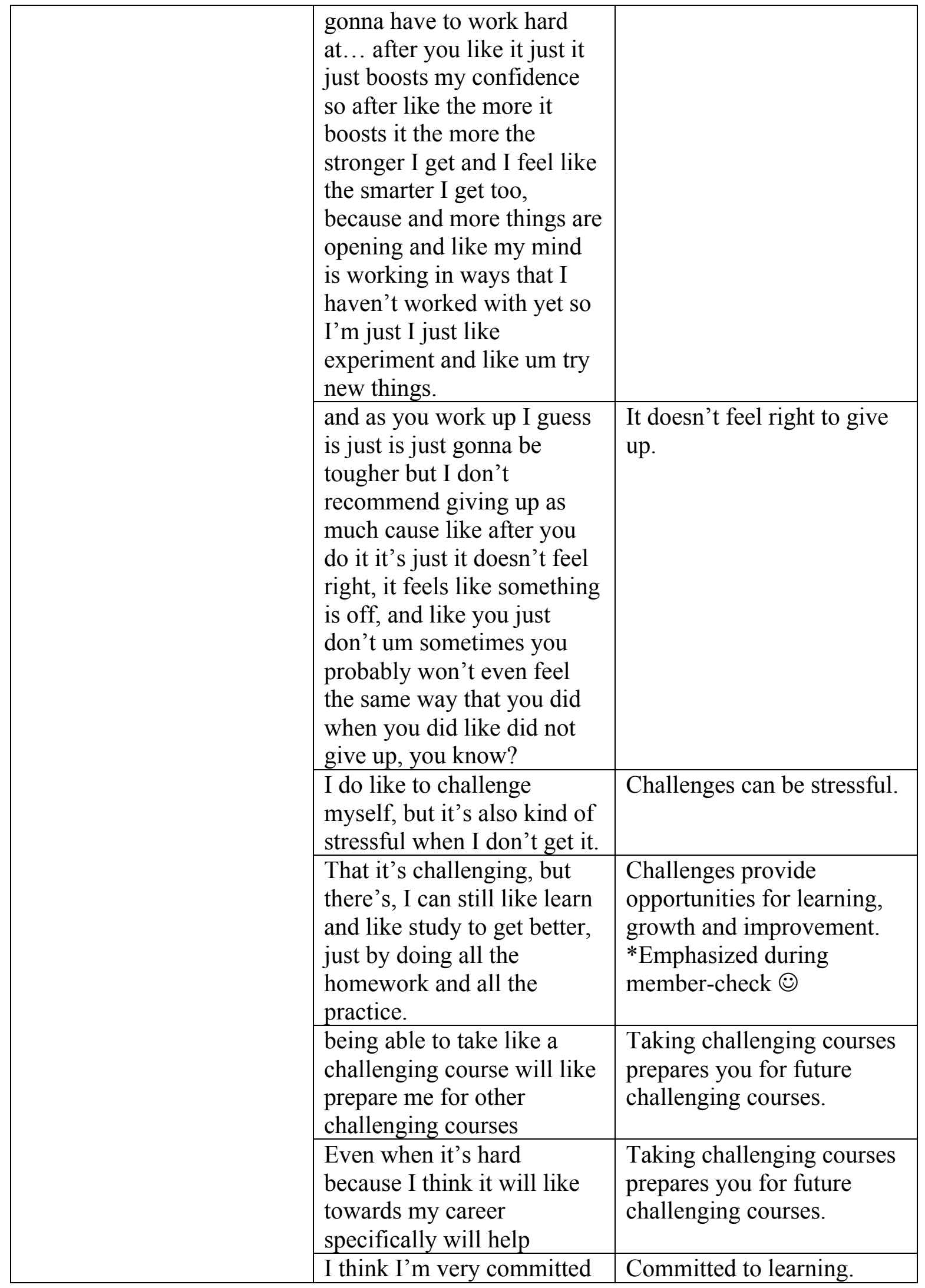




\begin{tabular}{|c|c|c|}
\hline & $\begin{array}{l}\text { to finding solutions and } \\
\text { finding a way to make it } \\
\text { work. }\end{array}$ & \\
\hline & $\begin{array}{l}\text { So I think after struggling } \\
\text { through something, getting } \\
\text { the reassurance that I can do } \\
\text { it. I think that's great. }\end{array}$ & $\begin{array}{l}\text { Challenges provide } \\
\text { opportunities for learning, } \\
\text { growth and improvement }\end{array}$ \\
\hline Confidence & $\begin{array}{l}\text { I also think peers should } \\
\text { help each other out like } \\
\text { having table groups so they } \\
\text { can solve problems together } \\
\text { or solve problems as a class } \\
\text { um having everybody } \\
\text { participate to increase your } \\
\text { confidence. }\end{array}$ & $\begin{array}{l}\text { Confidence building when } \\
\text { working with team } \\
\text { members } \\
* * \text { Repeat from } \\
\text { Collaboration }\end{array}$ \\
\hline & $\begin{array}{l}\text { I'm just not like the same } \\
\text { like understanding as } \\
\text { everyone else I think that's } \\
\text { probably why like I would } \\
\text { say that maybe my } \\
\text { confidence hasn't like been } \\
\text { like as high umm and I } \\
\text { think like in the past years } \\
\text { when like I was like doing } \\
\text { better not saying that I'm } \\
\text { doing bad but when I was } \\
\text { there like every single day } \\
\text { and like I really understood } \\
\text { the concept like I wasn't } \\
\text { like like scared to like go up } \\
\text { and like do something or } \\
\text { like like say an answer out } \\
\text { loud because I I knew what } \\
\text { was going on I knew I was } \\
\text { correct like but I think like } \\
\text { when you're just not like } \\
\text { um certain on something } \\
\text { like obviously you're not } \\
\text { gonna want to say } \\
\text { something out loud because } \\
\text { it might be like wrong or } \\
\text { like you just don't have the } \\
\text { best understanding so } \\
\text { you're not gonna like um } \\
\text { like feel as like oh I know }\end{array}$ & $\begin{array}{l}\text { Confidence lower when } \\
\text { comparing oneself to } \\
\text { classmates } \\
\text { *Member-check thought: } \\
\text { This is the main idea }\end{array}$ \\
\hline
\end{tabular}




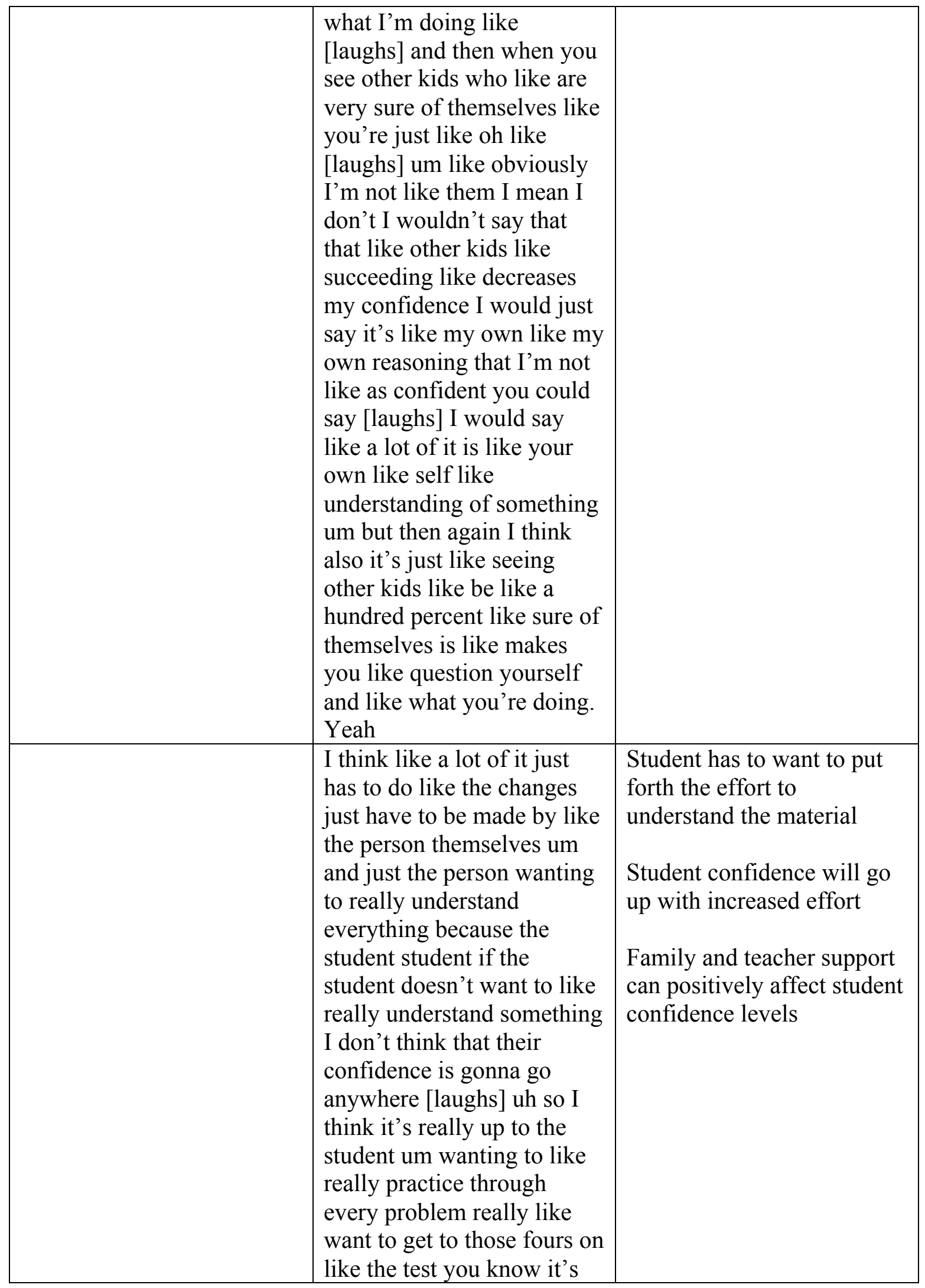




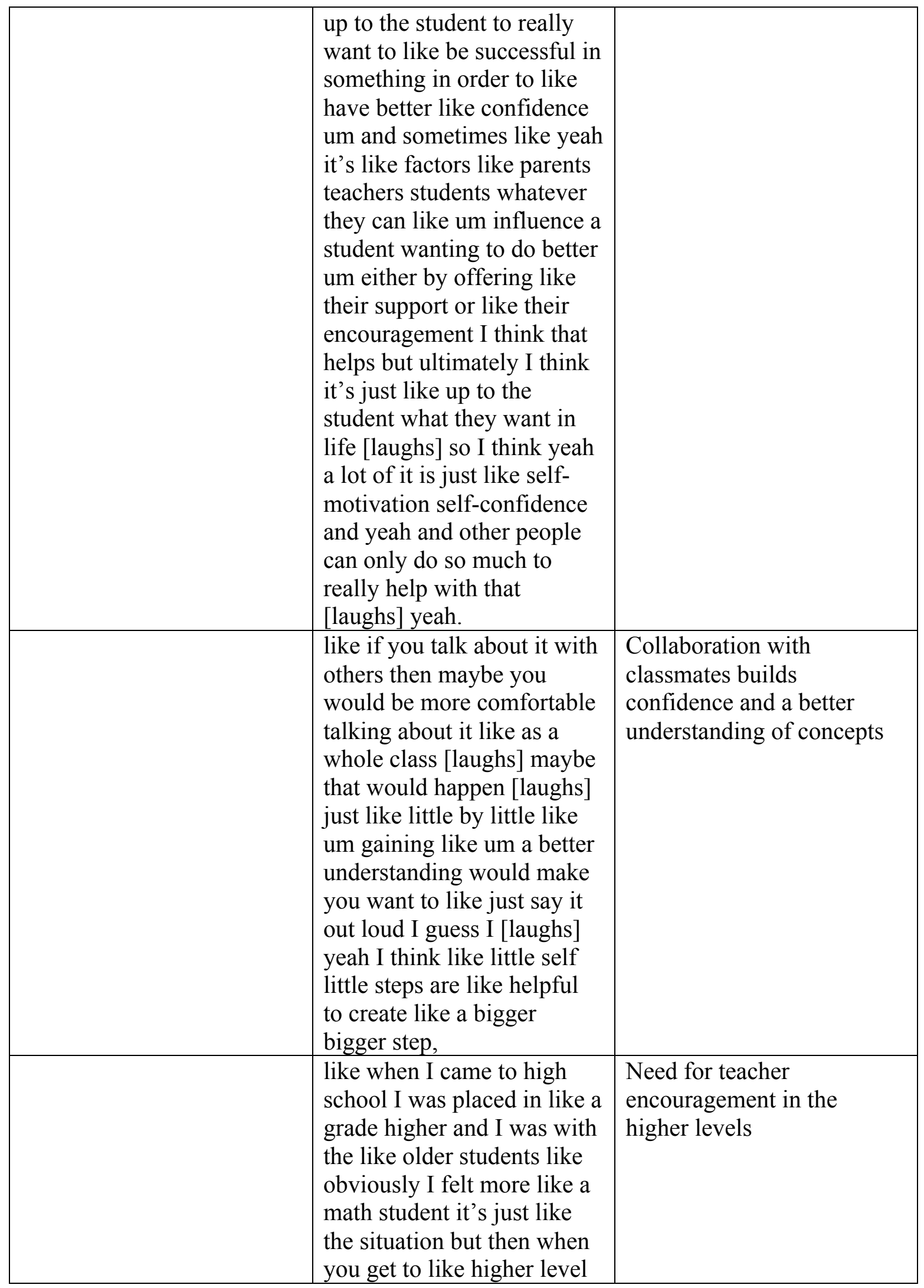




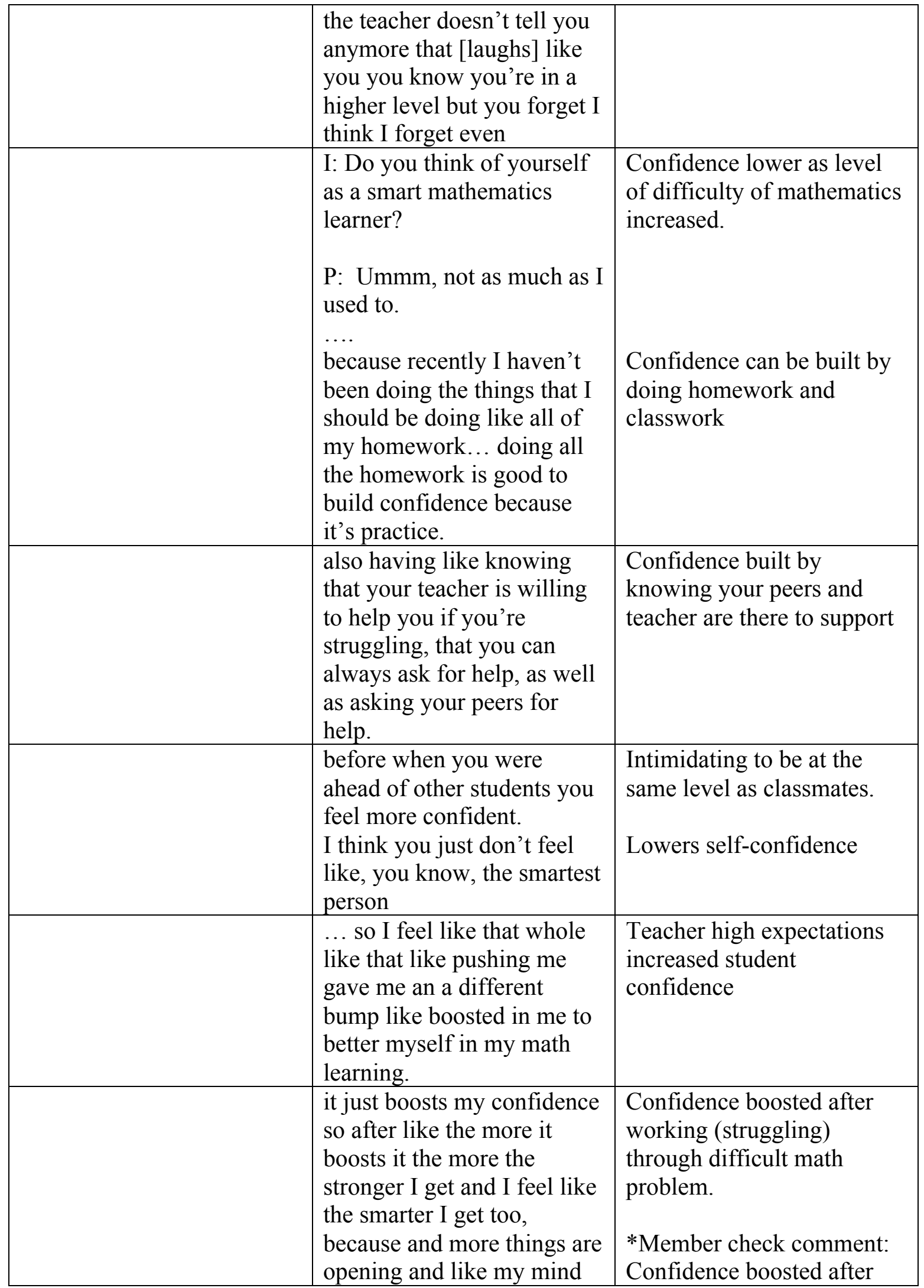




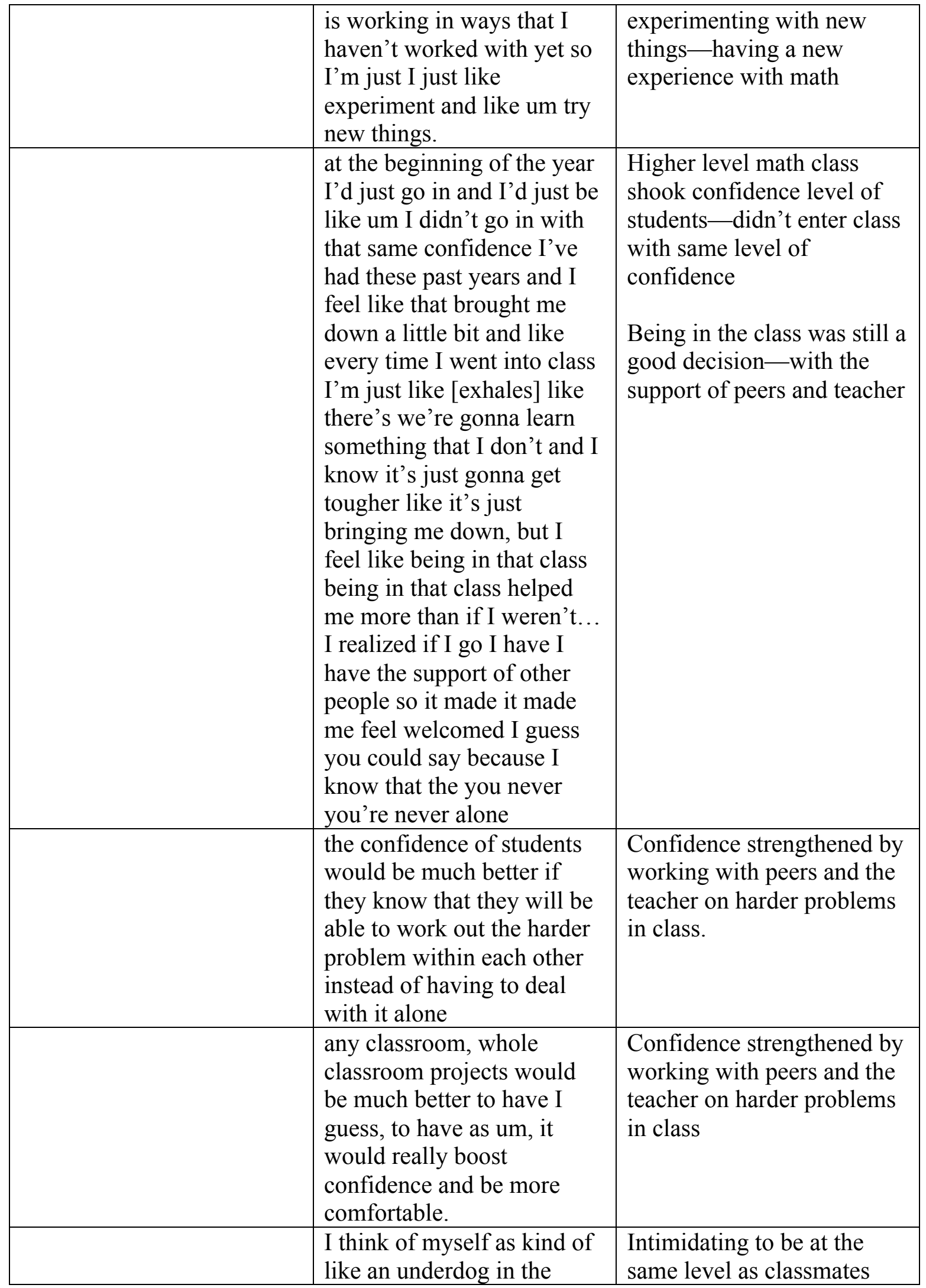




\begin{tabular}{|c|c|c|}
\hline & $\begin{array}{l}\text { classroom now, since } \\
\text { sometimes, well like, I } \\
\text { don't get it as fast. }\end{array}$ & \\
\hline \multirow[t]{4}{*}{$\begin{array}{l}\text { Math learner self- } \\
\text { identification }\end{array}$} & $\begin{array}{l}\text { like I saw the difference } \\
\text { between me and my friend } \\
\text { someone who wasn't like } \\
\text { really like into like math } \\
\text { and like really calculating } \\
\text { things out versus me who } \\
\text { was like no we have to see } \\
\text { [laughs] how many so we } \\
\text { know how many fit }\end{array}$ & $\begin{array}{l}\text { Recognize how to use math } \\
\text { outside of the classroom }\end{array}$ \\
\hline & $\begin{array}{l}\text { it's like a lifelong like thing } \\
\text { inside of me not just now }\end{array}$ & $\begin{array}{l}\text { mathematics as a part of } \\
\text { who she is, not just } \\
\text { something to learn and not } \\
\text { use. }\end{array}$ \\
\hline & $\begin{array}{l}\text { I think it's like more than } \\
\text { just talking about math } \\
\text { [laughs] that makes } \\
\text { someone a math thinker } \\
\text { learner }\end{array}$ & $\begin{array}{l}\text { Multiple contributing } \\
\text { factors in being a math } \\
\text { thinker }\end{array}$ \\
\hline & $\begin{array}{l}\text { So yeah, building that peer } \\
\text { support helps to build that } \\
\text { confidence, helps you to see } \\
\text { yourself more as more } \\
\text { comfortable in that } \\
\text { mathematics thinking role. }\end{array}$ & $\begin{array}{l}\text { Multiple contributing } \\
\text { factors in being a math } \\
\text { thinker }\end{array}$ \\
\hline \multirow[t]{2}{*}{$\begin{array}{l}\text { Teacher learning } \\
\text { about/supporting student }\end{array}$} & $\begin{array}{l}\text { I think the things that the } \\
\text { things that are um important } \\
\text { to help students learn math } \\
\text { is having teachers be } \\
\text { available to the students } \\
\text { even if it's really a dumb } \\
\text { question }\end{array}$ & $\begin{array}{l}\text { *Key theme: Teacher } \\
\text { learning the student to } \\
\text { better understand how they } \\
\text { think enables student to feel } \\
\text { more supported and } \\
\text { understood }\end{array}$ \\
\hline & $\begin{array}{l}\text { I think when teachers do } \\
\text { have conversations with } \\
\text { you um and they understand } \\
\text { like your your errors and } \\
\text { why you're struggling that's } \\
\text { more helpful then just } \\
\text { making the student try and } \\
\text { think about something that } \\
\text { [laughs] they're obviously } \\
\text { not understanding in the } \\
\text { first place so a conversation }\end{array}$ & $\begin{array}{l}\text { Teacher asking questions to } \\
\text { the student to help generate } \\
\text { understanding. }\end{array}$ \\
\hline
\end{tabular}




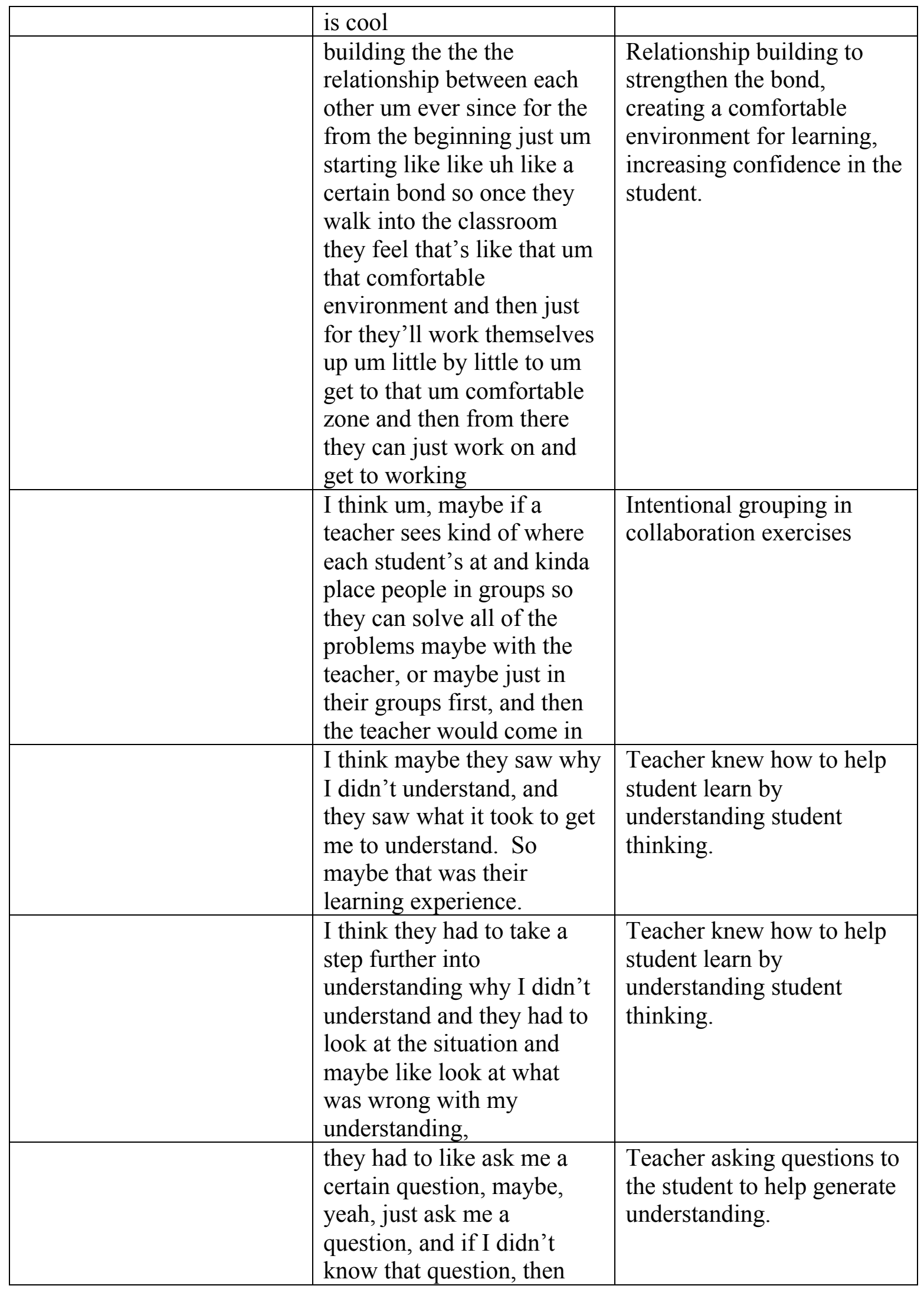




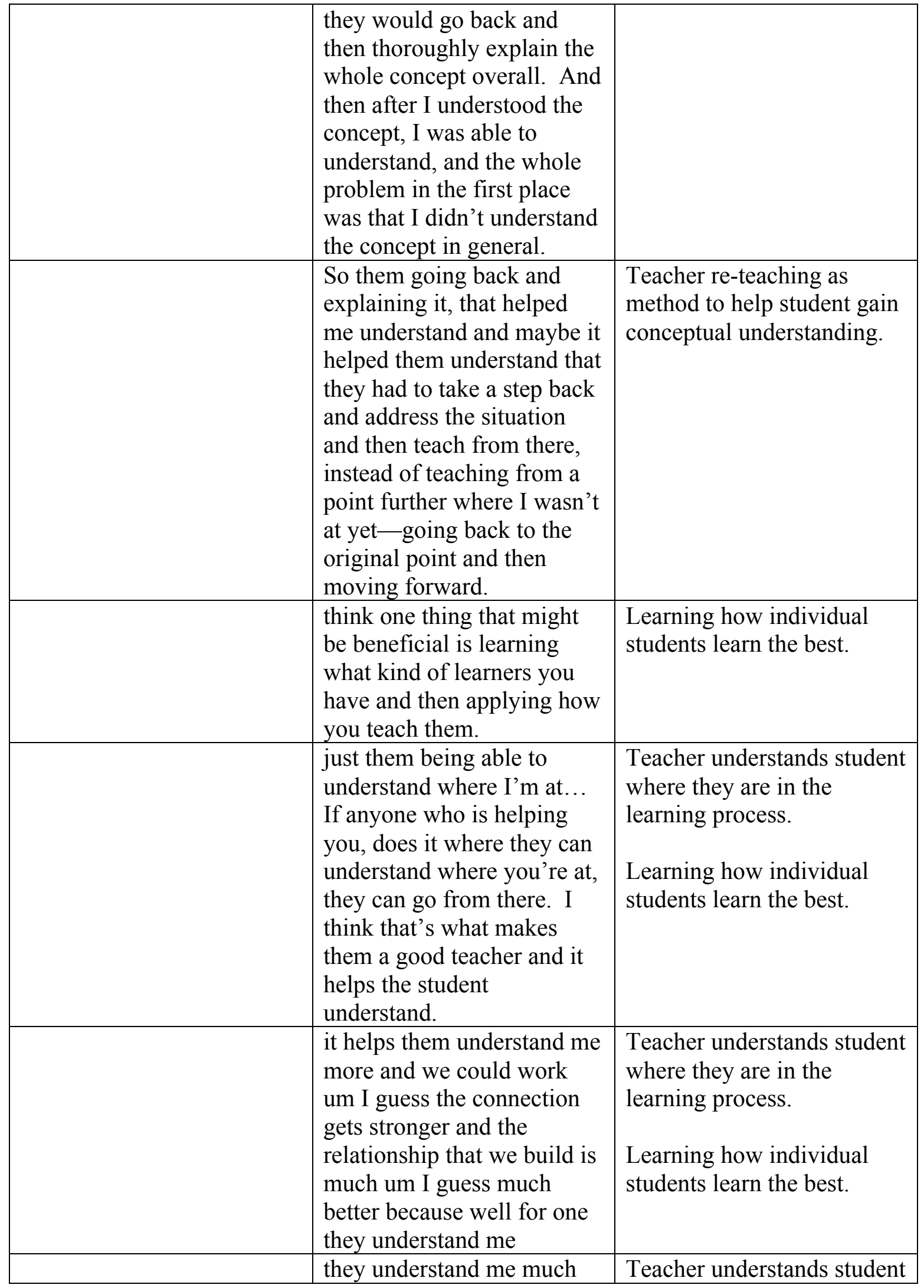




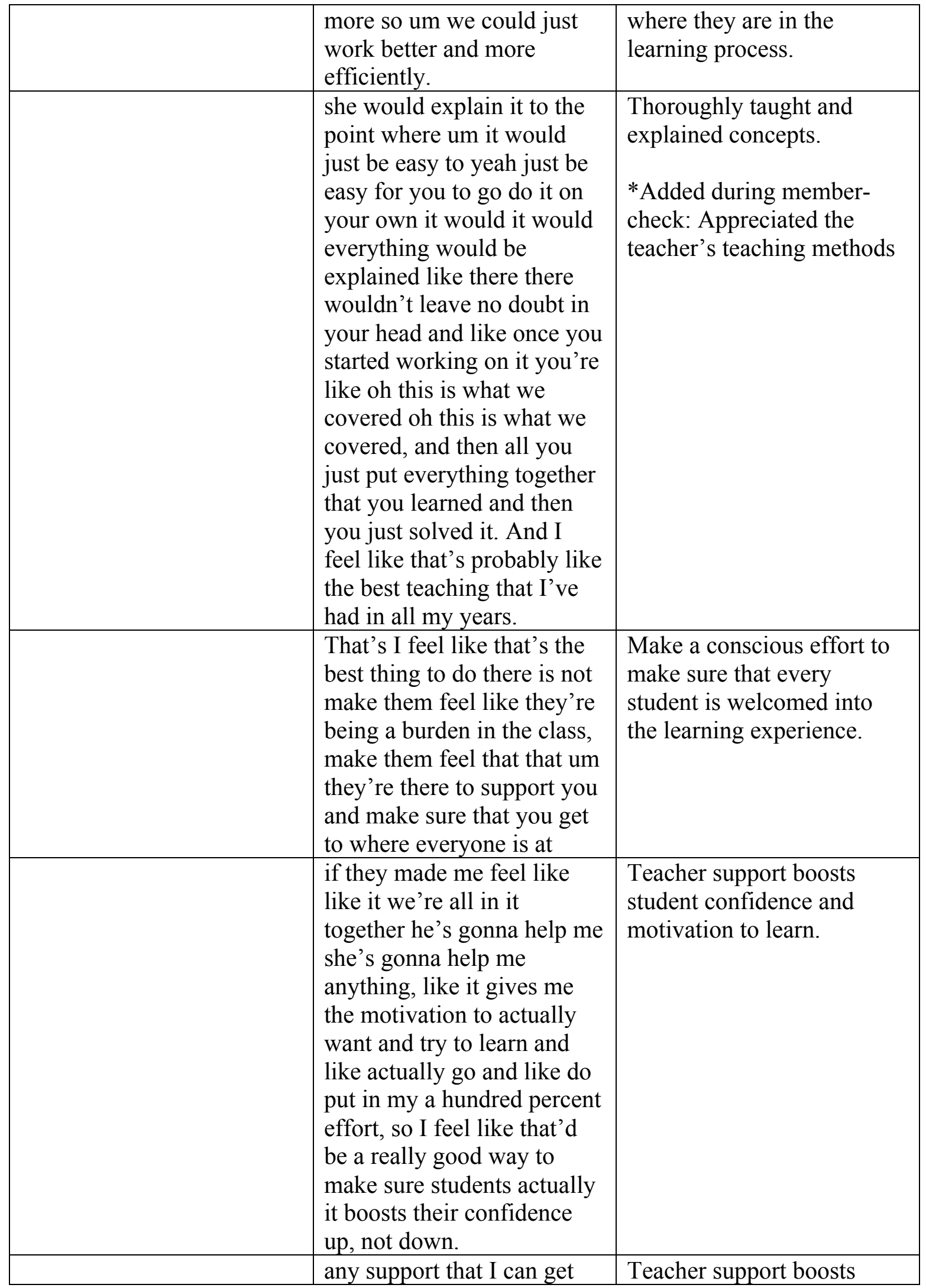




\begin{tabular}{|c|c|c|}
\hline & $\begin{array}{l}\text { really boosts my confidence } \\
\text { and it actually gives me the } \\
\text { um the what's the word I'm } \\
\text { looking for, like it just gives } \\
\text { me, makes me actually want } \\
\text { to learn }\end{array}$ & $\begin{array}{l}\text { student confidence and } \\
\text { motivation to learn. } \\
\text { *Added during member- } \\
\text { check: Gives me the desire } \\
\text { to learn }\end{array}$ \\
\hline & $\begin{array}{l}\text { being available to their } \\
\text { students and doing } \\
\text { intentional confidence } \\
\text { building exercises for } \\
\text { students so that they feel } \\
\text { heard }\end{array}$ & $\begin{array}{l}\text { Intentional confidence } \\
\text { building activities }\end{array}$ \\
\hline \multirow[t]{4}{*}{ Suggestions for teachers } & $\begin{array}{l}\text { finding another way to } \\
\text { make sure everything is } \\
\text { answered I feel like would } \\
\text { be really helpful because } \\
\text { that way you're set up to } \\
\text { like succeed more. }\end{array}$ & $\begin{array}{l}\text { Being thorough with } \\
\text { teaching and answering } \\
\text { questions. } \\
\text { Teacher understands student } \\
\text { where they are in the } \\
\text { learning process. }\end{array}$ \\
\hline & $\begin{array}{l}\text { I dunno if like requiring } \\
\text { teachers to have like a study } \\
\text { hall or just have more time } \\
\text { would be helpful or trying } \\
\text { to fit it into like the school } \\
\text { day or something but } \\
\text { having more than just a } \\
\text { class period I think would } \\
\text { be beneficial }\end{array}$ & $\begin{array}{l}\text { Students need more time } \\
\text { than just the class period to } \\
\text { puzzle through learning. } \\
\text { *Policy change? }\end{array}$ \\
\hline & $\begin{array}{l}\text { holding the student up to a } \\
\text { standard would help them } \\
\text { want to get to the standard } \\
\text { like if it was like like if the } \\
\text { teacher was like oh } \\
\text { everyone with like a four on } \\
\text { this test can like I dunno do } \\
\text { this or this or whatever like } \\
\text { just holding them to like an } \\
\text { expectation I think is } \\
\text { helpful }\end{array}$ & $\begin{array}{l}\text { Setting an maintaining high } \\
\text { expectations for students }\end{array}$ \\
\hline & $\begin{array}{l}\text { maybe like um like } \\
\text { implementing like a thing } \\
\text { where students like think } \\
\text { more about their future and } \\
\text { like stuff maybe that might } \\
\text { help with like maintaining }\end{array}$ & $\begin{array}{l}\text { Helping students to see } \\
\text { beyond high school }\end{array}$ \\
\hline
\end{tabular}




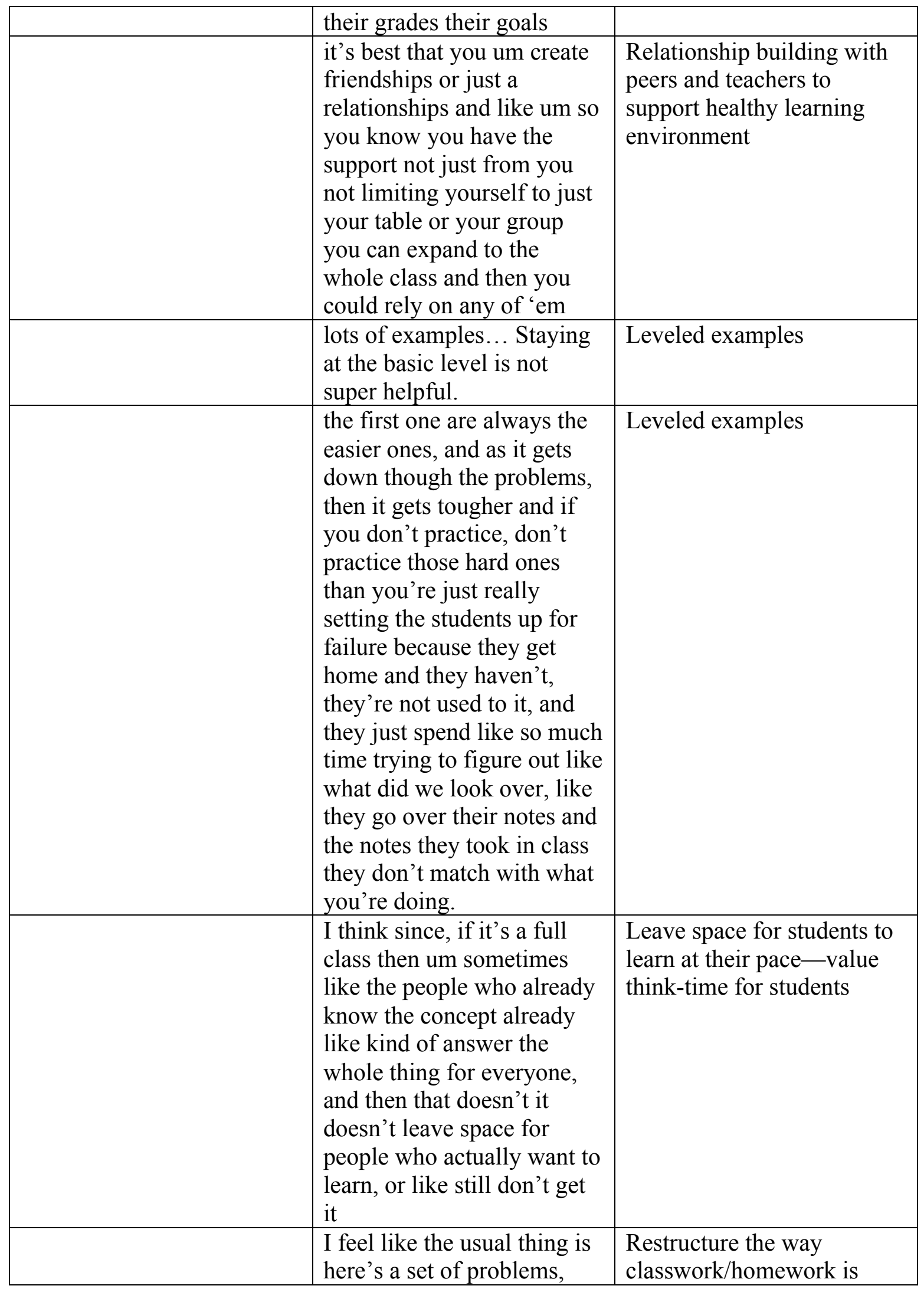




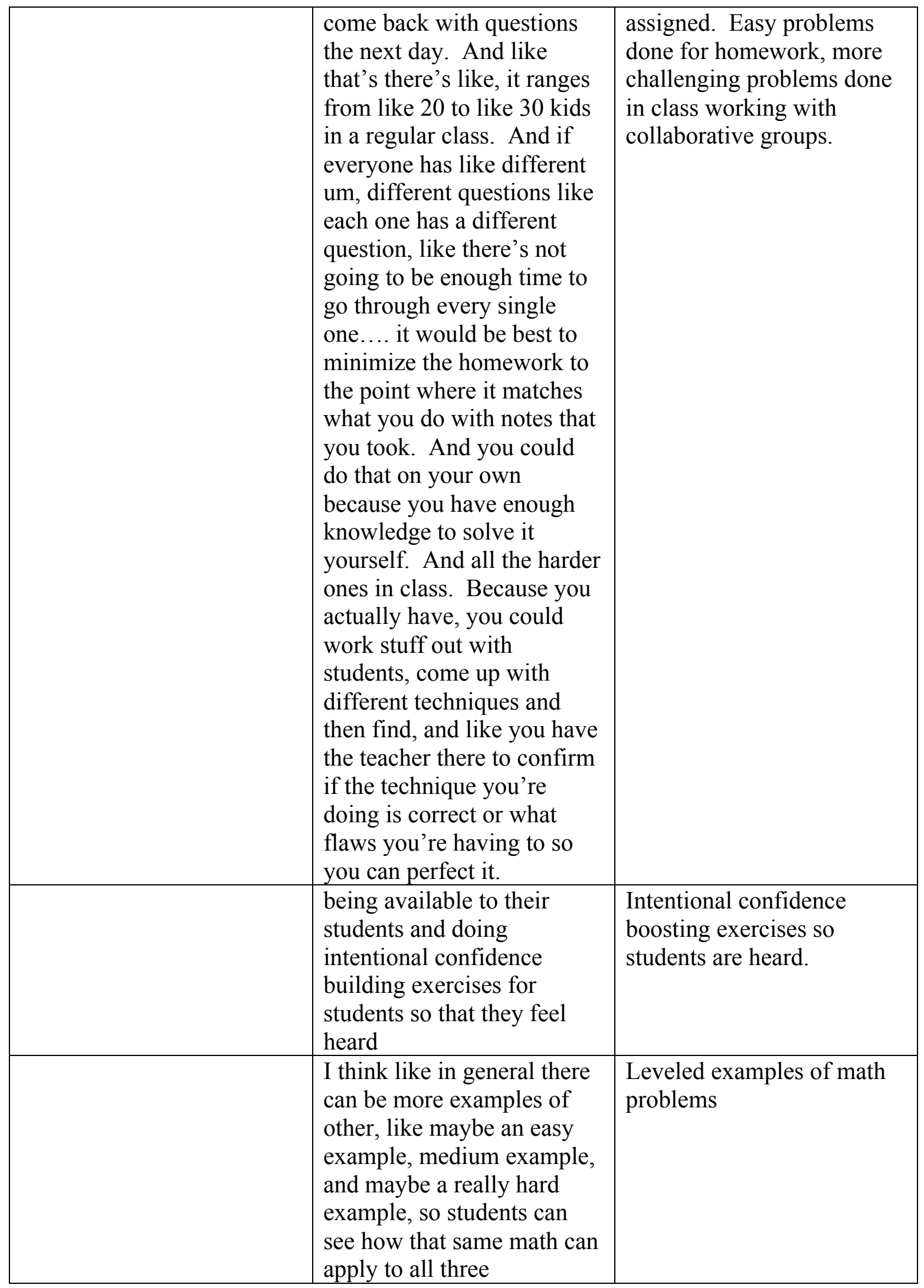




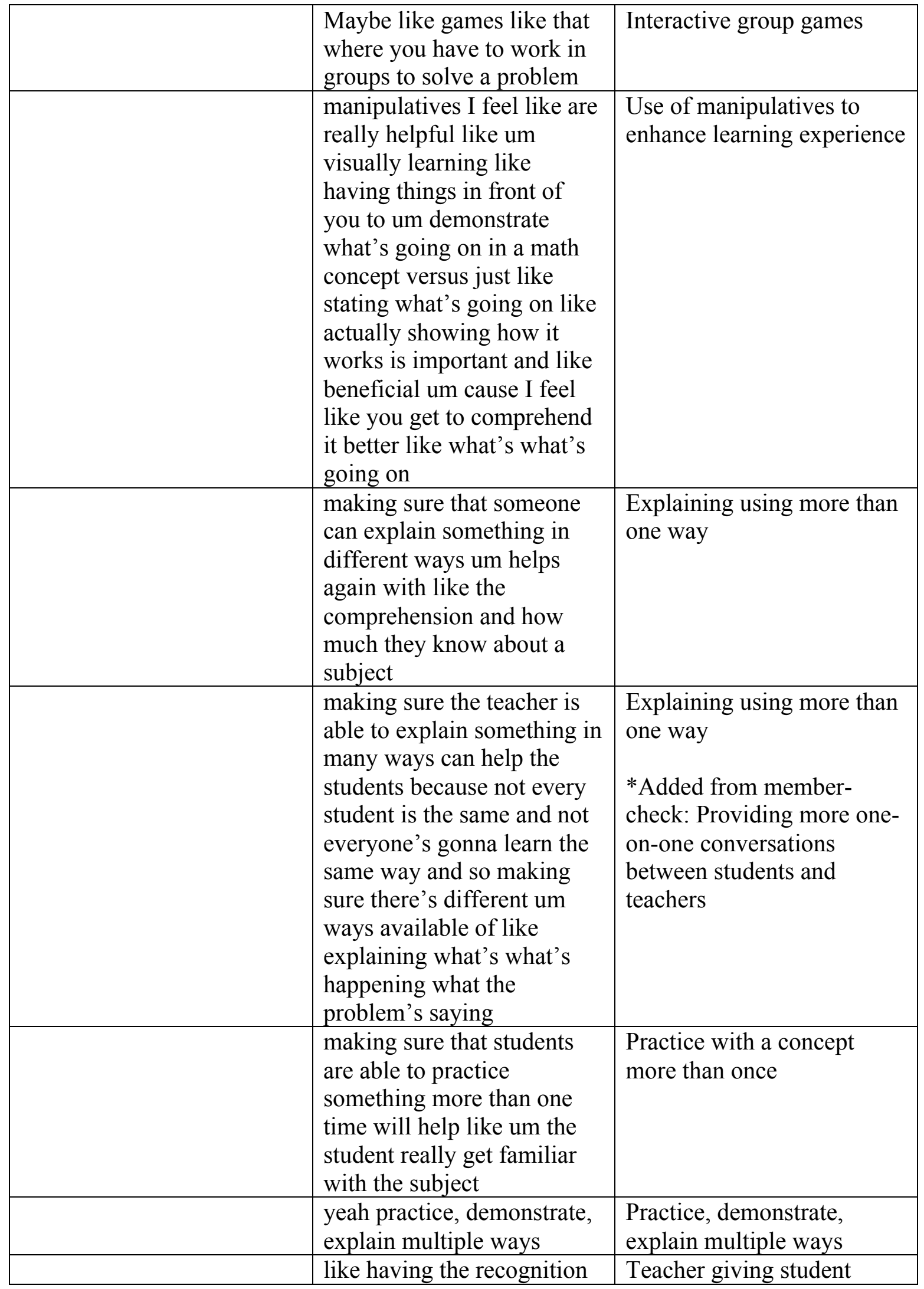




\begin{tabular}{|c|c|c|}
\hline & $\begin{array}{l}\text { have like someone telling } \\
\text { you like you know } \\
\text { but then when you get to } \\
\text { like higher level the teacher } \\
\text { doesn't tell you anymore } \\
\text { that [laughs] like you you } \\
\text { know you're in a higher } \\
\text { level but you forget I think I } \\
\text { forget even } \\
\text { I think maybe it's cause the } \\
\text { teacher doesn't I mean it's } \\
\text { not their job but like they } \\
\text { still don't like like remind } \\
\text { you like that that is } \\
\text { important but [laughs] } \\
\text { I: } \\
\text { math thinker and as a math } \\
\text { student, yeah } \\
\text { P: Yeah } \\
\text { I: That you are a } \\
\text { mathematician } \\
\text { P: Y Yeah [laughs] }\end{array}$ & $\begin{array}{l}\text { recognition of their math } \\
\text { thinking, that they identify } \\
\text { the student as a math } \\
\text { thinker } \\
\text { Upper levels students aren't } \\
\text { reminded of how they are } \\
\text { mathematics learners and } \\
\text { thinkers-students forget or } \\
\text { don't see themselves as } \\
\text { math thinkers as strongly } \\
\text { Being reminded that } \\
\text { students are math learners } \\
\text { and thinkers is important to } \\
\text { their self-concept and } \\
\text { identity as a math thinker }\end{array}$ \\
\hline \multirow[t]{2}{*}{$\begin{array}{l}\text { Teachers building } \\
\text { confidence in students }\end{array}$} & $\begin{array}{l}\text { I guess just building the the } \\
\text { the relationship between } \\
\text { each other um ever since for } \\
\text { the from the beginning just } \\
\text { um starting like like uh like } \\
\text { a certain bond so once they } \\
\text { walk into the classroom } \\
\text { they feel that's like that um } \\
\text { that comfortable } \\
\text { environment and then just } \\
\text { for they'll work themselves } \\
\text { up um little by little to um } \\
\text { get to that um comfortable } \\
\text { zone and then from there } \\
\text { they can just work on and } \\
\text { get to working }\end{array}$ & $\begin{array}{l}\text { Teachers can build } \\
\text { confidence in their students } \\
\text { by fostering relationships } \\
\text { with their students in a } \\
\text { classroom that supports a } \\
\text { healthy learning } \\
\text { environment }\end{array}$ \\
\hline & $\begin{array}{l}\text { I'd always struggle with } \\
\text { like just counting in general } \\
\text { and like I hit first grade and }\end{array}$ & $\begin{array}{l}\text { Importance of building } \\
\text { students' mathematics } \\
\text { identity and confidence }\end{array}$ \\
\hline
\end{tabular}




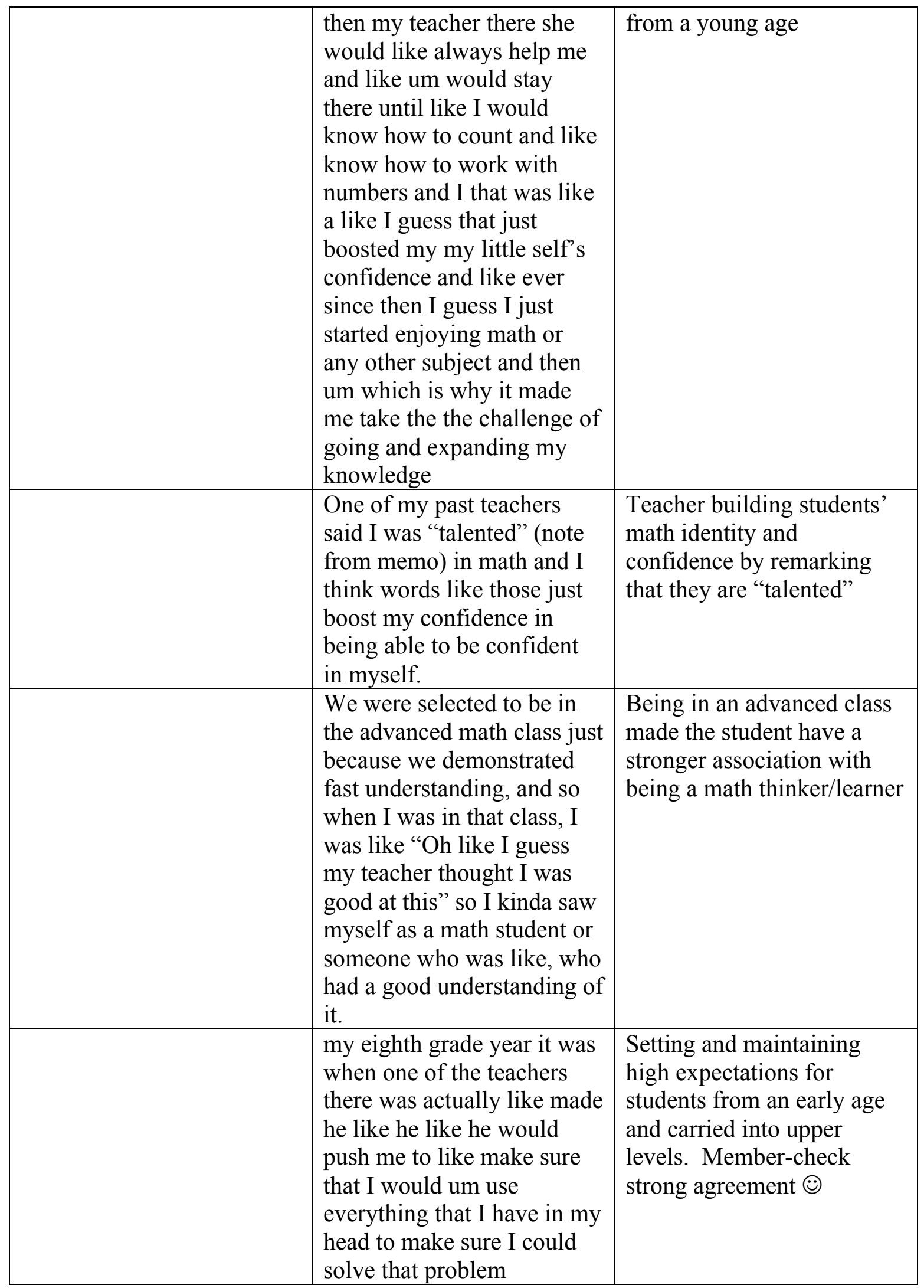




\begin{tabular}{|c|c|c|}
\hline & $\begin{array}{l}\text { so I feel like that whole like } \\
\text { that like pushing me gave } \\
\text { me an a different bump like } \\
\text { boosted in me to better } \\
\text { myself in my math learning. }\end{array}$ & $\begin{array}{l}\text { Setting high expectations } \\
\text { was a motivating factor for } \\
\text { the student to put more } \\
\text { energy into learning } \\
\text { mathematics. }\end{array}$ \\
\hline & $\begin{array}{l}\text { he was really strict, but in a } \\
\text { very positive way. It's not } \\
\text { like he would get mad, } \\
\text { instead of like dragging you } \\
\text { down, he would make sure } \\
\text { he's pushing you up and } \\
\text { challenging you to I guess } \\
\text { get to the right place that he } \\
\text { wants you to be in. }\end{array}$ & $\begin{array}{l}\text { Setting high expectations } \\
\text { was a motivating factor for } \\
\text { the student to put more } \\
\text { energy into learning } \\
\text { mathematics. }\end{array}$ \\
\hline & $\begin{array}{l}\text { And I feel like his } \\
\text { [teacher's] determination } \\
\text { and of teaching really put a } \\
\text { good place in me for me } \\
\text { actually learn and put that } \\
\text { effort in to try }\end{array}$ & $\begin{array}{l}\text { Teacher's determination } \\
\text { that students' should learn } \\
\text { at a high level. }\end{array}$ \\
\hline & $\begin{array}{l}\text { they don't like they don't } \\
\text { go like for like far enough } \\
\text { to like understand, they just } \\
\text { stop at it doesn't make } \\
\text { sense and I think that's the } \\
\text { problem with a lot of } \\
\text { students }\end{array}$ & $\begin{array}{l}\text { Students don't push } \\
\text { themselves to further to } \\
\text { understand the concepts at a } \\
\text { deeper level }\end{array}$ \\
\hline Weak math identity & $\begin{array}{l}\text { I was like working through } \\
\text { it with him and the problem } \\
\text { came when he couldn't do } \\
\text { like two minus negative } \\
\text { four and he was a junior in } \\
\text { high school you know... but } \\
\text { they're a junior in high } \\
\text { school and I think that's } \\
\text { when I realized like it's like } \\
\text { the basic um the basic math } \\
\text { that people don't like they } \\
\text { don't understand basic math } \\
\text { and then people expect } \\
\text { them to do like higher math } \\
\text { and if they're not } \\
\text { understanding they basics } \\
\text { they're not gonna move } \\
\text { through math and I think }\end{array}$ & $\begin{array}{l}\text { Low basic mathematics } \\
\text { literacy affects ability to } \\
\text { move on into the higher } \\
\text { math classes. Having a } \\
\text { strong basic mathematics } \\
\text { background can foster } \\
\text { deeper understanding of and } \\
\text { motivation to learn } \\
\text { mathematics }\end{array}$ \\
\hline
\end{tabular}




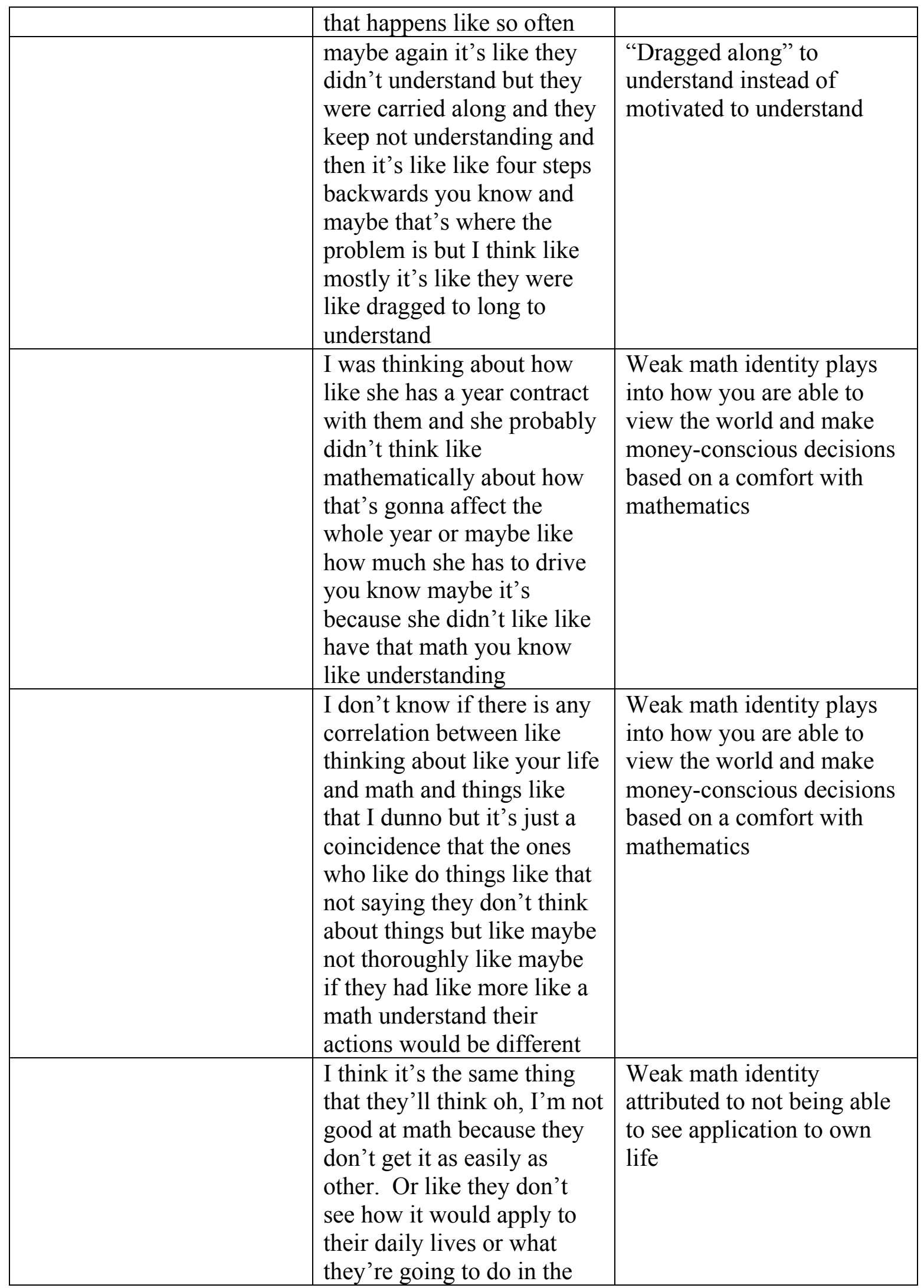




\begin{tabular}{|c|c|c|}
\hline & future & \\
\hline & $\begin{array}{l}\text { I think like maybe talking to } \\
\text { them aside or after school, } \\
\text { and see like like asking } \\
\text { questions like what are you } \\
\text { getting stuck on, or what do } \\
\text { you need to understand to } \\
\text { be able to do a certain math } \\
\text { problem. I think that would } \\
\text { be good. }\end{array}$ & $\begin{array}{l}\text { Suggestion to help students } \\
\text { who have weaker math } \\
\text { identities }\end{array}$ \\
\hline & $\begin{array}{l}\text { there's different people that } \\
\text { would just just give up } \\
\text { because they don't think of } \\
\text { the bigger picture }\end{array}$ & $\begin{array}{l}\text { Weak math identity } \\
\text { attributed to not being able } \\
\text { to see application to own } \\
\text { life }\end{array}$ \\
\hline & $\begin{array}{l}\text { sometimes people just lose } \\
\text { motivation because it gets } \\
\text { too hard and you feel like } \\
\text { there's no way of making it } \\
\text { better. }\end{array}$ & $\begin{array}{l}\text { Loss of motivation because } \\
\text { of difficulty level. }\end{array}$ \\
\hline & $\begin{array}{l}\text { others also see that I am } \\
\text { interested... as well. }\end{array}$ & Intrigued in learning \\
\hline \multirow[t]{5}{*}{ Peers see me as... } & $\begin{array}{l}\text { I think like for example in } \\
\text { table groups, in my past } \\
\text { experiences a lot of the time } \\
\text { in my table group they ask } \\
\text { if I know what's going on } \\
\text { and I'm able to explain it a } \\
\text { little bit. }\end{array}$ & $\begin{array}{l}\text { Students ask for guidance } \\
\text { but are very limited in } \\
\text { providing }\end{array}$ \\
\hline & $\begin{array}{l}\text { So then they come and ask } \\
\text { me for help when if there's } \\
\text { something they don't } \\
\text { understand and I'm I } \\
\text { already got through it }\end{array}$ & $\begin{array}{l}\text { Students trust my } \\
\text { knowledge to help guide } \\
\text { them to success }\end{array}$ \\
\hline & $\begin{array}{l}\text { most of my peers think that } \\
\text { I'm really smart because I } \\
\text { know how to do math when } \\
\text { they themselves are } \\
\text { struggling with it. }\end{array}$ & $\begin{array}{l}\text { Smart means know how to } \\
\text { do math }\end{array}$ \\
\hline & they think I'm good at math & \\
\hline & challenging myself & \\
\hline $\begin{array}{l}\text { No life connection to math } \\
\text { learned in class }\end{array}$ & $\begin{array}{l}\text { students just feel or think } \\
\text { that um math is pretty } \\
\text { useless after like Algebra } 2 \\
\text { so they just talk and are like }\end{array}$ & $\begin{array}{l}\text { Higher level math views as } \\
\text { unnecessary }\end{array}$ \\
\hline
\end{tabular}




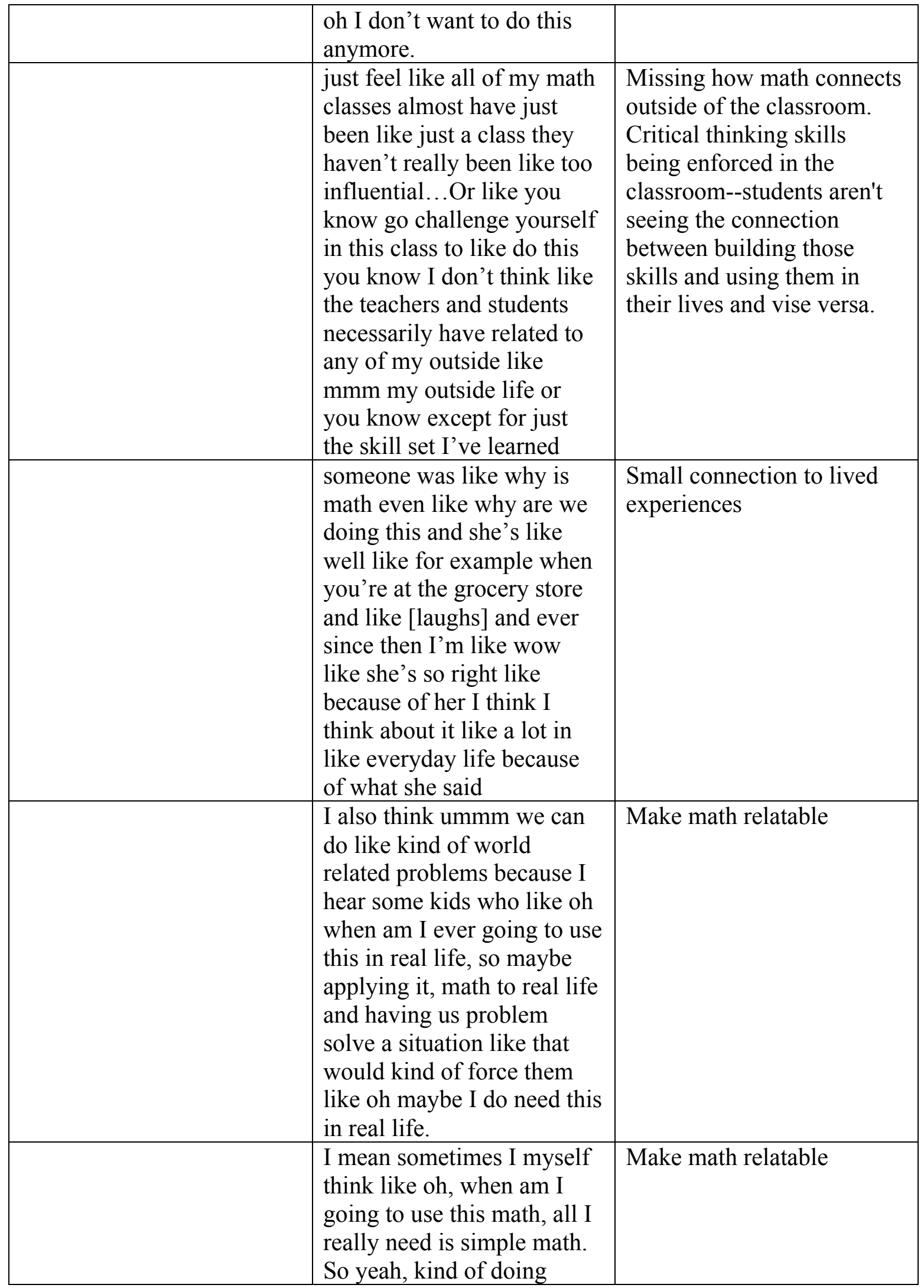




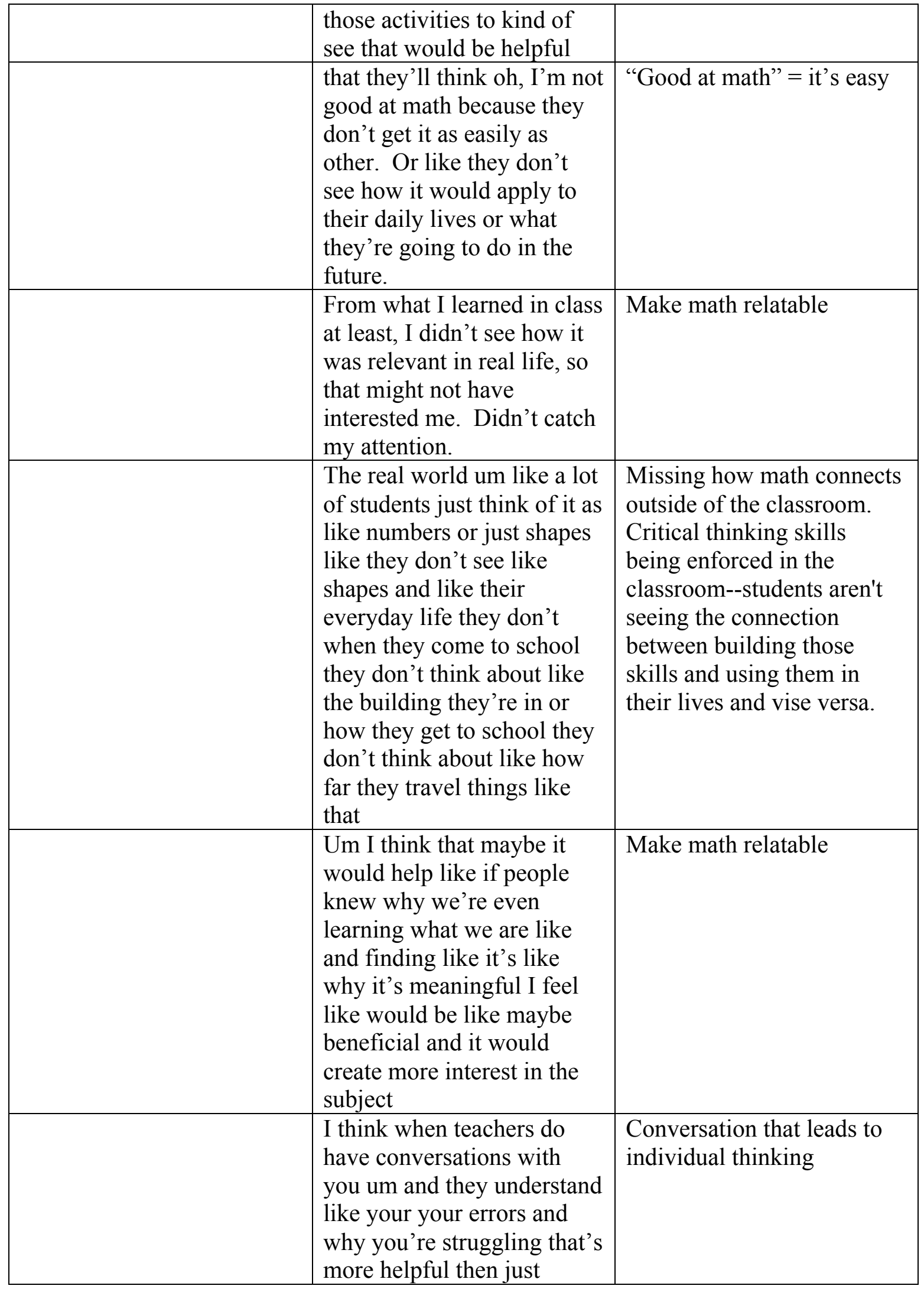




\begin{tabular}{|c|c|c|}
\hline & $\begin{array}{l}\text { making the student try and } \\
\text { think about something that } \\
\text { [laughs] they' re obviously } \\
\text { not understanding in the } \\
\text { first place so a conversation } \\
\text { is cool }\end{array}$ & \\
\hline \multirow[t]{5}{*}{ Talking about math } & $\begin{array}{l}\text { I kinda just comprehend it } \\
\text { better. And then with a } \\
\text { group, like you get } \\
\text { everybody's input in how to } \\
\text { solve a math problem. Or } \\
\text { you, it could be vice versa } \\
\text { you can give them input } \\
\text { also. }\end{array}$ & $\begin{array}{l}\text { Comprehend concept } \\
\text { better-reciprocal learning } \\
\text { with group members }\end{array}$ \\
\hline & $\begin{array}{l}\text { I think it is helpful because } \\
\text { it's kinda the same thing as } \\
\text { me thinking about it } \\
\text { pronouncing my work. So } \\
\text { it's just kinda, I think it's } \\
\text { kinda the same but you } \\
\text { have someone there I guess, } \\
\text { so it makes it better. }\end{array}$ & Creates processing time \\
\hline & $\begin{array}{l}\text { And since we all do it } \\
\text { separately and then talk } \\
\text { about it, like if someone } \\
\text { gets a different answer, then } \\
\text { we all try to solve it } \\
\text { together to see what each } \\
\text { person did. }\end{array}$ & $\begin{array}{l}\text { Collaboration to see } \\
\text { outcome }\end{array}$ \\
\hline & $\begin{array}{l}\text { first talking about } \\
\text { something with your group, } \\
\text { and then going in a new } \\
\text { group, and then talking } \\
\text { about it again with different } \\
\text { people. I think the more } \\
\text { ideas there are the better it } \\
\text { is. }\end{array}$ & $\begin{array}{l}\text { Structure collaboration } \\
\text { activities to incorporate } \\
\text { greater mixture of } \\
\text { classmates }\end{array}$ \\
\hline & $\begin{array}{l}\text { And when you have to think } \\
\text { about how to explain it in } \\
\text { another way yourself } \\
\text { instead of only the teacher } \\
\text { having to explain the } \\
\text { different ways this concept } \\
\text { works. When you have to } \\
\text { explain it in different ways, }\end{array}$ & $\begin{array}{l}\text { Math dialogue supports } \\
\text { student conceptual } \\
\text { comprehension }\end{array}$ \\
\hline
\end{tabular}




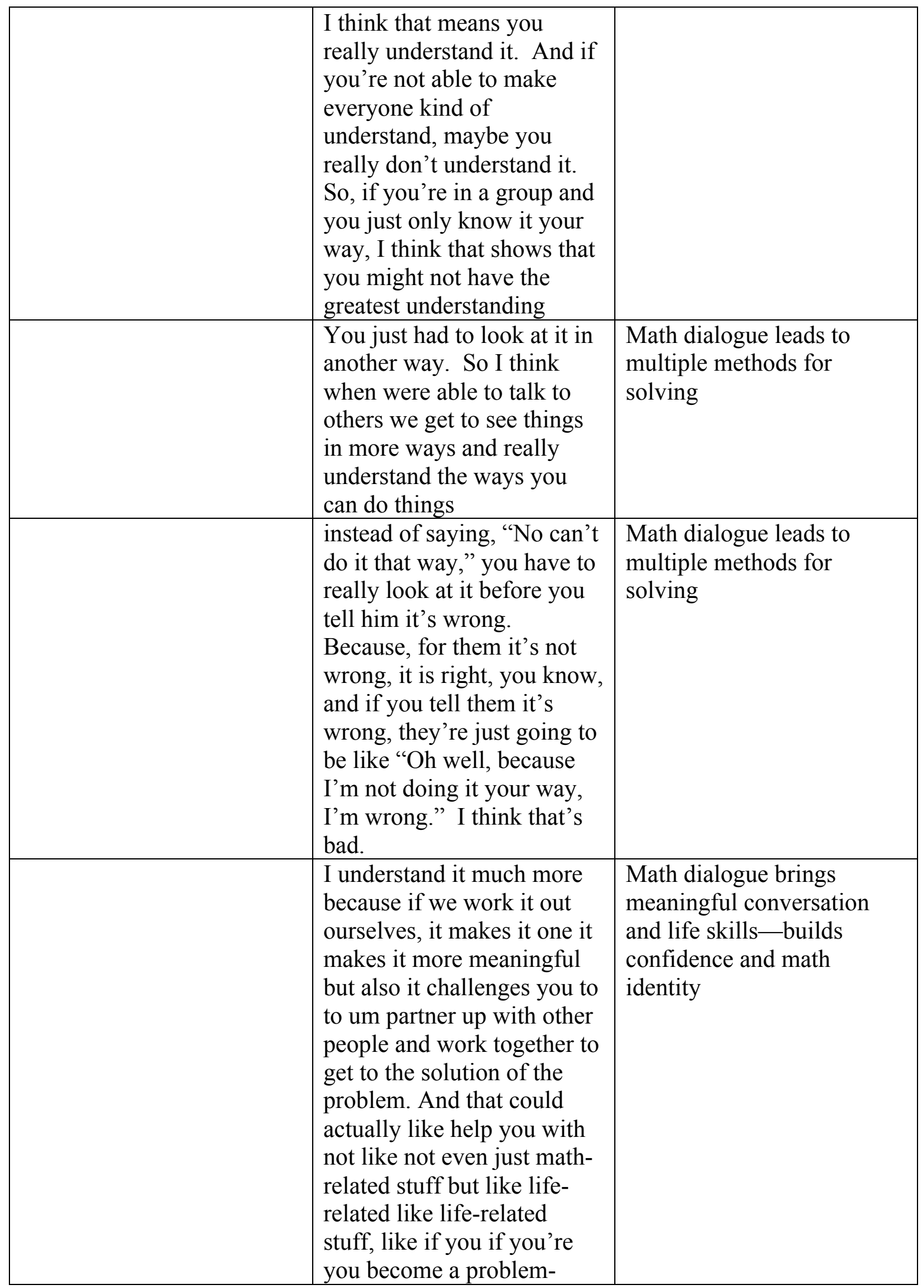




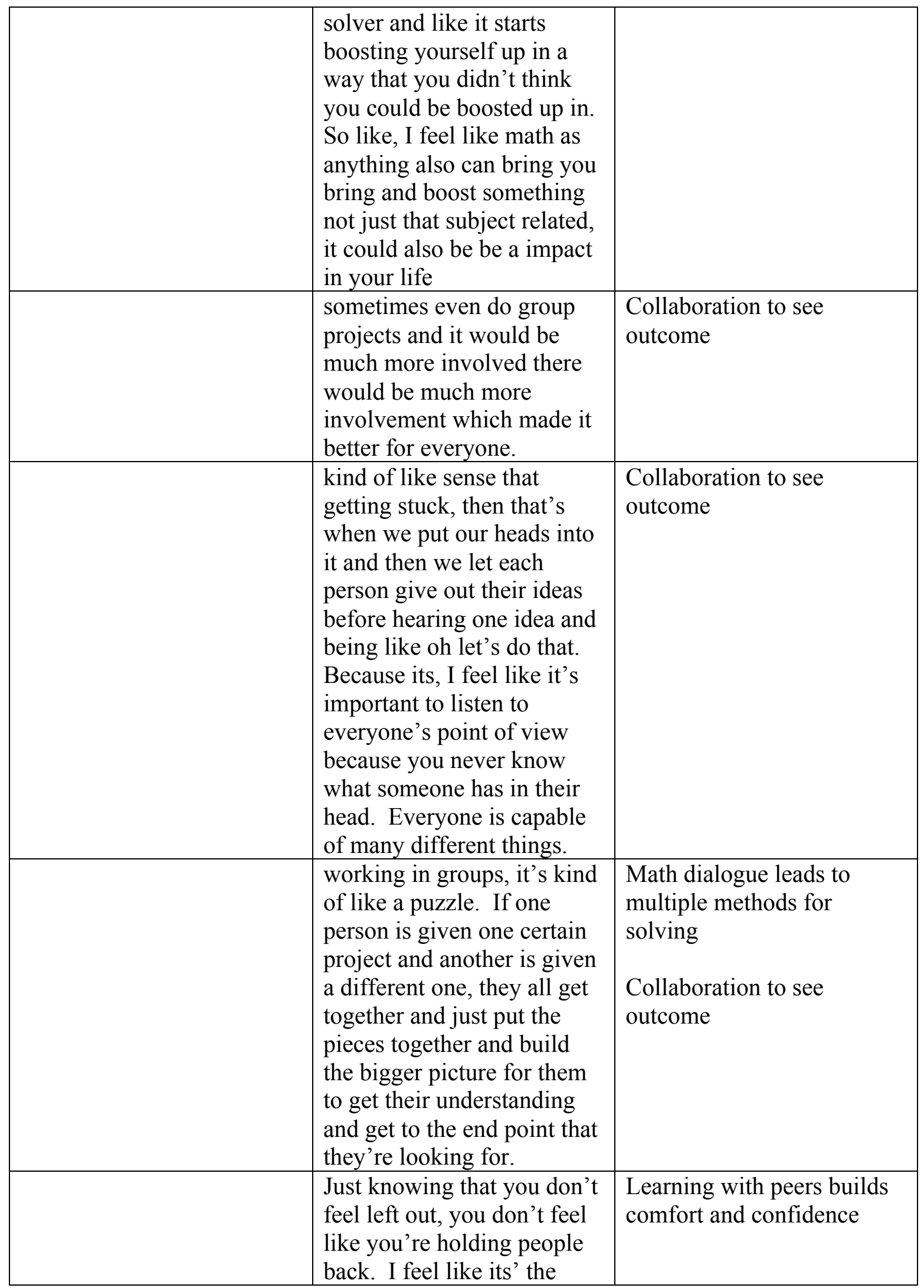




\begin{tabular}{|c|c|c|}
\hline & right way to put it. & \\
\hline & $\begin{array}{l}\text { having to work with others } \\
\text { um gives a better like um } \\
\text { like it helps like } \\
\text { communication skills } \\
\text { [laughs] that's what I was } \\
\text { thinking um so instead of } \\
\text { like explaining to just like } \\
\text { your teacher or like to } \\
\text { yourself you have to explain } \\
\text { to others so like } \\
\text { communicating }\end{array}$ & $\begin{array}{l}\text { Math dialogue brings } \\
\text { meaningful conversation } \\
\text { and life skills-builds } \\
\text { confidence and math } \\
\text { identity }\end{array}$ \\
\hline \multirow[t]{3}{*}{ Using math in the future } & $\begin{array}{l}\text { Right now I'm still } \\
\text { undecided on what I want to } \\
\text { but I do know that I want to } \\
\text { focus on math and science I } \\
\text { want to focus on something } \\
\text { around those fields or } \\
\text { involving both of them... } \\
\text { Maybe a type of } \\
\text { engineering I'm not sure or } \\
\text { pharmacy. }\end{array}$ & STEM related career \\
\hline & $\begin{array}{l}\text { having those skills to help } \\
\text { you kind of everywhere you } \\
\text { go cause there is math like } \\
\text { in some places uh like one } \\
\text { of our teachers um when we } \\
\text { were learning umm sine } \\
\text { waves and cosine waves he } \\
\text { told us that we use those all } \\
\text { the time um I think he said } \\
\text { something about music }\end{array}$ & $\begin{array}{l}\text { Math connections outside } \\
\text { the classroom }\end{array}$ \\
\hline & $\begin{array}{l}\text { I mean it will put me to a } \\
\text { better advantage than } \\
\text { someone who doesn't-I } \\
\text { feel like if that person is } \\
\text { looking for someone that } \\
\text { like has the certain um uh I } \\
\text { guess certain... assets that } \\
\text { they have then like if } \\
\text { they're looking for someone } \\
\text { that it has high knowledge } \\
\text { in in math over and like I } \\
\text { guess their competition isn't }\end{array}$ & $\begin{array}{l}\text { Math literacy is a valuable } \\
\text { asset in the working world }\end{array}$ \\
\hline
\end{tabular}




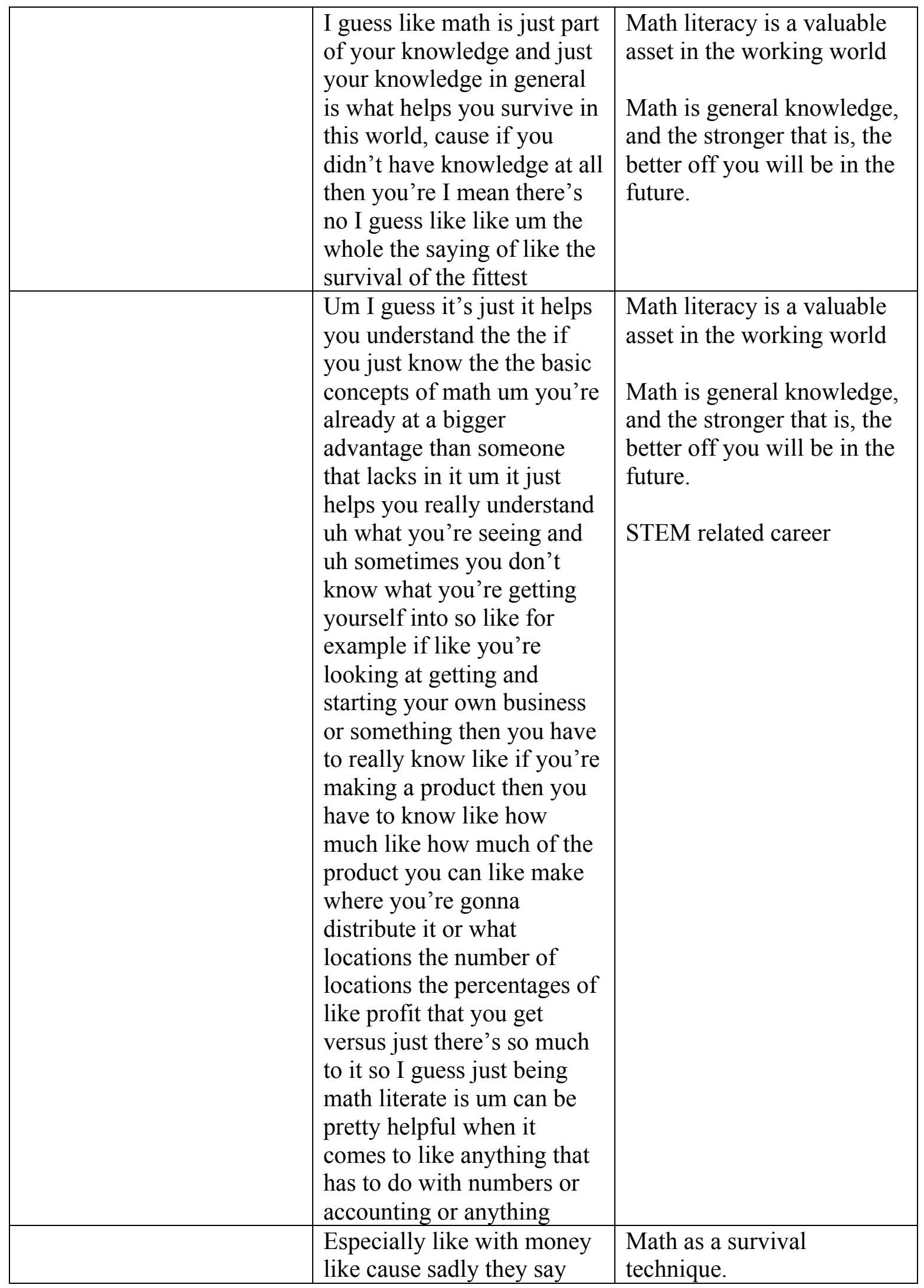




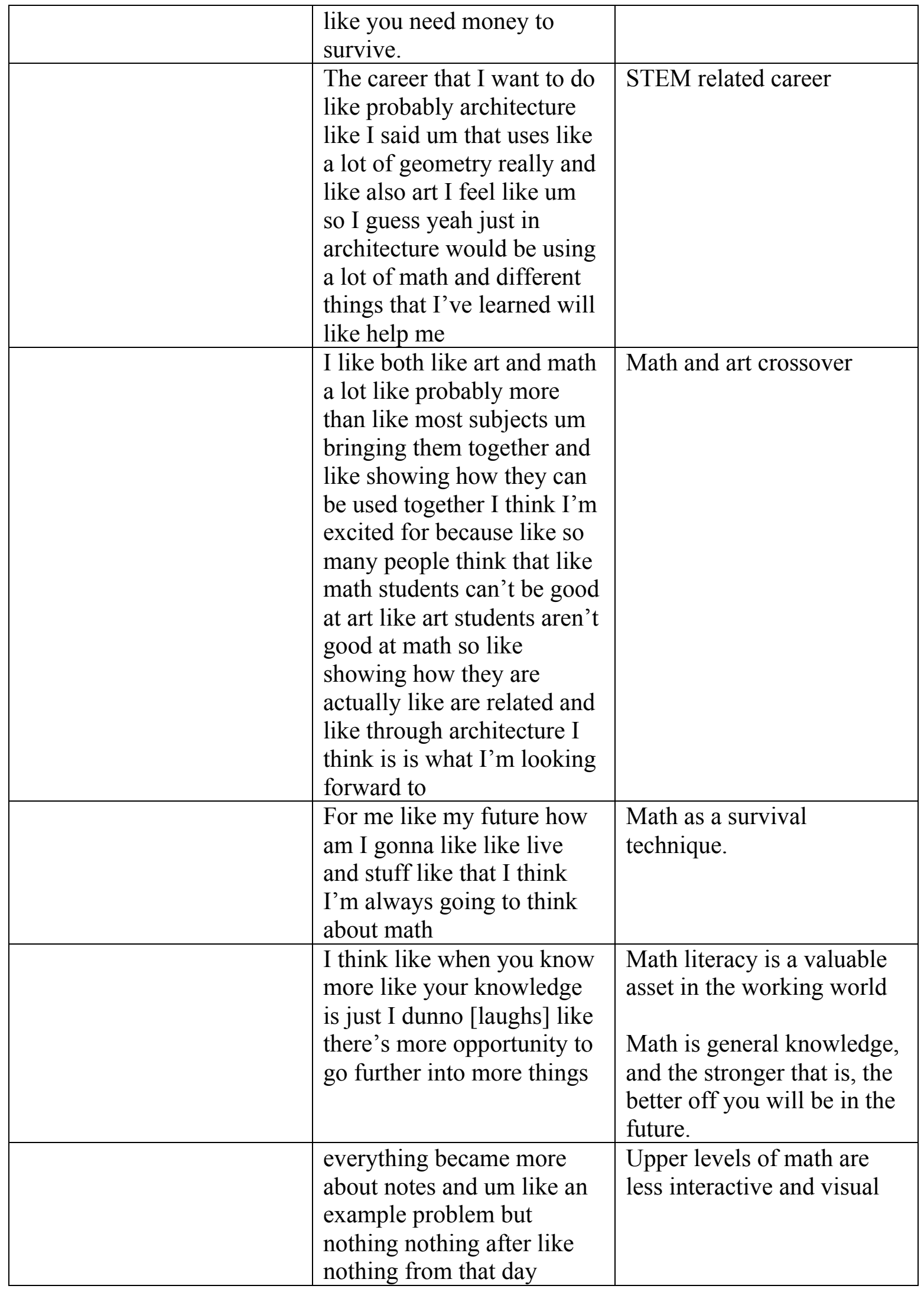




\begin{tabular}{|c|c|c|}
\hline & $\begin{array}{l}\text { forward was interactive it } \\
\text { wasn't like anything like } \\
\text { visual }\end{array}$ & \\
\hline \multirow[t]{4}{*}{$\begin{array}{l}\text { Visualizing math to aid } \\
\text { comprehension }\end{array}$} & $\begin{array}{l}\text { In 1st grade one thing that } \\
\text { helped me was like } \\
\text { visualizing what was going } \\
\text { on. The teacher asked us } \\
\text { create a pattern, any pattern, } \\
\text { with shapes, and uh, I } \\
\text { couldn't really think of any } \\
\text { to do, so then she gave me a } \\
\text { sheet that showed me what } \\
\text { was an example of pattern. } \\
\text { And so after seeing what } \\
\text { she was referring to visually } \\
\text { I was able to do it. After } \\
\text { seeing what was going on I } \\
\text { was able to do it myself. So } \\
\text { visuals helped when I was } \\
\text { younger. }\end{array}$ & $\begin{array}{l}\text { Visual aids helps students } \\
\text { understand concepts more } \\
\text { concretely }\end{array}$ \\
\hline & $\begin{array}{l}\text { I think my teacher showed } \\
\text { me the line, but I had to } \\
\text { look at every point and look } \\
\text { at the growth within the } \\
\text { table to see the amount it } \\
\text { was increasing by. And } \\
\text { then I saw the graph and I } \\
\text { understood why it looked } \\
\text { like that versus looking at } \\
\text { the graph and being like I } \\
\text { have no idea why it's like } \\
\text { this. So looking at the } \\
\text { details helped me. }\end{array}$ & $\begin{array}{l}\text { Multiple visuals to support } \\
\text { conceptual understanding } \\
\text { *Emphasized point during } \\
\text { member-check }:-\end{array}$ \\
\hline & Dry ice demonstration & $\begin{array}{l}\text { Demonstrations to guide } \\
\text { learning }\end{array}$ \\
\hline & $\begin{array}{l}\text { You see shapes or } \\
\text { sometimes you even } \\
\text { encounter them in person so } \\
\text { like there's just it just adds } \\
\text { fun to it um cause for me } \\
\text { personally like when I'm } \\
\text { out and like I see it's like a } \\
\text { certain shape that I'm like } \\
\text { learning or like like like } \\
\text { measuring or something um }\end{array}$ & $\begin{array}{l}\text { Making connections } \\
\text { between math that is } \\
\text { learned in class and math in } \\
\text { the world }\end{array}$ \\
\hline
\end{tabular}




\begin{tabular}{|c|c|c|}
\hline & $\begin{array}{l}\text { I'm just like oh I'm looking } \\
\text { at that in class }\end{array}$ & \\
\hline & $\begin{array}{l}\text { it's it sometimes it works } \\
\text { better to have a visual and a } \\
\text { verbal so you could } \\
\text { combine em and make } \\
\text { better understanding of it, }\end{array}$ & $\begin{array}{l}\text { Combine verbal with visual } \\
\text { to aid conceptual } \\
\text { understanding }\end{array}$ \\
\hline & $\begin{array}{l}\text { um manipulatives I feel like } \\
\text { are really helpful like um } \\
\text { visually learning like } \\
\text { having things in front of } \\
\text { you to um demonstrate } \\
\text { what's going on in a math } \\
\text { concept versus just like } \\
\text { stating what's going on like } \\
\text { actually showing how it } \\
\text { works is important and like } \\
\text { beneficial um cause I feel } \\
\text { like you get to comprehend } \\
\text { it better like what's what's } \\
\text { going on }\end{array}$ & $\begin{array}{l}\text { Demonstrations to guide } \\
\text { learning }\end{array}$ \\
\hline & $\begin{array}{l}\text { one thing I think is really } \\
\text { important is showing how } \\
\text { something actually is } \\
\text { happening how it's working } \\
\text { um I think like learning in } \\
\text { more than one way how to } \\
\text { do something like showing } \\
\text { it um like saying what's } \\
\text { going on writing what's } \\
\text { going on just having } \\
\text { different ways to explain } \\
\text { something I think is } \\
\text { important }\end{array}$ & $\begin{array}{l}\text { Demonstrations to guide } \\
\text { learning }\end{array}$ \\
\hline & $\begin{array}{l}\text { I feel like sometimes it it it } \\
\text { feels like a like a sort of } \\
\text { competition and instead of } \\
\text { pushing each other up we're } \\
\text { just dragging ourselves } \\
\text { down }\end{array}$ & $\begin{array}{l}\text { Competition instead of } \\
\text { collaborative atmosphere }\end{array}$ \\
\hline $\begin{array}{l}\text { Improving classroom } \\
\text { environment }\end{array}$ & $\begin{array}{l}\text { I think that it's not very like } \\
\text { inviting. I feel like there's } \\
\text { no, like, nobody says that } \\
\text { you can go to another } \\
\text { group. No one says that. }\end{array}$ & $\begin{array}{l}\text { Collaboration is only group } \\
\text { work, which isn't real } \\
\text { collaboration. Need for } \\
\text { more involvement with } \\
\text { moving around the }\end{array}$ \\
\hline
\end{tabular}




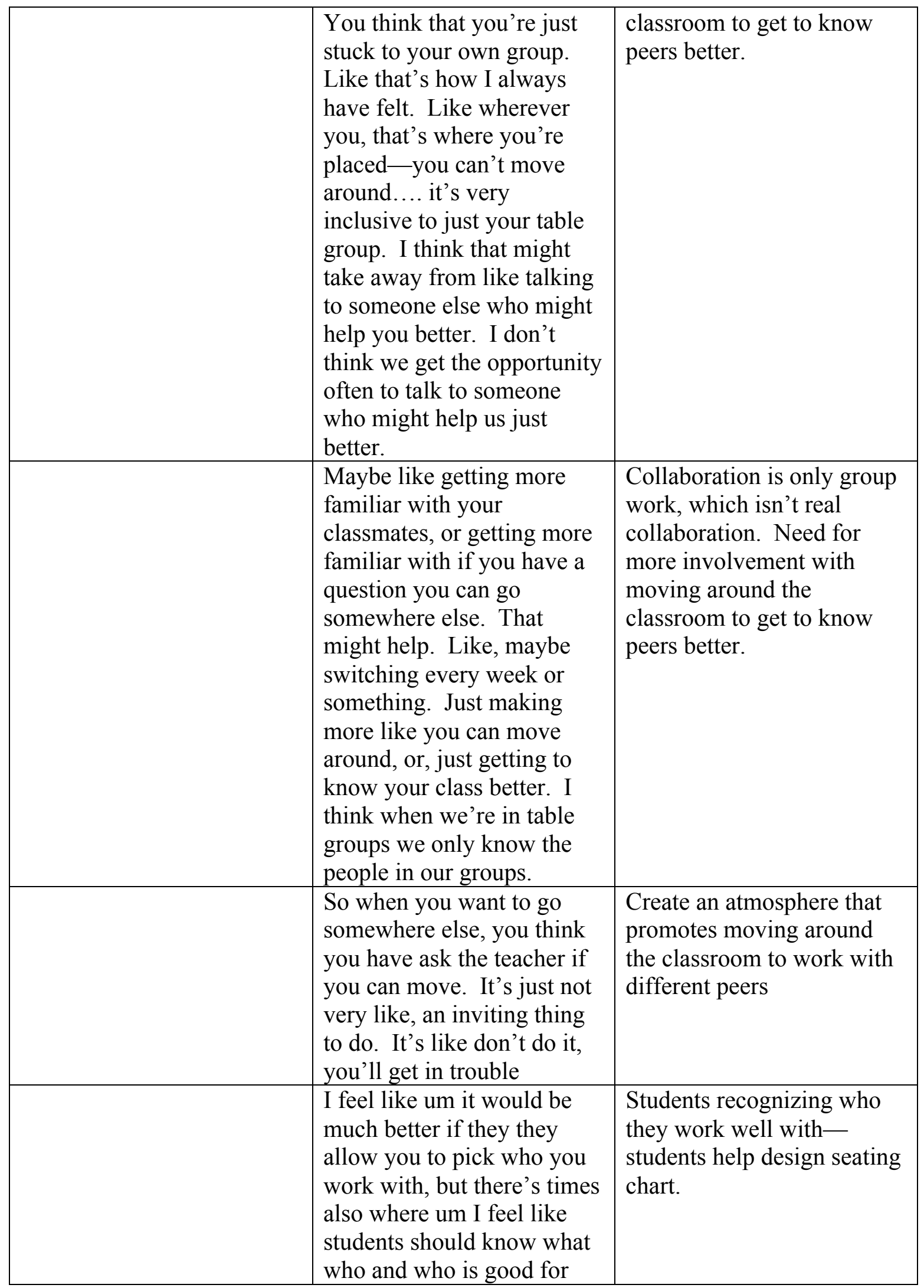




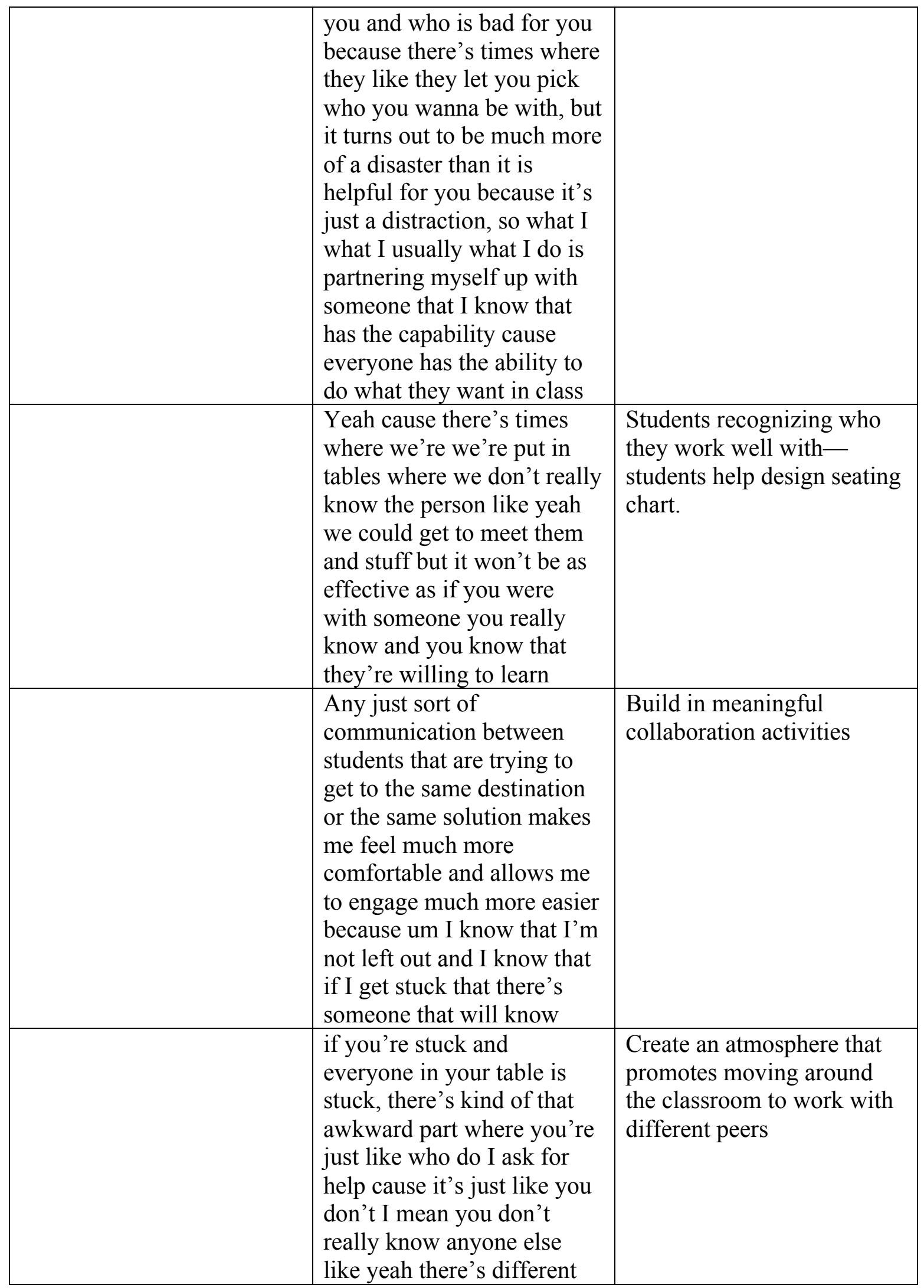




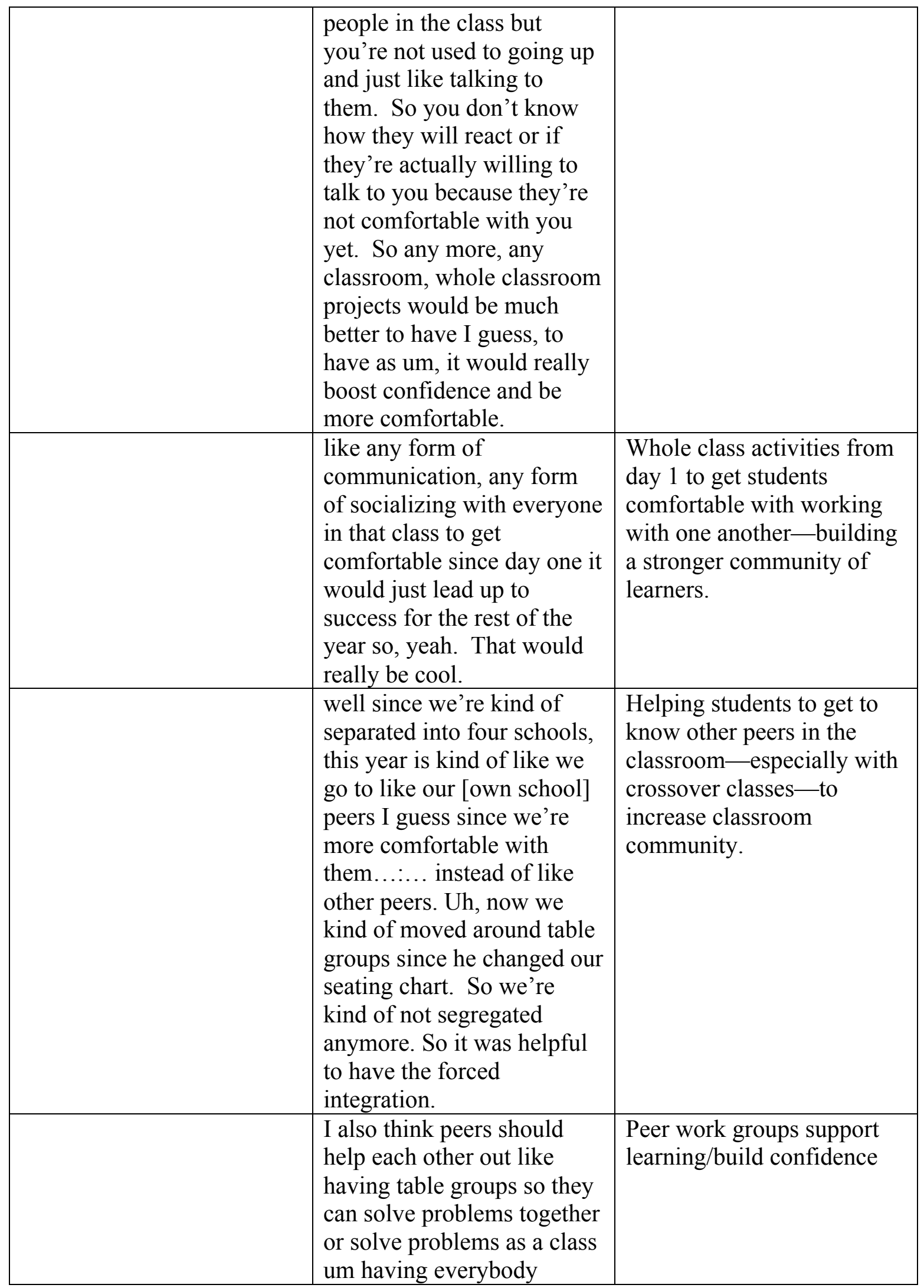




\begin{tabular}{|c|c|c|}
\hline & $\begin{array}{l}\text { participate to increase your } \\
\text { confidence }\end{array}$ & \\
\hline \multirow[t]{2}{*}{ Working with peers } & $\begin{array}{l}\text { I'll um just show them like } \\
\text { where I am not um finishing } \\
\text { and where I got like stuck } \\
\text { where I where I didn't like } \\
\text { continue and usually then } \\
\text { it's like they'll be like oh } \\
\text { why didn't you like use this } \\
\text { and like oh I didn't know I } \\
\text { should have used that } \\
\text { because I didn't know about } \\
\text { it um and then from there I } \\
\text { can use what they gave me } \\
\text { and continue um so yeah } \\
\text { there's those two things is } \\
\text { either not being able to } \\
\text { continue and asking then or } \\
\text { continuing and then still } \\
\text { messing up and asking } \\
\text { where you went wrong. }\end{array}$ & $\begin{array}{l}\text { Groups offer support by } \\
\text { answering questions }\end{array}$ \\
\hline & $\begin{array}{l}\text { it might be helpful yeah if } \\
\text { like every student did talk } \\
\text { about their work in like a } \\
\text { group and then umm they } \\
\text { try and like understand } \\
\text { other students' struggles at } \\
\text { the same time but like if } \\
\text { there was time for that but } \\
\text { usually there isn't time for } \\
\text { that so it does like mmm it } \\
\text { does just make like limited } \\
\text { time just like a quick like } \\
\text { look over and that's it we } \\
\text { don't really have any time } \\
\text { to talk to [laughs] people in } \\
\text { our groups again people in } \\
\text { our groups because like no } \\
\text { one's really gonna go to } \\
\text { another group and ask, first } \\
\text { there's no time second it's } \\
\text { not really like the normal } \\
\text { [laughs] it's like to go to } \\
\text { another group um yeah and } \\
\text { then um when there's no }\end{array}$ & $\begin{array}{l}\text { Need to make time for } \\
\text { structured conversations } \\
\text { with table groups and with } \\
\text { other groups. }\end{array}$ \\
\hline
\end{tabular}




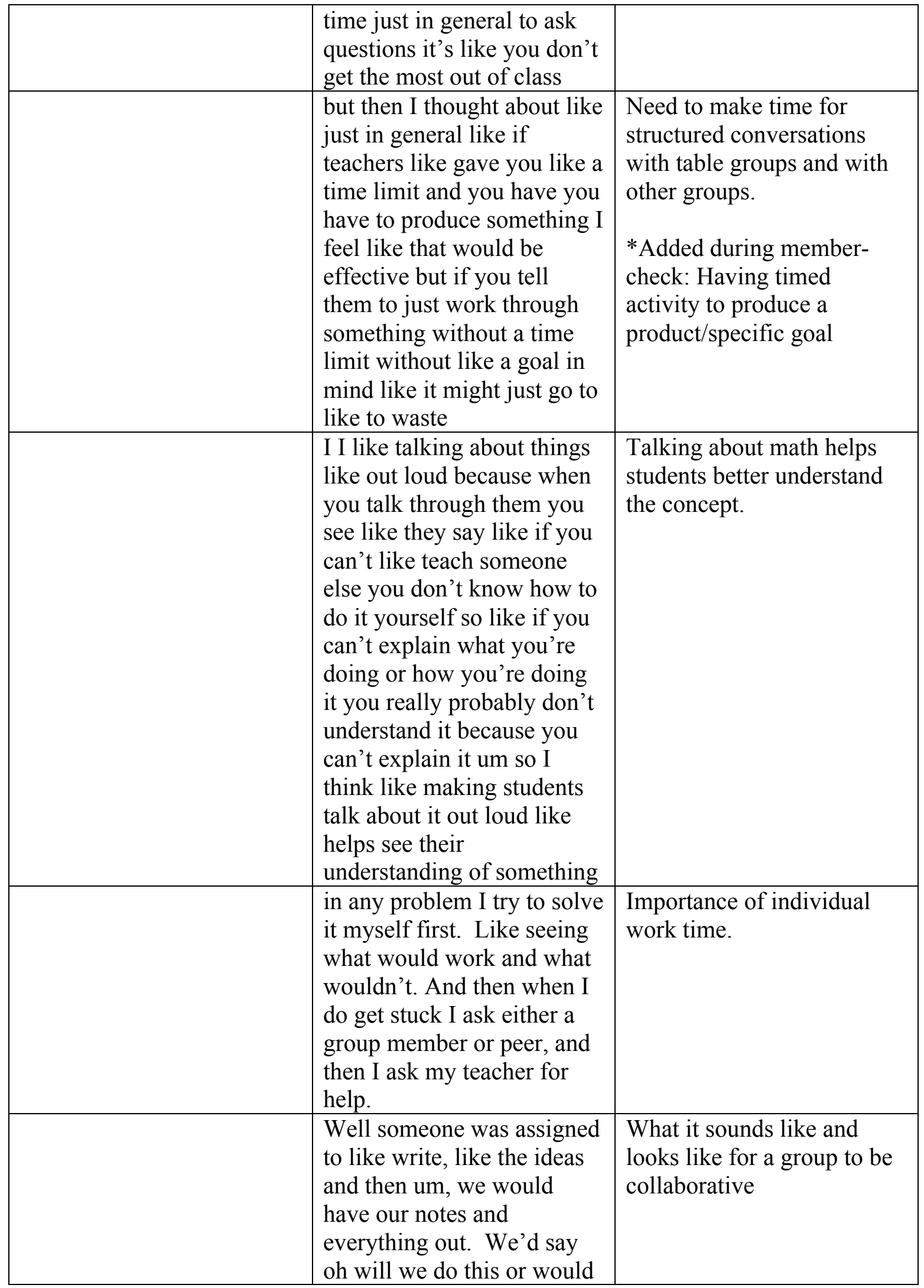




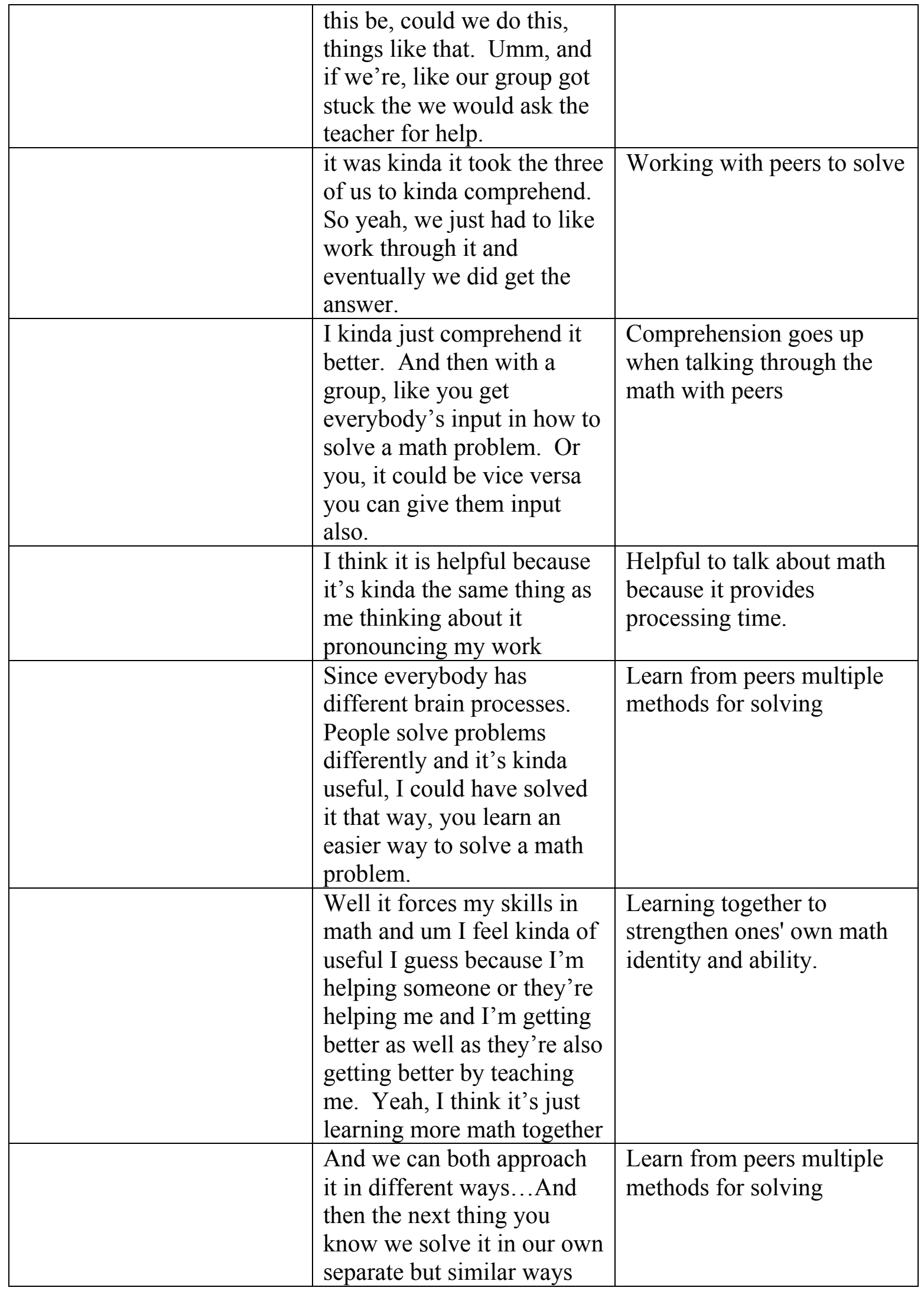









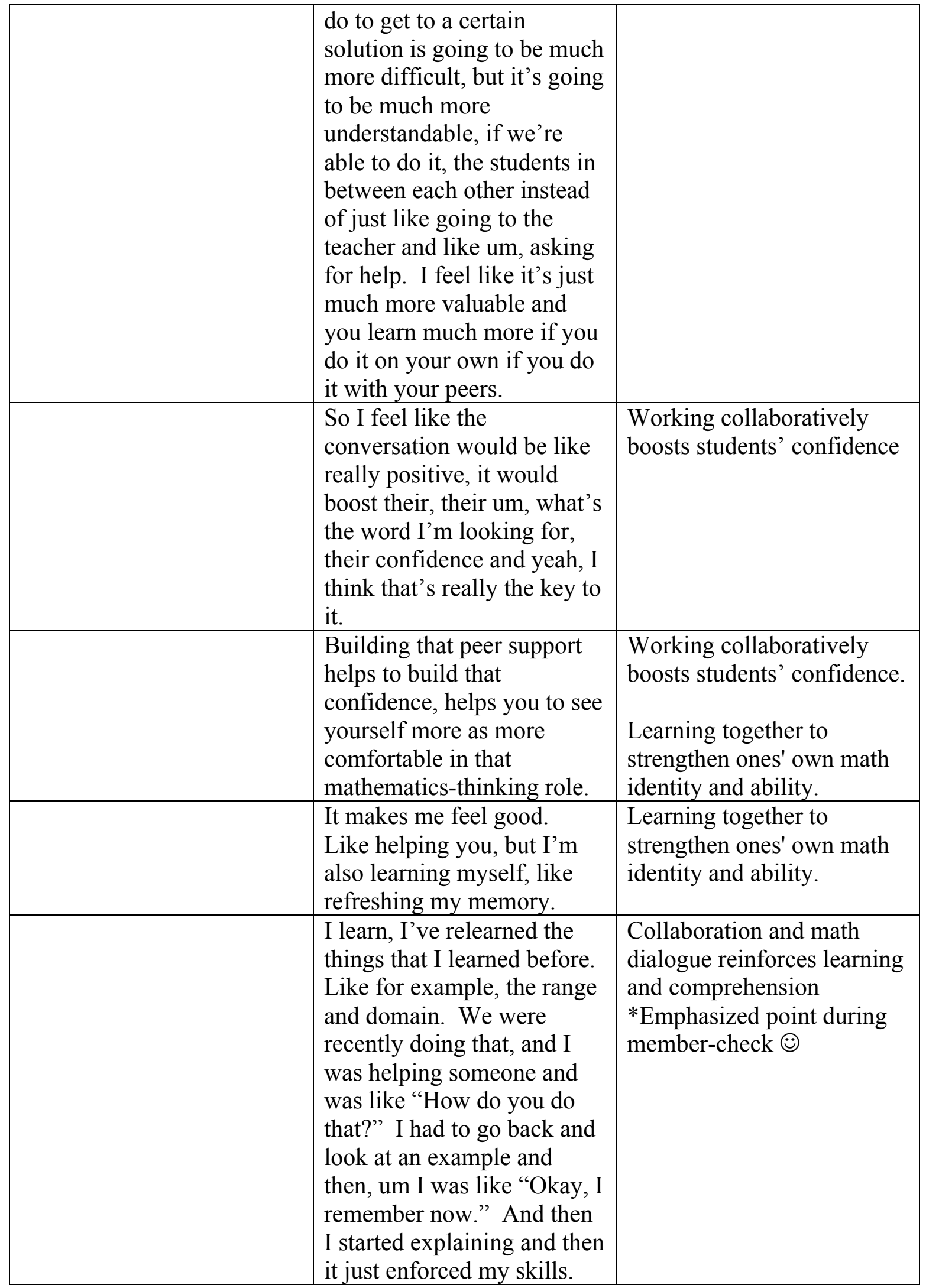




\begin{tabular}{|c|c|c|}
\hline & $\begin{array}{l}\text { I think like group work } \\
\text { would just help like make } \\
\text { sure that students see in } \\
\text { different ways like whether } \\
\text { it be like having to explain } \\
\text { it in different ways because } \\
\text { there would be like a group } \\
\text { so not everyone is gonna } \\
\text { get like the answer the same } \\
\text { way so having a group } \\
\text { might help like expand on } \\
\text { that like be a way to like } \\
\text { help with the different um } \\
\text { ways of solving and stuff }\end{array}$ & $\begin{array}{l}\text { Learn from peers multiple } \\
\text { methods for solving }\end{array}$ \\
\hline & $\begin{array}{l}\text { Having to work with others } \\
\text { um gives a better like um } \\
\text { like it helps like } \\
\text { communication skills } \\
\text { [laughs] that's what I was } \\
\text { thinking um so instead of } \\
\text { like explaining to just like } \\
\text { your teacher or like to } \\
\text { yourself you have to explain } \\
\text { to others so like } \\
\text { communicating }\end{array}$ & $\begin{array}{l}\text { Collaboration supports } \\
\text { communication skills, being } \\
\text { able to explain a concept to } \\
\text { their peers. }\end{array}$ \\
\hline \multirow[t]{3}{*}{ Latinx and Math } & $\begin{array}{l}\text { I: How does that make you } \\
\text { feel as a Latina female } \\
\text { interested in math } \\
\text { P: It makes me feel great } \\
\text { because all the years I've } \\
\text { been learning math I've } \\
\text { only had two female um } \\
\text { math teachers compared to } \\
\text { all of the male teachers that } \\
\text { I've had um kind of seeing } \\
\text { that difference kind of } \\
\text { knowing that I can be that } \\
\text { difference for someone else } \\
\text { especially being a minority } \\
\text { in the math field }\end{array}$ & $\begin{array}{l}\text { Sees how she can be a role } \\
\text { model for other females } \\
\text { who might be interested in } \\
\text { pursuing STEM fields. } \\
\text { Recognizes the importance } \\
\text { of females in STEM. }\end{array}$ \\
\hline & $\begin{array}{l}\text { Yeah I think that could be } \\
\text { inspiring to other people }\end{array}$ & $\begin{array}{l}\text { Being female and in a math } \\
\text { related field could be } \\
\text { inspiring to other people. }\end{array}$ \\
\hline & I don't really think about & She doesn't think about \\
\hline
\end{tabular}




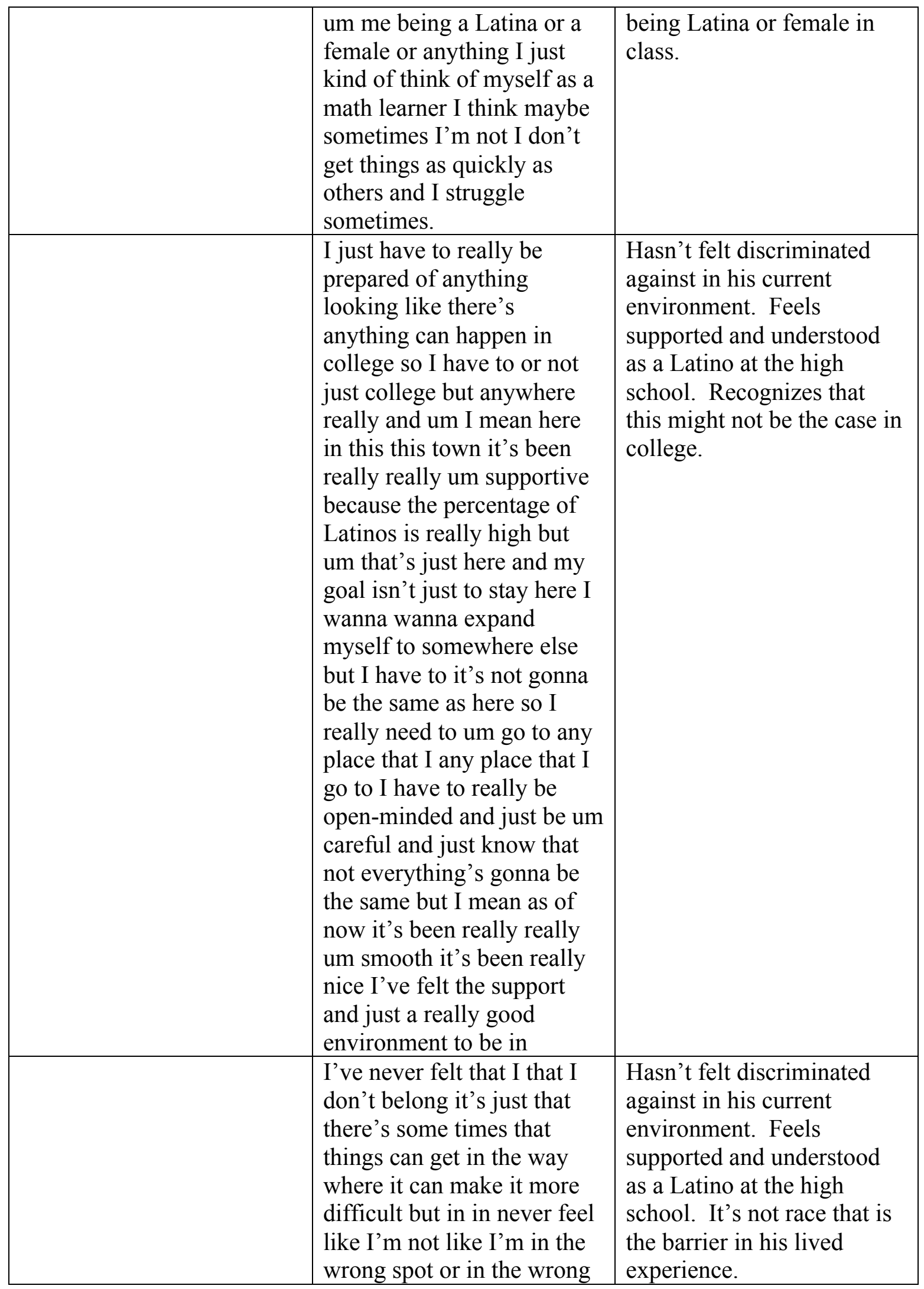




\begin{tabular}{|l|l|l|}
\hline & $\begin{array}{l}\text { place, which is good } \\
\text { feel like it has been pretty } \\
\text { equal at least where I'm } \\
\text { coming from }\end{array}$ & $\begin{array}{l}\text { Hasn't felt discriminated } \\
\text { against because of race. }\end{array}$ \\
\hline & $\begin{array}{l}\text { I don't think I've ever seen } \\
\text { like separation but I'm also } \\
\text { surrounded by many like } \\
\text { me so it's hard to really like } \\
\text { see the difference. }\end{array}$ & $\begin{array}{l}\text { Surrounded by students of a } \\
\text { similar racial background. }\end{array}$ \\
& $\begin{array}{l}\text { I think though like when } \\
\text { you look at like who goes to } \\
\text { like the ACT tests or like } \\
\text { SAT and like who scores } \\
\text { the highest um I feel like } \\
\text { it's people who are like } \\
\text { better prepared for like um } \\
\text { their future in college and } \\
\text { stuff like their background I } \\
\text { feel like made them more } \\
\text { like mmm prepared for it } \\
\text { just like college and things } \\
\text { like that }\end{array}$ & $\begin{array}{l}\text { Attributing race to higher } \\
\text { test scores and preparedness }\end{array}$ \\
\hline $\begin{array}{l}\text { in Woodburn I feel like it's } \\
\text { like pretty equal } \\
\text { opportunity but when you } \\
\text { go like outside you go to } \\
\text { like South Salem and you } \\
\text { like take your ACT over } \\
\text { there like it's like a lot } \\
\text { different than how it is here }\end{array}$ & $\begin{array}{l}\text { Surrounded by students of a } \\
\text { similar racial background. } \\
\text { Recognizes the racial } \\
\text { districts }\end{array}$ \\
\hline
\end{tabular}

